\author{
UNIVERSIDADE DE SÃO PAULO \\ ESCOLA POLITÉCNICA \\ PROGRAMA DE PÓS-GRADUAÇÃO EM ENGENHARIA QUÍMICA
}

ISADORA LUIZA CLÍMACO CUNHA

Avaliação de Processos Oxidativos Avançados na Remoção de Pesticidas

Presentes em Efluentes da Agroindústria

São Paulo 

ISADORA LUIZA CLÍMACO CUNHA

\section{Avaliação de Processos Oxidativos Avançados na Remoção de Pesticidas Presentes em Efluentes da Agroindústria}

\section{Versão Corrigida}

Dissertação apresentada ao Programa de PósGraduação em Engenharia Química da Escola Politécnica da Universidade de São Paulo para obtenção do título de Mestre em Ciências.

Área de Concentração: Engenharia Química

Orientador: Prof. Dr. Antonio Carlos Silva Costa Teixeira

São Paulo 
Autorizo a reprodução e divulgação total ou parcial deste trabalho, por qualquer meio convencional ou eletrônico, para fins de estudo e pesquisa, desde que citada a fonte.

Este exemplar foi revisado e corrigido em relação à versão original, sob responsabilidade única do autor e com a anuência de seu orientador.

São Paulo, 27 de abril de 2021

Assinatura do autor: Liklumbas

Assinatura do orientador:

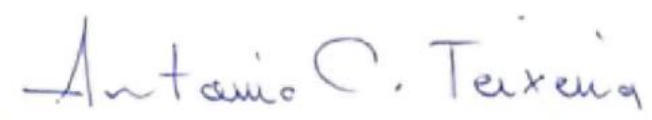

Catalogação-na-publicação

Clímaco Cunha, Isadora Luiza

Avaliação de Processos Oxidativos Avançados na Remoção de Pesticidas Presentes em Efluentes da Agroindústria / I. L. Clímaco Cunha -- versão corr. - São Paulo, 2021.

$133 \mathrm{p}$.

Dissertação (Mestrado) - Escola Politécnica da Universidade de São Paulo. Departamento de Engenharia Química.

1.Processos Oxidativos Avançados 2.Azoxistrobina 3.Difenoconazol 4.Imidacloprido 5.UVC/H2O2 I.Universidade de São Paulo. Escola Politécnica. Departamento de Engenharia Química II.t. 
Aos meus pais, Sérgio e Regina, exemplo de amor, dedicação e fé e a todos os pesquisadores que desenvolvem projetos em prol do meio ambiente. 



\section{AGRADECIMENTOS}

"Combati o bom combate, terminei a minha carreira, guardei a fé" (2Tm, 4, 78). Essas foram as palavras escritas pelo apóstolo Paulo a Timóteo quando se encontrava encarcerado em Roma, aguardando seu martírio eminente. Essas palavras de São Paulo visaram estimular o seu amigo a ser firme em seu propósito de zelar pela pregação do Evangelho, sempre com a fidelidade necessária.

Comecei o curso de mestrado na busca de contribuir com o desenvolvimento sustentável do nosso país, quiçá do planeta, já tão sofrido com as explorações degradantes, muitas realçadas pela mídia em geral.

Muitos desafios surgiram, ora demonstravam-se fáceis de resolver, estavam ali perto do meu alcance as soluções. Ora pareciam ultrapassar minha capacidade humana, e que somente o Criador poderia me mostrar o caminho a seguir.

E seguindo esse caminho, percebi que um bom combate não se faz sozinha. E, assim, guardando a fé, me foi permitido conhecer pessoas maravilhosas, que, direta ou indiretamente, contribuíram significativamente para a concretização desse trabalho, sustentando os esforços despendidos para o seu alcance.

Nesse sentido, venho assentar nessas linhas os meus mais sinceros agradecimentos a esses amigos, coadjuvantes nessa minha carreira:

Ao meu orientador, Prof. Dr. Antonio Carlos Silva Costa Teixeira, pela paciência, pelo apoio, e, sobretudo, por estimular minha perseverança nas pesquisas e acreditar que os resultados podem fazer a diferença na busca de tecnologias sustentáveis.

Aos meus pais, Sérgio e Regina, meu alicerce. Se sou capaz de sonhar e ir cada vez mais longe, tudo isso se deve ao seu apoio diário e amor incondicional. 

Ao Thiago, companheiro de vida e jornada, pelo carinho, ombro amigo, paciência para escutar meus raciocínios, contribuindo construtivamente no desempenho de minhas tarefas.

Aos amigos e colegas de laboratório do AdOx, que animaram os dias de labuta, em especial Carolina Mendes Rocha (amizade desde os tempos de graduação, parceria para a vida dentro e fora do meio acadêmico); Juliana Mendonça Silva de Jesus (minha designer e consultora), Patrícia Metolina (sempre atenciosa e pelo apoio no cálculo dos rendimentos quânticos da fotólise direta), Natalia Klanovicz (por transmitir com tanto domínio o conhecimento para os testes de citotoxicidade genotoxicidade), Priscila Hasse Palharim, Arlen Mabel Lastre-Acosta e Bruno Ramos.

À Gracyelle Nuves Leocádio do CIRRA, pela assistência nos testes de caracterização das matrizes reais da agroindústria.

Aos engenheiros agrônomos da EMATER-MG, Srs. Georgeton Soares Ribeiro Silveira, Gilberto Dias Villela, Deny Sanábio e Bernardino Cangussu Guimarães, pela disposição em dividir conhecimentos e informações sobre a produção agrícola de tomates, morangos e café (e demais produtos agrícolas cultivados no território nacional), essenciais ao desenvolvimento das pesquisas acadêmicas.

À equipe da empresa Predilecta Alimentos Ltda., em especial à Profa. Katia Ribeiro e aos Srs. Antônio Carlos e Bruno Trevizanelli, pela disposição em recebernos sempre tão bem nas visitas técnicas e tão prontamente fornecer-nos valiosas informações sobre o processamento dos tomates para fabricação de alimentos.

Ao Programa de Pós-Graduação em Engenharia Química e aos professores do Departamento de Engenharia Química da Escola Politécnica da USP por todos os ensinamentos a mim compartilhados durante a execução deste projeto.

Por fim, à Coordenadoria de Pessoal de Nível Superior (CAPES) pelo suporte financeiro durante o período de Mestrado. 

A Terra está viva e nós somos sua porção consciente e inteligente. Não estamos fora em cima dela, mas participando da rede de relações que envolvem todos os seres, para o bem e para o mal. Se poluo o ar, acabo adoecendo e afetando todos os demais seres vivos. Se recupero a mata ciliar do rio que passa em meu terreno, preservo as águas, colaboro com o aumento de seu volume e melhoro minha qualidade de vida, dos pássaros e dos insetos que polinizam as árvores frutíferas e as flores do jardim. [...] Sustentabilidade como substantivo acontece quando nos fazemos responsáveis pela preservação da vitalidade e da integridade dos ecossistemas e cuidadores da Casa Comum. [...] (BOFF, 2012). 



\section{RESUMO}

A degradação dos ingredientes ativos (IA) azoxistrobina (AZO), difenoconazol (DFZ) e imidacloprido (IMD), constituintes de diversos produtos comerciais aplicados em larga escala nas lavouras brasileiras e encontrados na água de lavagem de tomates da agroindústria, foi investigada através da fotólise direta UVC (251-257 nm) e do processo oxidativo avançado $\mathrm{UVC} / \mathrm{H}_{2} \mathrm{O}_{2}$. Os resultados indicaram que a fotólise direta segue cinética de pseudo-primeira ordem, com remoção total de AZO e IMD após 15 minutos de irradiação, usando 21,8 e $28,6 \mathrm{~W} \mathrm{~m}$-2, respectivamente. O DFZ demonstrou ser mais persistente à fotólise, com máxima degradação observada de $51,7 \%$, para $28,6 \mathrm{~W} \mathrm{~m}^{-2}$. Considerando as diferentes condições de irradiação e o coeficiente de absorção molar dos compostos para essa faixa de comprimento de onda, foram estimados os valores de rendimento quântico dos IA $(0,572,0,028$ e 0,061 mol Einstein ${ }^{-1}$ para AZO, DFZ e IMD, respectivamente). No processo $\mathrm{UVC} / \mathrm{H}_{2} \mathrm{O}_{2}$, a remoção total dos compostos ocorreu para a maioria das condições após 10 minutos de irradiação, com concentrações dos IA abaixo dos limites de detecção. O projeto experimental Doehlert sequencial permitiu maior compreensão da influência das variáveis de processo $\left[\mathrm{H}_{2} \mathrm{O}_{2}\right]_{0}$ e Euvc na taxa específica de degradação dos compostos, e através da análise estatística, foram obtidas as condições ótimas para o sistema-modelo baseado na água de lavagem sintética, isto é, aproximadamente $\left[\mathrm{H}_{2} \mathrm{O}_{2}\right]_{0}=130,0 \mathrm{mg} \mathrm{L}^{-1}$ e 26,0 $\mathrm{W} \mathrm{m}^{-2}$. Ensaios com amostras de água reais coletadas na indústria, geradas na lavagem de tomates, indicaram que a matriz não influencia a degradação da AZO, enquanto a remoção total de DFZ e IMD ocorreu apenas para a água coletada na esteira de lavagem. $O$ estudo da citotoxicidade e genotoxicidade com Allium cepa (bulbos de cebola) não demonstrou anormalidades durante a divisão das células para os ensaios com os padrões analíticos individuais e para a água da esteira de lavagem, com a remoção total dos IA após 15 minutos, demonstrando o potencial de aplicação do processo $\mathrm{UVC} / \mathrm{H}_{2} \mathrm{O}_{2}$ como alternativa potencialmente viável de tratamento localizado de água de lavagem de tomates na agroindústria, com foco em um possível reúso da água tratada.

Palavras-chave: processos oxidativos avançados, azoxistrobina, difenoconazol, imidacloprido, $\mathrm{UVC} / \mathrm{H}_{2} \mathrm{O}_{2}$. 



\begin{abstract}
The degradation of the active ingredients azoxystrobin (AZO) difenoconazole (DFZ) and imidacloprid (IMD), constituents of several commercial products applied in Brazilian cultivations and commonly found in tomato rinse water in the agroindustry was investigated through UVC photolysis (251-257 nm) and the advanced oxidation process $\mathrm{UVC} / \mathrm{H}_{2} \mathrm{O}_{2}$. The results indicated that direct photolysis follows pseudo-first order kinetics, with total AZO and IMD removal after 15 minutes of irradiation, using 21.8 and $28.6 \mathrm{~W} \mathrm{~m}^{-2}$, respectively. DFZ proved to be more persistent to photolysis, with maximum $51.7 \%$ removal using $28.6 \mathrm{~W} \mathrm{~m}^{-2}$. Considering different irradiation conditions and the molar absorption coefficients of the compounds for the wavelength range studied, the photolysis quantum yields were estimated as $0.572,0.028$ and 0.061 mol Einstein $^{-1}$ for AZO, DFZ and IMD, respectively. With regard to the $\mathrm{UVC} / \mathrm{H}_{2} \mathrm{O}_{2}$ process, total removal of the pesticides occurred for most conditions after 10 minutes of irradiation, with concentrations below the detection limits. The sequential Doehlert design allowed a better understanding of the effects of process variables $\left[\mathrm{H}_{2} \mathrm{O}_{2}\right]_{0}$ and Euvc on the specific degradation rate, with the optimal conditions for the model system using synthetic rinse water obtained through statistical analysis, i.e., approximately $\left[\mathrm{H}_{2} \mathrm{O}_{2}\right]_{0}=130.0 \mathrm{mg} \mathrm{L}^{-1}$ and $26.0 \mathrm{~W} \mathrm{~m}^{-2}$. Assays with real rinse water collected in an industry, generated in tomatoes washing, showed that the matrix does not influence AZO degradation, while the total removal of DFZ and IMD occurred only for tomato rinse water from washing belts. The study of cytotoxicity and genotoxicity with Allium cepa (onion bulbs) showed no abnormalities during cell divisions for individual assays with pure compounds and for the tomato rinse water from washing belts, demonstrating the potential application of the $\mathrm{UVC} / \mathrm{H}_{2} \mathrm{O}_{2}$ process as a viable alternative localized treatment of tomato rinse water in the agroindustry, with a focus on the possible reuse of the treated water.
\end{abstract}

Keywords: advanced oxidation processes, azoxystrobin, difenoconazole, imidacloprid, $\mathrm{UVC} / \mathrm{H}_{2} \mathrm{O}_{2}$. 



\section{LISTA DE ILUSTRAÇÕES}

Figura 1 - Consumo anual de agrotóxicos no Brasil (2000-2019) em toneladas de ingrediente ativo. 54

Figura 2 - Total de vendas dos ingredientes ativos AZO, DFZ e IMD no Brasil (20092019) em toneladas.

Figura 3 - Estruturas químicas dos compostos AZO (a), DFZ (b) e IMD (c). .58

Figura 4 - Lavagem de tomates para processamento na agroindústria. .59

Figura 5 - Equipamento empregado nos ensaios de degradação 79

Figura 6 - Matrizes Doehlert usadas nos experimentos $\mathrm{UVC} / \mathrm{H}_{2} \mathrm{O}_{2}$. .83

Figura 7 - Pontos de coleta da água de lavagem de tomate na agroindústria. À esquerda: descarregamento dos caminhões contendo frutos recém-colhidos, com o auxílio jatos de água (pré-lavagem). À direita: Etapa final de lavagem realizada nas esteiras transportadoras, anterior à seleção dos frutos para processamento e produção de produtos alimentícios (esteira de lavagem). .84

Figura 8 - Representação esquemática dos ensaios de citotoxicidade e genotoxicidade com Allium cepa. .88

Figura 9 - Espectros de absorção molar para AZO, DFZ e IMD. .90

Figura 10 - Variação da concentração de AZO, DFZ e IMD na solução sintética após 72 horas. 

Figura 11 - Decaimento da concentração relativa de AZO, DFZ e IMD com o tempo para a fotólise direta, para $E \cup v c=15,0 \mathrm{~W} \mathrm{~m}^{-2}(\square), 21,8 \mathrm{~W} \mathrm{~m}^{-2}(\bullet)$ e $28,6 \mathrm{~W} \mathrm{~m}^{-2}(\triangle)$. Experimentos realizados com a água de lavagem sintética contendo os três ingredientes ativos: $[A Z O]_{0}=2,83 \pm 0,06 \mathrm{mg} \mathrm{L}^{-1}$; [DFZ $]_{0}=1,54 \pm 0,03 \mathrm{mg} \mathrm{L}^{-1} ;[\text { IMD }]_{0}=$ $2,74 \pm 0,01 \mathrm{mg} \mathrm{L}^{-1}$. Experimentos realizados em triplicata, sendo os erros percentuais médios iguais a $1,8 \%$ (AZO), 1,1\% (DFZ) e 2,8\% (IMD). .92

Figura 12 - Decaimento das concentrações relativas de AZO, DFZ e IMD com o tempo para processo $\mathrm{UVC} / \mathrm{H}_{2} \mathrm{O}_{2}$. Experimentos 7 (ם) e 8 (०), usando $15,0 \mathrm{~W} \mathrm{~m}^{-2}$ (matriz Doehlert, experimentos 1-9). Experimentos realizados com água de lavagem sintética contendo os três ingredientes ativos. $[A Z O]_{0}=(2,60 \pm 0,04) \mathrm{mg} \mathrm{L}^{-1} ;[\mathrm{DFZ}]_{0}=(1,72 \pm$ $0,05) \mathrm{mg} \mathrm{L}^{-1} ;[\mathrm{IMD}]_{0}=(2,55 \pm 0,01) \mathrm{mg} \mathrm{L}^{-1}$

Figura 13 - Decaimento das concentrações relativas de AZO, DFZ e IMD com o tempo para processo $\mathrm{UVC} / \mathrm{H}_{2} \mathrm{O}_{2}$. Experimentos 6 (ロ) e 4 (•), usando 21,8 $\mathrm{W} \mathrm{m}^{-2}$ (matriz Doehlert, experimentos 1-9). Experimentos realizados com água de lavagem sintética contendo os três ingredientes ativos. $[A Z O]_{0}=(2,60 \pm 0,04) \mathrm{mg} \mathrm{L}^{-1} ;[\mathrm{DFZ}]_{0}=(1,72 \pm$ $0,05) \mathrm{mg} \mathrm{L}^{-1} ;[\mathrm{IMD}]_{0}=(2,55 \pm 0,01) \mathrm{mg} \mathrm{L}^{-1}$. 96

Figura 14 - Decaimento das concentrações relativas de AZO, DFZ e IMD com o tempo para processo UVC/ $/ \mathrm{H}_{2} \mathrm{O}_{2}$. Experimentos 9 () e $5(\bullet)$, usando $28,6 \mathrm{~W} \mathrm{~m}^{-2}$ (matriz Doehlert, experimentos 1-9). Experimentos realizados com água de lavagem sintética contendo os três ingredientes ativos. [AZO $]_{0}=(2,60 \pm 0,04) \mathrm{mg} \mathrm{L}^{-1} ;$ [DFZ] $0=(1,72 \pm$ $0,05) \mathrm{mg} \mathrm{L}^{-1} ;[\mathrm{IMD}]_{0}=(2,55 \pm 0,01) \mathrm{mg} \mathrm{L}^{-1}$

Figura 15 - Decaimento das concentrações relativas de AZO, DFZ e IMD com o tempo para processo $\mathrm{UVC} / \mathrm{H}_{2} \mathrm{O}_{2}$. Experimentos 1 ( $\square$ ), 2 (०) e $3(\triangle)$, usando 21,8 $\mathrm{W} \mathrm{m}^{-2}$ (matriz Doehlert, experimentos 1-9). Experimentos realizados com água de lavagem sintética contendo os três ingredientes ativos. $[A Z O]_{0}=(2,60 \pm 0,04) \mathrm{mg} \mathrm{L}^{-1} ;[\mathrm{DFZ}]_{0}=$ $(1,72 \pm 0,05) \mathrm{mg} \mathrm{L}^{-1} ;[\mathrm{IMD}] \mathrm{o}=(2,55 \pm 0,01) \mathrm{mg} \mathrm{L}^{-1}$ 

Figura 16 - Decaimento das concentrações relativas de AZO, DFZ e IMD com o tempo para processo $\mathrm{UVC} / \mathrm{H}_{2} \mathrm{O}_{2}$. Experimentos 10 (), 11 (o) e $12(\triangle)$ (matriz Doehlert, experimentos 10-12). Experimentos realizados com água de lavagem sintética contendo os três ingredientes ativos. $[A Z O]_{0}=(2,60 \pm 0,04) \mathrm{mg} \mathrm{L}^{-1} ;[\mathrm{DFZ}]_{0}=(1,72 \pm$ $0,05) \mathrm{mg} \mathrm{L}^{-1} ;[\mathrm{IMD}]_{0}=(2,55 \pm 0,01) \mathrm{mg} \mathrm{L}^{-1}$ .99

Figura 17 - Decaimento das concentrações relativas de AZO, DFZ e IMD com o tempo para processo $\mathrm{UVC} / \mathrm{H}_{2} \mathrm{O}_{2}$. Experimentos $13(\square), 14(\bullet), 15(\triangle), 16(\nabla), 17(\diamond)$ e 18 $(\triangleleft)$ (matriz Doehlert, experimentos 13-18). Experimentos realizados com água de lavagem sintética contendo os três ingredientes ativos. [AZO] $0=(2,60 \pm 0,04) \mathrm{mg} \mathrm{L}^{-1}$; $[D F Z]_{0}=(1,72 \pm 0,05) \mathrm{mg} \mathrm{L}^{-1} ;\left[\mathrm{IMD}_{0}=(2,55 \pm 0,01) \mathrm{mg} \mathrm{L}^{-1}\right.$. 100

Figura 18 - Taxas de degradação de pseudo-primeira ordem para experimentos $\mathrm{UVC} / \mathrm{H}_{2} \mathrm{O}_{2}$ da matriz Doehlert e de fotólise direta UVC $\left(\left[\mathrm{H}_{2} \mathrm{O}_{2}\right]_{0}=0\right)$, realizados em diferentes condições de $\left[\mathrm{H}_{2} \mathrm{O}_{2}\right] 0$ e Euvc. (a) $15,0 \mathrm{~W} \mathrm{~m}^{-2}$, (b) $21,8 \mathrm{~W} \mathrm{~m}^{-2}$ e (c) $28,6 \mathrm{~W} \mathrm{~m}$ 2

Figura 19 - Gráfico de Pareto para $k_{A z O}$ (processo UVC/ $\mathrm{H}_{2} \mathrm{O}_{2}$, experimentos 1-9). 105 Figura 20 - Gráfico de Pareto para $k_{D F Z}$ (processo UVC/ $\mathrm{H}_{2} \mathrm{O}_{2}$, experimentos 1-9). 105 Figura 21 - Gráfico de Pareto para kIMD (processo UVC/ $\mathrm{H}_{2} \mathrm{O}_{2}$, experimentos 1-9).. 105 Figura 22 - Gráfico de Pareto para $k_{A z O}$ (processo UVC/ $\mathrm{H}_{2} \mathrm{O}_{2}$, experimentos 1-18). 106

Figura 23 - Gráfico de Pareto para $k_{D F Z}$ (processo UVC/ $\mathrm{H}_{2} \mathrm{O}_{2}$, experimentos 1-18). 107

Figura 24 - Gráfico de Pareto para $k_{I M D}$ (processo UVC/ $\mathrm{H}_{2} \mathrm{O}_{2}$, experimentos 1-18). 

Figura 25 - Superfície de resposta e gráfico de contorno para kAZO (processo $\mathrm{UVC} / \mathrm{H}_{2} \mathrm{O}_{2}$, experimentos 1-18). Condições: $[A Z \mathrm{O}]_{0}=(2,81 \pm 0,23) \mathrm{mg} \mathrm{L}^{-1} ;[D F Z]_{0}=$ $(1,86 \pm 0,16) \mathrm{mg} \mathrm{L}^{-1} ;[\mathrm{IMD}]_{0}=(2,71 \pm 0,19) \mathrm{mg} \mathrm{L}^{-1}$ 108

Figura 26 - Superfície de resposta e gráfico de contorno para kDFz (processo UVC $/ \mathrm{H}_{2} \mathrm{O}_{2}$, experimentos 1-18). Condições: $[A Z O]_{0}=(2,81 \pm 0,23) \mathrm{mg} \mathrm{L}^{-1} ;[D F Z]_{0}=$ $(1,86 \pm 0,16) \mathrm{mg} \mathrm{L}^{-1} ;[\mathrm{IMD}]_{0}=(2,71 \pm 0,19) \mathrm{mg} \mathrm{L}^{-1}$ 109

Figura 27 - Superfície de resposta e gráfico de contorno para kIMD (processo $\mathrm{UVC} / \mathrm{H}_{2} \mathrm{O}_{2}$, experimentos 1-18). Condições: $[A Z O]_{0}=(2,81 \pm 0,23) \mathrm{mg} \mathrm{L}^{-1} ;[D F Z]_{0}=$ $(1,86 \pm 0,16) \mathrm{mg} \mathrm{L}^{-1} ;[\mathrm{IMD}]_{0}=(2,71 \pm 0,19) \mathrm{mg} \mathrm{L}^{-1}$

Figura 28 - Decaimento das concentrações relativas de AZO, DFZ e IMD em função do tempo para experimentos com as matrizes reais obtidas na lavagem de tomates na indústria, dopadas com os produtos comerciais Amistar Top ${ }^{\circledR}$ e Provado 200 SC $^{\circledR}$ e submetidas ao processo $\mathrm{UVC} / \mathrm{H}_{2} \mathrm{O}_{2}$ nas condições $\left[\mathrm{H}_{2} \mathrm{O}_{2}\right] 0=130 \mathrm{mg} \mathrm{L}^{-1}$ e Euvc $=$ $28,6 \mathrm{~W} \mathrm{~m}^{-2}$. Amostras de água da pré-lavagem (o) e esteira de lavagem ( $\square$ ). [AZO]0 = $2,22 \pm 0,05 ;[D F Z]_{0}=1,48 \pm 0,04 ;[I M D]_{0}=2,94 \pm 0,14 \mathrm{mg} \mathrm{L}^{-1}$. Os erros médios são $5,5 \%$ (AZO), 13,9\% (DFZ) e 2,75\% (IMD). 112

Figura 29 - Taxas de degradação de pseudo-primeira ordem para ensaios da matriz Doehlert (experimentos 1-18) e ensaios realizados com as matrizes reais coletadas na indústria, dopadas com os produtos comerciais Amistar Top ${ }^{\circledR}$ e Provado $200 \mathrm{SC}^{\circledR}$ e submetidas ao tratamento $\mathrm{UVC} / \mathrm{H}_{2} \mathrm{O}_{2}$ nas condições de $\left[\mathrm{H}_{2} \mathrm{O}_{2}\right] \mathrm{o}=130 \mathrm{mg} \mathrm{L}^{-1}$ e Euvc $=28,6 \mathrm{~W} \mathrm{~m}^{-2}$. E: água da esteira de lavagem; PL: água de pré-lavagem. 113 

Figura 30 - Observações visuais dos efeitos genotóxicos em A. cepa, empregando ampliações de $40 \times$, para ensaios com os IA padrão analítico e matrizes reais coletadas na indústria, dopadas com os produtos comerciais Amistar Top ${ }^{\circledR}$ e Provado $200 \mathrm{SC}^{\circledR}$. (a) controle negativo 1 (água de torneira) (b) solução AZO, antes do tratamento, (c) solução DFZ, antes do tratamento, (d) solução IMD, antes do tratamento, (e) solução $A Z O$, após tratamento $U V C / H_{2} \mathrm{O}_{2}$, (f) solução $D F Z$, após tratamento $\mathrm{UVC} / \mathrm{H}_{2} \mathrm{O}_{2}$, (g) solução IMD, após tratamento $\mathrm{UVC} / \mathrm{H}_{2} \mathrm{O}_{2}$, (h) controle negativo 2 (água de torneira), (i) água de pré-lavagem, antes do tratamento, (j) água da esteira de lavagem, antes do tratamento, (k) água de pré-lavagem, após tratamento $\mathrm{UVC} / \mathrm{H}_{2} \mathrm{O}_{2}$, (I) água da esteira de lavagem, após tratamento $\mathrm{UVC} / \mathrm{H}_{2} \mathrm{O}_{2}$. 118

Figura A1 - Curvas de calibração em HPLC obtida para os padrões analíticos dos compostos AZO, DFZ e IMD. 133

Figura A2 - Curvas de calibração em HPLC obtida para os compostos AZO, DFZ e IMD em soluções obtidas a partir dos produtos formulados Amistar Top ${ }^{\circledR}$ e Provado 200 SC $^{\circledR}$ 133 



\section{LISTA DE TABELAS}

Tabela 1 - Classificação dos pesticidas de acordo com organismo-alvo de controle.

Tabela 2 - Classificação toxicológica dos agrotóxicos. .56

Tabela 3 - Propriedades físico-químicas dos IA estudados. .58

Tabela 4 - Estudos de lavagem de tomates. .60

Tabela 5 - Aplicação dos POA para tratamento dos IA estudados em meio aquoso.65

Tabela 5 (cont.) - Aplicação dos POA para tratamento dos IA estudados em meio aquoso. .66

Tabela 5 (cont.) - Aplicação dos POA para tratamento dos IA estudados em meio aquoso.

Tabela 5 (cont.) - Aplicação dos POA para tratamento dos IA estudados em meio aquoso. 68

Tabela 6 - Características físico-químicas de soluções de $\mathrm{H}_{2} \mathrm{O}_{2}$ a $25^{\circ} \mathrm{C}$. .72

Tabela 7 - Estudos envolvendo a degradação do IMD pelo processo UVC/ $\mathrm{H}_{2} \mathrm{O}_{2} \ldots . . .73$

Tabela 8 - Reagentes e produtos comerciais utilizados neste trabalho. 75

Tabela 9 - Número de lâmpadas UVC e respectivas irradiâncias à distância de $15 \mathrm{~cm}$ (superfície do líquido).

Tabela 10 - Condições experimentais usadas nos ensaios de $\mathrm{UVC} / \mathrm{H}_{2} \mathrm{O}_{2}$ seguindo a matriz experimental Doehlert para duas variáveis. 

Tabela 12 - Resultados dos parâmetros de validação analíticos das curvas de calibração dos compostos (AZO, DFZ e IMD) em padrão analítico e nos produtos comerciais em HPLC. A: área da curva; [C]: concentração do composto $\left(\mathrm{mg} \mathrm{L}^{-1}\right) ; R^{2}$ : coeficiente de determinação; AM: Amistar Top ${ }^{\circledR}$; P: Provado 200 SC $^{\circledR}$

Tabela 13 - Constantes de pseudo-primeira ordem ( $k$ ') para AZO, DFZ e IMD em diferentes condições de irradiância.

Tabela 14 - Valores obtidos para as taxas de degradação de pseudo-primeira ordem para cada IA nos experimentos $\mathrm{UVC} / \mathrm{H}_{2} \mathrm{O}_{2}$ e respectivos coeficientes de determinação $\left(R^{2}\right)$. Experimentos realizados conforme o planejamento Doehlert (Tabela 10 e Figura $6)$. 101

Tabela 15 - Análise de variância (ANOVA) para kAzo (processo $\mathrm{UVC} / \mathrm{H}_{2} \mathrm{O}_{2}$, matriz Doehlert, experimentos 1-9). 104

Tabela 16 - Análise de variância (ANOVA) para $k_{D F Z}$ (processo $U \mathrm{VV} / \mathrm{H}_{2} \mathrm{O}_{2}$, matriz Doehlert, experimentos 1-9). 104

Tabela 17 - Análise de variância (ANOVA) para kIMD (processo UVC/ $\mathrm{H}_{2} \mathrm{O}_{2}$, matriz Doehlert, experimentos 1-9) 104

Tabela 18 - Análise de variância (ANOVA) para kAZO (processo $U \mathrm{VC} / \mathrm{H}_{2} \mathrm{O}_{2}$, experimentos 1-18). 106

Tabela 19 - Análise de variância (ANOVA) para kDFZ (processo UVC/ $\mathrm{H}_{2} \mathrm{O}_{2}$, experimentos 1-18). 106

Tabela 20 - Análise de variância (ANOVA) para kimD (processo $\mathrm{UVC} / \mathrm{H}_{2} \mathrm{O}_{2}$, experimentos 1-18). 106 

Tabela 21 - Resultados da caracterização das amostras de matriz real coletadas na indústria.

Tabela 22 - Taxas de degradação de pseudo-primeira ordem ( $\left.k^{\prime}\right)$ para AZO, DFZ e IMD em ensaios $\mathrm{UVC} / \mathrm{H}_{2} \mathrm{O}_{2}$ com as matrizes reais obtidas na lavagem de tomates na indústria. 113

Tabela 23 - Índice mitótico (IM) das células meristemáticas das raízes de Allium cepa (para um aumento de $40 \times$ ) para ensaios com soluções dos padrões analíticos dos compostos e amostras reais coletadas na indústria, dopadas com os produtos comerciais Amistar Top ${ }^{\circledR}$ e Provado $200 \mathrm{SC}^{\circledR}$ e submetidas ao tratamento UVC/ $\mathrm{H}_{2} \mathrm{O}_{2}$ nas condições $\left[\mathrm{H}_{2} \mathrm{O}_{2}\right] 0=130 \mathrm{mg} \mathrm{L}^{-1}$ e Euvc $=28,6 \mathrm{~W} \mathrm{~m}^{-2}$ indicadas pela matriz Doehlert. 115

Tabela 24 - Valores para a taxa média obtidos através da parametrização dos dados experimentais para IM. 



\section{LISTA DE ABREVIATURAS E SIGLAS}

AdOx - Grupo de Pesquisa em Processos Oxidativos Avançados

ANOVA - análise de variância

ANVISA - Agência Nacional de Vigilância Sanitária

AZO - azoxistrobina

BPA - boas práticas agrícolas

CAS - Chemical Abstract Service

CIRRA - Centro Internacional de Referência em Reúso de Água

DDT - dicloro-difenil-tricloroetano

DFZ - difenoconazol

DL50 - dose letal

EMATER-MG - Empresa de Assistência Técnica e Extensão Rural do Estado de Minas Gerais

$E_{E O}$ - energia elétrica por ordem de grandeza de poluente removido por unidade de volume

EDO - equações diferenciais ordinárias

HPLC - High Performance Liquid Chromatography

IA - ingredientes ativos 

Ibama - Instituto Brasileiro de Meio Ambiente e Recursos Renováveis

IDA - ingestão diária aceitável

IM - índice mitótico

IMD - imidacloprido

LD - limite de detecção

LMR - limite máximo de resíduos

LQ - limite de quantificação

MM - massa molar

MAPA - Ministério da Agricultura, Pecuária e Abastecimento

$\mathrm{MBH}$ - microbacias hidrográficas

MS - Ministério da Saúde

nAChRs - receptores nicotínicos de acetilcolina

NCD - número de células em divisão celular

NCT - número total de células

PA - padrão analítico

POA - processos oxidativos avançados

PNDA - Programa Nacional de Defensivos Agrícolas 

PVDF - polyvinylidene difluoride

TOC - carbono orgânico total

UFLC - ultra fast liquid chromatography

UVC - ultravioleta C

UV/VIS - UV-visível

VMP - valores máximos permitidos 



\section{LISTA DE SÍMBOLOS}

$A_{10}$ - absorbância decádica
c- concentração molar $\left(\mathrm{mol} \mathrm{L}^{-1}\right)$
$C_{i}$ - valores codificados da variável $i$
$E_{\mathrm{p}, 0}$ - taxa específica de fótons incidentes $\left(\mathrm{mol}\right.$ fótons $\left.\mathrm{L}^{-1} \mathrm{~s}^{-1}\right)$
Euvc - irradiância no UVC $(251-257 \mathrm{~nm})\left(\mathrm{W} \mathrm{m}^{-2}\right)$
fo - função objetivo
$k$ - taxa específica de pseudo-primeira ordem $\left(\mathrm{s}^{-1}\right)$
log Kow - coeficiente de partição octanol-água em pH 7 a $20^{\circ} \mathrm{C}$

$\ell$ - caminho óptico $(\mathrm{cm})$

$l_{\text {reator }}$ - caminho óptico de propagação da radiação no reator fotoquímico $(\mathrm{cm})$

$\mathrm{Pv}$ - pressão de vapor a $25^{\circ} \mathrm{C}(\mathrm{mPa})$

$R^{2}$ - coeficiente de determinação

$x_{i}$ - valores reais da variável $i$

$x_{i}^{0}$ - condições no ponto central da matriz experimental base

símbolos gregos

$\alpha$-valor codificado limite para cada variável 

$\alpha_{254 \mathrm{~nm}}$ - coeficiente de absorção desconsiderando a espécie $\mathrm{P}\left(\mathrm{cm}^{-1}\right)$

$\Delta x_{i}$ - passo de variação

$\varepsilon \lambda$ - coeficiente de absorção molar decádico $\left(\mathrm{L} \mathrm{mol}^{-1} \mathrm{~cm}^{-1}\right)$

$\lambda$ - comprimento de onda $(\mathrm{nm})$

$\Phi$ - rendimento quântico $\left(\mathrm{mol} \mathrm{Einstein}^{-1}\right)$

Øinterno - diâmetro interno $(\mathrm{cm})$ 



\section{SUMÁRIO}

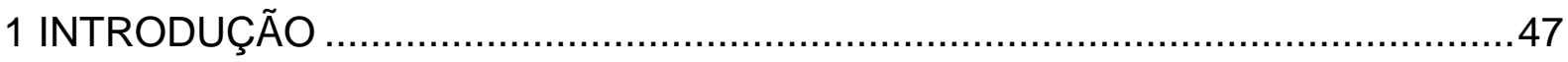

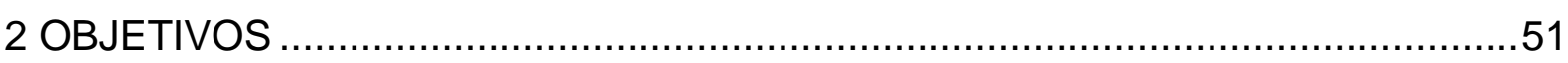

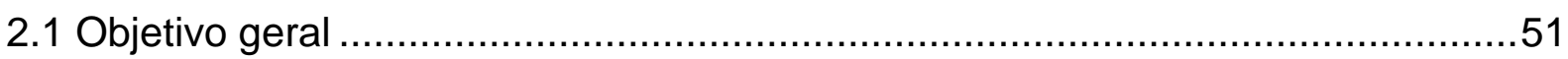

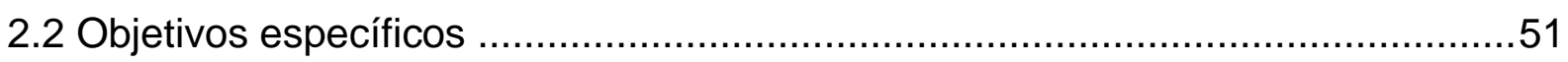

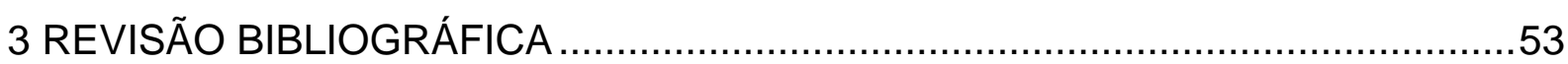

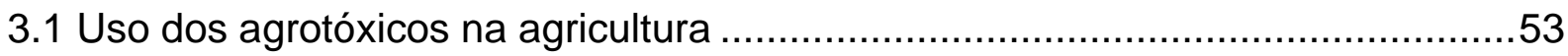

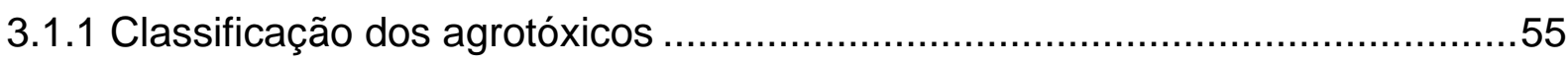

3.1.2 Vias de contaminação e legislação vigente ................................................58

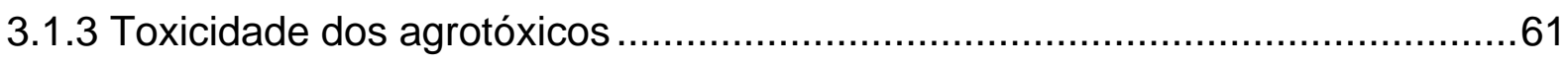

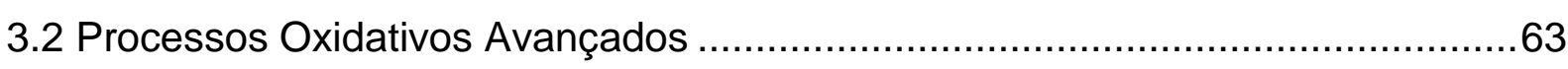

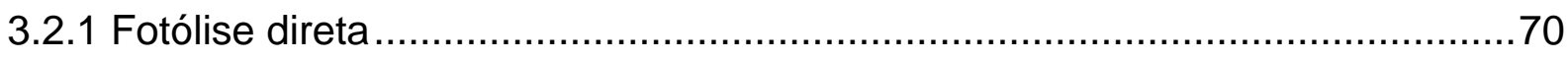

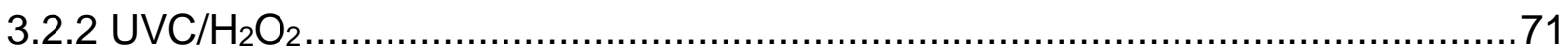

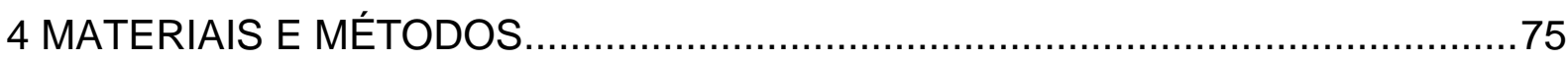

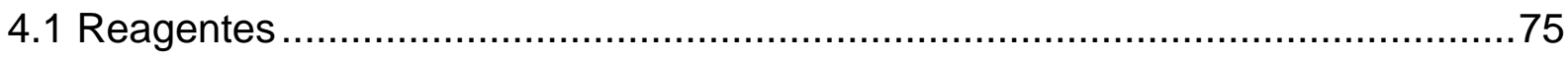

4.2 Estimativa da concentração dos IA na calda dos produtos comerciais e na água

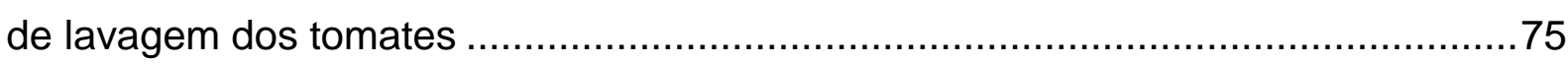

4.3 Obtenção do espectro de absorção UV-visível dos IA …..................................77

4.4 Avaliação da estabilidade dos IA na água de lavagem sintética .........................77

4.5 Fotodegradação dos IA utilizando água de lavagem sintética: fotólise direta e

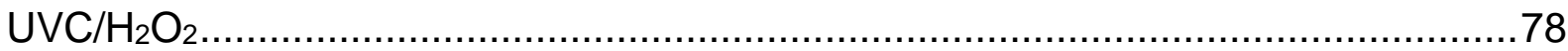

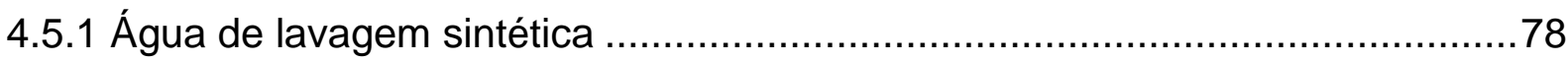

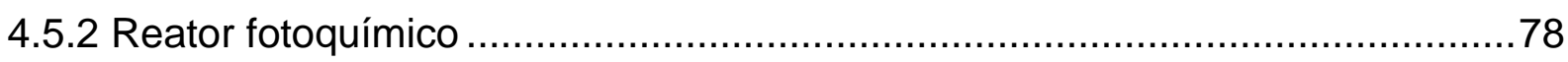

4.5.3 Determinação do rendimento quântico da fotólise dos IA ……........................79

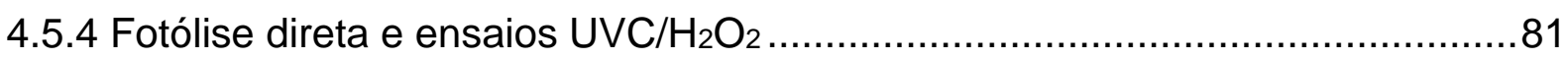

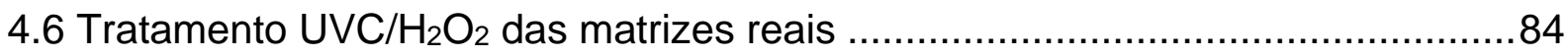

4.6.1 Coleta e caracterização físico-química da matriz real ....................................84

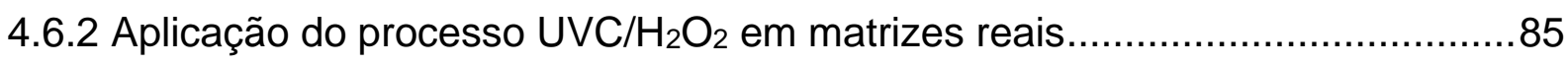

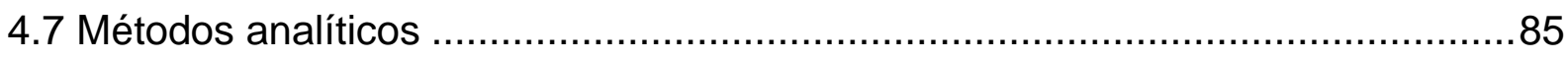

4.8 Ensaios de citotoxicidade e genotoxicidade com Allium cepa............................87

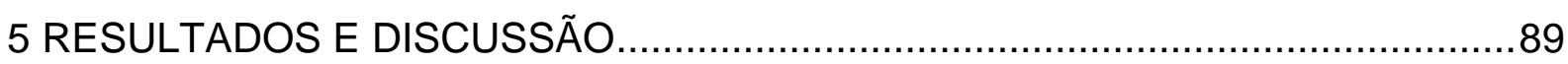

5.1 Espectros de absorção dos ingredientes ativos .............................................. 89

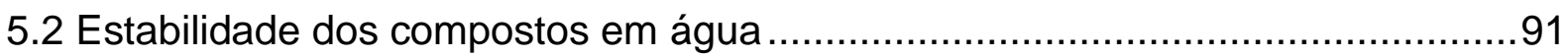





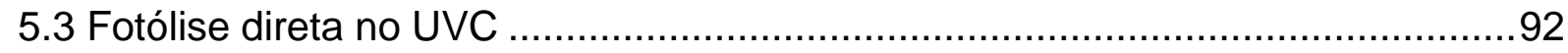

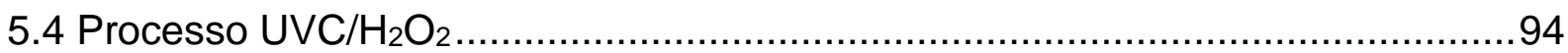

5.5 Aplicação do processo $\mathrm{UVC} / \mathrm{H}_{2} \mathrm{O}_{2}$ ao tratamento de matrizes reais..................111

5.6 Estudo da citotoxicidade e genotoxicidade com o organismo-teste Allium cepa 114

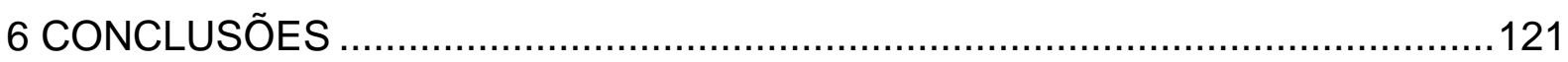

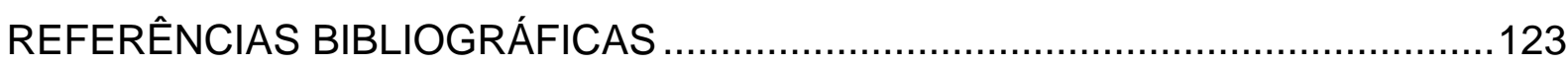

APÊNDICE A - CURVAS DE CALIBRAÇÃO CROMATOGRÁFICA ......................133 



\section{INTRODUÇÃO}

Com o crescimento populacional, tem aumentado a demanda da população por alimentos de qualidade e, em consequência, têm sido cada vez mais utilizados agrotóxicos para controle de pragas durante o cultivo de frutas e vegetais. Atualmente, o Brasil é um dos maiores produtores agropecuários do mundo e, desde 2008, o maior consumidor mundial de agrotóxicos (ALBUQUERQUE et al., 2016; BIANCHI; FERNANDES; MARIN-MORALES, 2016), tendo sido consumidas cerca de 620.000 toneladas de ingredientes ativos (IA) somente no ano de 2019 (IBAMA, 2019). Cresce também a cada ano o número de registros de novos produtos, tendo sido registrados 321 em 2020 (MAPA, 2020).

Dentre esses compostos, a azoxistrobina (AZO) é um fungicida sistêmico do grupo das estrobilurinas, que atua na inibição da germinação de esporos e no crescimento micelial de fungos (ALI; DESOKY; RADY, 2019; YANG et al., 2019). Por sua vez, o difenoconazol (DFZ) é um fungicida sistêmico do grupo triazol, utilizado na prevenção e cura de diversas culturas, capaz de interferir no crescimento dos fungos (LI; MA; LU, 2013). Por fim, o imidacloprido (IMD) é um inseticida sistêmico do grupo do neonicotinóides, eficiente contra insetos sugadores, atuando diretamente no sistema nervoso central desses organismos (FENOLL et al., 2015). Esses compostos são constituintes de diversos produtos comerciais manipulados nas lavouras brasileiras, incluindo a cultura de tomate, matéria-prima de diversos produtos da agroindústria.

De acordo com as Boas Práticas Agrícolas (BPA) estabelecidas pelo Ministério da Agricultura, Pecuária e Abastecimento (MAPA), o produtor deve respeitar o intervalo de segurança ou período de carência, que corresponde ao tempo entre a aspersão dos produtos formulados na cultura e a colheita, de forma que os compostos possam agir de maneira eficiente no combate às pragas e resíduos presentes nos frutos sejam reduzidos. No entanto, estudos tais como o de Andrade et al. (2015) e Rodrigues et al. (2017) comprovam que, ainda que essas práticas sejam adotadas, na etapa de lavagem dos frutos durante seu processamento, resíduos dos compostos não absorvidos ainda na lavoura são transferidos para a fase aquosa gerada na lavagem.

Ainda que em concentrações residuais, esses compostos podem causar efeitos adversos à saúde humana e ao meio ambiente. Han et al. (2016) verificaram o efeito 
nocivo da AZO em organismos aquáticos, enquanto Pan et al. (2017) perceberam que o DFZ é capaz de atuar como perturbador endócrino. Além disso, Silva et al. (2016) investigaram que a exposição contínua de abelhas a concentrações do IMD de 4,25 e $21,25 \mathrm{mg} \mathrm{L}^{-1}$ altera sua capacidade locomotora, podendo afetar sua busca por alimentos e comprometer o funcionamento das colônias.

De acordo com Maurya et al. (2019), fungicidas do grupo triazol, como o DFZ, possuem estabilidade fotoquímica e baixa biodegradabilidade. Monsalvo et al. (2014) investigaram a biodegradabilidade e toxicidade de três pesticidas, dentre eles o IMD, em um reator biológico de leito granular, e constataram que o IMD não foi removido após mais de 20 dias, enquanto Tišler et al. (2009) verificaram que o IMD não é rapidamente biodegradado em ambientes aquáticos; cabe lembrar que este composto foi recentemente adicionado à lista de Substâncias Prioritárias na Europa, através da Decisão 2015/495/EU (BARBOSA et al., 2016). Uma vez que os processos convencionais de tratamento de efluentes não são capazes de remover esses compostos, devido principalmente à sua estabilidade ou à baixa biodegradabilidade, uma alternativa que tem ganhado destaque são os Processos Oxidativos Avançados (POA). Esses processos são eficientes na remoção de compostos orgânicos persistentes, através da geração de radicais hidroxila $\left(\mathrm{HO}^{*}\right)$, capazes de reagir com os poluentes, alcançando praticamente sua degradação completa (BETHI et al., 2016; AMETA; AMETA, 2018).

No que se refere ao tratamento de efluentes contendo pesticidas, a literatura registra estudos relacionados à degradação dos IA em estudo por POA, tais como fotocatálise (NAVARRO et al., 2009; RÓZSA et al., 2019; ALISTE et al., 2020), fotoFenton (NAVARRO et al., 2011; FIORENZA et al., 2020) e ozonização (BAGHIRZADE; YETIS; DILEK, 2020). Ademais, os três compostos já foram detectados em águas superficiais brasileiras (BORTOLUZZI et al., 2006; MONTAGNER et al., 2014). No entanto, não foram encontrados na literatura estudos referentes à degradação desses três compostos em mistura ou relacionados à sua presença em água de lavagem de frutos gerada na agroindústria.

O processo $\mathrm{UVC} / \mathrm{H}_{2} \mathrm{O}_{2}$ consiste na geração dos radicais $\left(\mathrm{HO}^{\circ}\right)$ através da quebra da ligação $\mathrm{O}-\mathrm{O}$ das moléculas de peróxido de hidrogênio $\left(\mathrm{H}_{2} \mathrm{O}_{2}\right)$, por meio de radiação ultravioleta (UVC) (MIERZWA; RODRIGUES; TEIXEIRA, 2018). Em comparação com outros $\mathrm{POA}$, podem ser mencionadas as seguintes vantagens desse processo (TANG, 2004): (i) os poluentes orgânicos podem ser degradados tanto 
através da fotólise quando pelos radicais hidroxila; (ii) os microrganismos podem ser inativados pela radiação UVC, enquanto os radicais hidroxila são gerados de maneira eficiente (MIERZWA; RODRIGUES; TEIXEIRA, 2018); (iii) a alta solubilidade do $\mathrm{H}_{2} \mathrm{O}_{2}$ permite armazenamento de suas soluções, facilitando o manuseio, de forma que ele se mistura facilmente com o efluente a ser tratado, em comparação com a ozonização, em que a transferência do oxidante gasoso para a fase aquosa é limitada pela transferência de massa; (iv) não há geração de lodo (como no caso dos processos Fenton e Foto-Fenton) ou emissões de gases; (v) não são necessários processos complementares de separação ou descarte (como na fotocatálise utilizando $\mathrm{TiO}_{2}$ ); (vi) é um processo de simples operação e implantação. Por outro lado, em termos de aplicação industrial, Miklos et al. (2018) consideraram o processo $\mathrm{UVC} / \mathrm{H}_{2} \mathrm{O}_{2}$ como energeticamente viável, baseado no parâmetro de energia elétrica por ordem de grandeza de poluente removido por unidade de volume $\left(E_{E O}\right)$, que representa a energia elétrica em quilowatt-hora ( $\mathrm{kWh}$ ) necessária para a degradação de um contaminante em uma ordem de grandeza, presente em $1 \mathrm{~m}^{3}$ de água contaminada, e corresponde à maior parcela dos custos envolvidos (BOLTON et al., 1996). No entanto, ainda que esse processo já seja amplamente utilizado, poucos dados existem sobre sua aplicação para descontaminação dos compostos estudados.

Nesse contexto, o presente trabalho tem como objetivo avaliar a degradação dos ingredientes ativos AZO, DFZ e IMD, usados na cultura de tomates processados na agroindústria e presentes em efluentes aquosos gerados na lavagem dos frutos, através da fotólise direta e do processo oxidativo avançado $\mathrm{UVC} / \mathrm{H}_{2} \mathrm{O}_{2}$. 



\section{OBJETIVOS}

\subsection{Objetivo geral}

O objetivo deste trabalho consiste em avaliar a degradação dos ingredientes ativos (IA) azoxistrobina (AZO), difenoconazol (DFZ) e imidacloprido (IMD) em meio aquoso, através da fotólise direta e do processo oxidativo avançado UVC/ $\mathrm{H}_{2} \mathrm{O}_{2}$.

\subsection{Objetivos específicos}

a) Estimar as concentrações esperadas dos IA selecionados na calda aplicada aos frutos na lavoura e na água de lavagem da agroindústria;

b) Avaliar o comportamento dos IA selecionados quanto à absorção de radiação UV-visível e à hidrólise na ausência de luz;

c) Avaliar e comparar a eficiência da fotólise direta e $U V C / \mathrm{H}_{2} \mathrm{O}_{2}$ quanto à degradação dos compostos;

d) Investigar os efeitos das variáveis de processo, tais como irradiância e concentração inicial de oxidante e encontrar as condições ótimas do processo $\mathrm{UVC} / \mathrm{H}_{2} \mathrm{O}_{2}$;

e) Verificar a influência da matriz no processo $\mathrm{UVC} / \mathrm{H}_{2} \mathrm{O}_{2}$ a partir das condições ótimas obtidas no sistema modelo;

f) Avaliar a citotoxicidade e genotoxicidade das soluções antes e após a aplicação do tratamento UVC/ $\mathrm{H}_{2} \mathrm{O}_{2}$, utilizando organismo Allium cepa. 



\section{REVISÃO BIBLIOGRÁFICA}

\subsection{Uso dos agrotóxicos na agricultura}

Desde os primórdios da civilização, o desenvolvimento da agricultura foi um dos fatores determinantes para que o ser humano pudesse abandonar a condição de nômade e fixar moradia em determinados locais, bem como aprimorar suas condições de vida. Com o aumento da população e consequentemente da demanda por alimentos, foram surgindo cada vez mais técnicas que permitissem o aumento da produção e fossem capazes de controlar as pragas que viessem a surgir nas lavouras, tais como a irrigação e o emprego de agroquímicos, que incluem os fertilizantes e os agrotóxicos (também chamados de pesticidas, defensivos agrícolas ou produtos fitossanitários) (SILVA; FAY, 2004).

A lei $n^{\circ} 7.802$, de 11 de julho de 1989 , regulamentada pelo Decreto $n^{\circ} \mathbf{4 . 0 7 4}$, de 2002, define o termo agrotóxico como sendo:

Produtos e agentes de processos físicos, químicos ou biológicos, destinados ao uso nos setores de produção, armazenamento e beneficiamento de produtos agrícolas, nas pastagens, na proteção de florestas nativas ou implantadas e de outros ecossistemas e também de ambientes urbanos, hídricos e industriais, cuja finalidade seja alterar a composição da flora ou da fauna, a fim de preservá-las da ação danosa de seres vivos considerados nocivos, e as substâncias e produtos empregados como desfolhantes, dessecantes, estimulantes e inibidores de crescimento (BRASIL, 1989).

Os primeiros compostos utilizados na prevenção de doenças e insetos remontam a 1000 a. C. e eram à base de enxofre. No século XVI, os chineses utilizavam arsênio como inseticida e, no século XVII, deu-se início à produção de pesticidas naturais a partir da nicotina, que era obtida através das folhas de tabaco (SILVA; FAY, 2004).

Já em 1934, inaugurou-se a era moderna dos agrotóxicos orgânicos sintéticos, com o uso dos chamados ditiocarbamatos e do dicloro-difenil-tricloroetano (DDT), que durante o período da Segunda Guerra Mundial era utilizado pelas tropas aliadas e populações civis no combate a doenças causadas por insetos como a malária, o tifo e a febre amarela, e devido ao seu baixo custo, começou a ser aplicado nas lavouras, se tornando o inseticida mais utilizado (SILVA; FAY, 2004).

Na década de 1950, com a chamada Revolução Verde nos Estados Unidos, foi 
incentivado o uso em massa dos agrotóxicos, para aumento da produtividade nas lavouras e modernização das técnicas agrícolas. No Brasil, esse movimento chegou na década de 1960 e ganhou força em 1970, com a criação do Programa Nacional de Defensivos Agrícolas (PNDA) (LOPES; ALBUQUERQUE, 2018).

Com as políticas da Revolução Verde, o uso de sementes transgênicas, o aumento dos créditos agrícolas subsidiados e a isenção de tributos, atualmente, o Brasil é um dos principais produtores e exportadores agrícolas (PIGNATI et al., 2017) e, desde 2008, o maior consumidor de agrotóxicos do mundo, o que corresponde a cerca de $20 \%$ do uso global (ALBUQUERQUE et al., 2016; BIANCHI; FERNANDES; MARIN-MORALES, 2016).

Segundo estudo de Bombardi (2017), o consumo de ingredientes ativos no Brasil aumentou cerca de 135\% nos anos 2000 a 2014 e de acordo com o último boletim publicado pelo Instituto Brasileiro de Meio Ambiente e Recursos Renováveis (Ibama), cerca de 620.000 toneladas foram utilizadas somente no ano de 2019 (Figura 1) (IBAMA, 2019).

Figura 1 - Consumo anual de agrotóxicos no Brasil (2000-2019) em toneladas de ingrediente ativo.

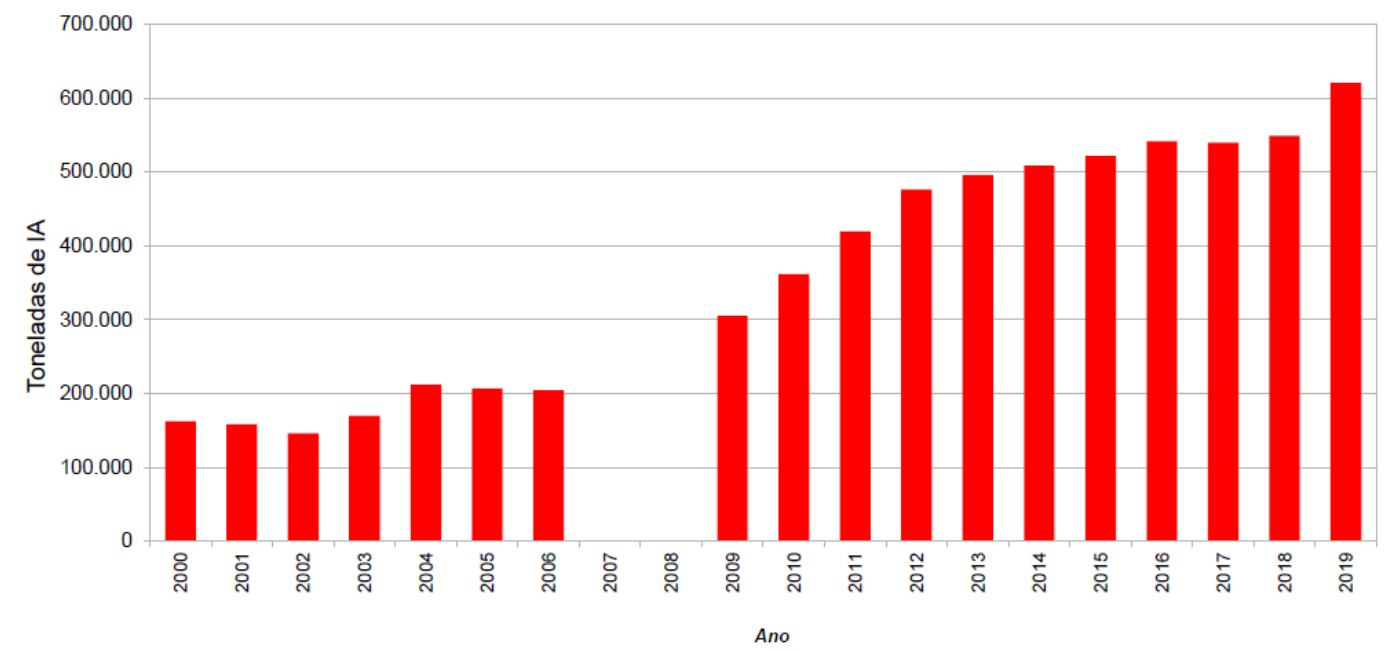

Fonte: Ibama (2019).

Além disso, nos últimos anos vem crescendo o número de liberações de produtos pelo Ministério da Agricultura, Pecuária e Abastecimento (MAPA), tendo sido registrados 321 produtos em 2020 (MAPA, 2020). 


\subsubsection{Classificação dos agrotóxicos}

A ação dos agrotóxicos se deve à presença em sua composição de compostos denominados ingredientes ativos (IA), que incidem sobre a atividade biológica dos organismos sensíveis a eles, sendo eficazes contra a praga ou enfermidade a ser combatida (TERRA; PELAEZ, 2008).

Para a fabricação dos produtos comerciais, um composto químico, chamado produto técnico, que contém determinada concentração dos IA, é misturado a ingredientes inertes, a fim de facilitar o controle e aplicação dos mesmos (BRITO; MELO; GIONGO, 2010). Essa mistura é chamada de produto formulado e pode ser feita através da diluição em solventes, pulverização em argila ou mistura com carreadores. As formulações podem ser sólidas (pó-seco, pó-molhável e grânulo) ou líquidas (que incluem as solúveis em água e as emulsionáveis) e dependem de fatores tais como propriedades físico-químicas, eficiência biológica do IA, relação entre a praga e o organismo hospedeiro e equipamento de aplicação disponível (SILVA; FAY, 2004).

Por compreenderem uma vasta gama de substâncias químicas e biológicas, os agrotóxicos podem ser classificados de acordo com o organismo alvo de controle, a estrutura química das substâncias ativas e com seus efeitos ao meio ambiente e à saúde (PERES; MOREIRA, 2003). A Tabela 1 ilustra a classificação desses compostos de acordo com o organismo-alvo que combatem.

Tabela 1 - Classificação dos pesticidas de acordo com organismo-alvo de controle.

\begin{tabular}{cc}
\hline Classe & Organismo-alvo de controle \\
\hline Acaricidas & Ácaros \\
Avicidas & Aves \\
Bactericidas & Bactérias \\
Carrapaticidas & Carrapatos \\
Columbicidas & Pombos \\
Formicidas & Formigas \\
Fungicidas & Fungos \\
Herbicidas & Ervas daninhas \\
Inseticidas & Insetos \\
Larvicidas & Larvas \\
Molusquicidas & Moluscos \\
Nematicidas & Vermes \\
Piolhicidas & Piolhos \\
Pisticidas & Peixes \\
Predacidas & Vertebrados \\
Purgicidas & Pulgas \\
Raticidas & Roedores \\
\hline
\end{tabular}

Fonte: Melnikov (1971). 
No que se refere aos efeitos desses compostos ao meio ambiente e à saúde do ser humano, os agrotóxicos podem ser classificados de acordo com a toxicidade, que é relacionada à dose letal (DL50) (PERES; MOREIRA, 2003). A Lei oㅡ 7802, de 11 de julho de 1989, regulamenta que nos rótulos desses produtos devem constar suas respectivas classificações toxicológicas, indicadas por faixas coloridas (BRASIL, 1989), como informa a Tabela 2.

Tabela 2 - Classificação toxicológica dos agrotóxicos.

\begin{tabular}{cccc}
\hline Classe toxicológica & Toxicidade & $\mathbf{D L}_{\mathbf{5 0}}\left(\mathbf{m g ~ \mathbf { ~ g g } ^ { - 1 } )}\right.$ & $\begin{array}{c}\text { Cor da faixa de } \\
\text { rótulo e bula }\end{array}$ \\
\hline I & Extremamente tóxico & $\leq 5$ & Vermelha \\
II & Altamente tóxico & $5-50$ & Amarela \\
III & Medianamente tóxico & $50-500$ & Azul \\
IV & Pouco tóxico & $500-5000$ & Verde \\
\hline
\end{tabular}

Fonte: Adaptada de Peres e Moreira (2003); ANVISA (2018).

Ademais, de acordo com o mecanismo de ação, os agrotóxicos podem ser divididos em (SILVA; FAY, 2004):

a) Agrotóxicos de contato (ou não sistêmicos): Não penetram no tecido vegetal, não sendo transportados através do sistema vascular das plantas;

b) Agrotóxicos sistêmicos: São capazes de penetrar no sistema vascular das plantas e se movimentar através dele.

Os agrotóxicos de contato têm como desvantagem o fato de que, por não penetrarem na cutícula vegetal, são mais suscetíveis a variações do clima, deixando a planta desprotegida ao ataque de organismos danosos. No entanto, não apresentam problemas de fitotoxicidade, o que pode ocorrer no caso dos pesticidas sistêmicos. Estes, por sua vez, são pouco afetados pelo clima, conferindo proteção e inibindo o crescimento de organismos danosos (SILVA; FAY, 2004).

Dentre os IA existentes e autorizados no Brasil, destacam-se os compostos azoxistrobina (AZO), difenoconazol (DFZ) e imidacloprido (IMD), presentes em produtos comerciais formulados amplamente utilizados em culturas como a do tomate, comum na dieta dos brasileiros e matéria prima para diversos produtos da agroindústria. A Figura 2 apresenta um histórico das vendas por tonelada desses ingredientes ativos no Brasil entre os anos de 2009 e 2019. 
Figura 2 - Total de vendas dos ingredientes ativos AZO, DFZ e IMD no Brasil (20092019) em toneladas.

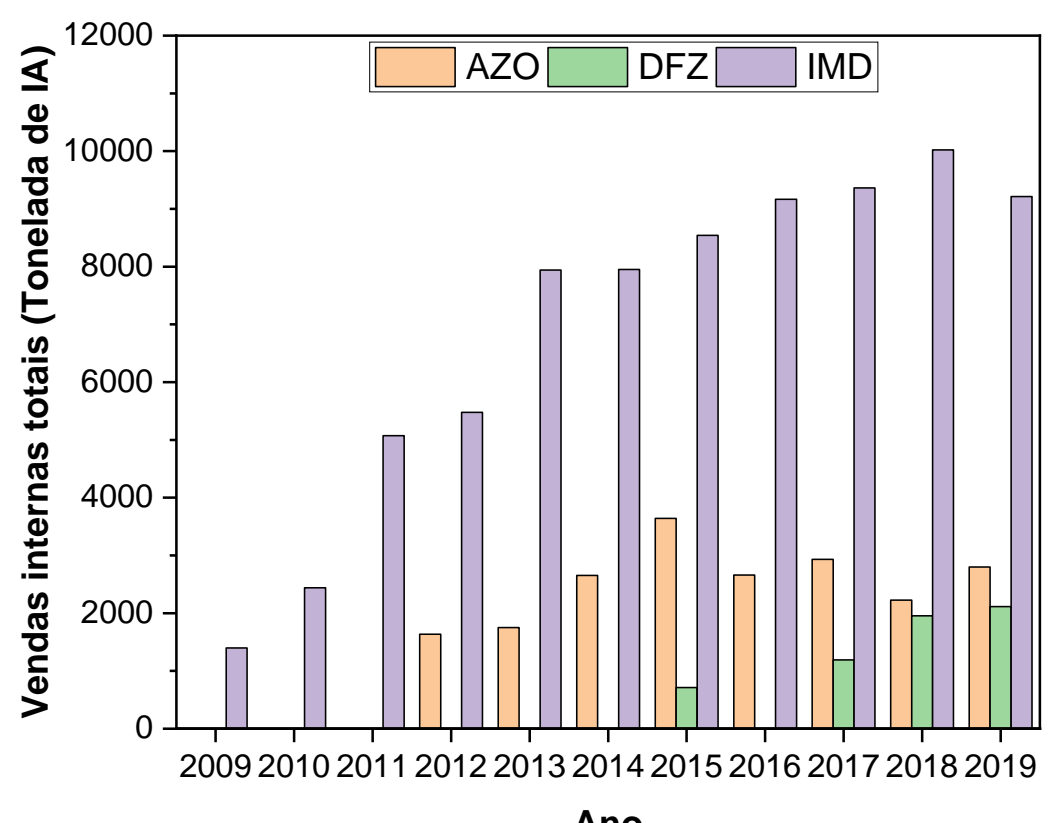

Ano

Fonte: Adaptado de Ibama (2019).

Representante do grupo das estrobilurinas, a AZO (metil (E)-2-\{2-[6-(2cianofenoxi)pirimidina-4-iloxi]fenil\}-3-metoxiacrilato) é um fungicida sistêmico que apresenta propriedades protetoras e curativas, atuando na inibição da germinação de esporos e no crescimento micelial de fungos (ALI; DESOKY; RADY, 2019; YANG et al., 2019). Segundo Venancio et al. (2003), as moléculas desse grupo são capazes de estimular o crescimento de certas espécies de plantas, o que resulta em sua maior eficiência no uso de água e nitrogênio, no aumento da atividade antioxidante e da produtividade. No Brasil, está presente em 55 produtos formulados (AGROFIT, 2021).

O DFZ (cis-trans-3-cloro-4-[4-metil-2-(1H-1,2,4-triazol-1-ilmetil)-1,3-dioxolan-2il]fenil 4-clorofenil eter) é um fungicida sistêmico do grupo químico triazol, aplicado normalmente de maneira foliar em culturas como café, maracujá, morango, goiaba e tomate (ANVISA, 2019) no controle de pragas tais como a ferrugem e mofo (BERNARDES et al., 2015) e está presente em 26 produtos formulados (AGROFIT, 2021).

Por fim, o IMD (1-(6-cloro-3-piridilmetil)-N-nitroimidazolidina-2-ilideneamina) é o inseticida sistêmico do grupo dos neonicotinóides mais utilizado, que age diretamente no sistema nervoso central dos insetos ligando-se seletivamente a 
receptores nicotínicos de acetilcolina (nAChRs), causando fadiga e interferindo na transmissão de impulsos nervosos (ARAGAHEGN et al., 2016; BIANCHI; FERNANDES; MARIN-MORALES, 2016). É eficaz no controle de insetos sugadores (BOURGIN et al., 2011) e está presente em 36 produtos formulados registrados no país (AGROFIT, 2021). A Figura 3 apresenta as fórmulas estruturais desses compostos, enquanto a Tabela 3 apresenta suas principais propriedades físicoquímicas.

Figura 3 - Estruturas químicas dos compostos AZO (a), DFZ (b) e IMD (c).

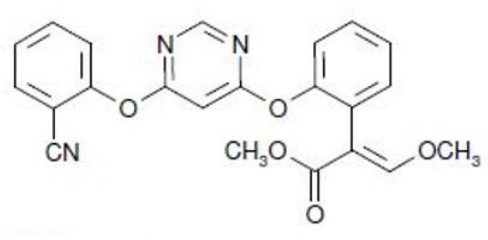

(a)

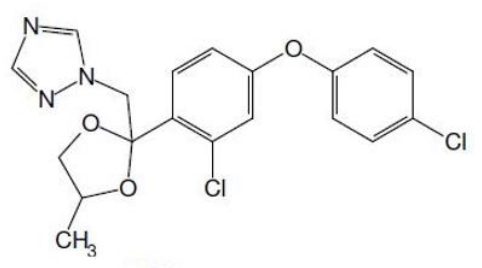

(b)

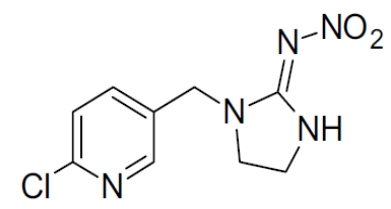

(c)

Fonte: ANVISA (2019).

Tabela 3 - Propriedades físico-químicas dos IA estudados.

\begin{tabular}{|c|c|c|c|c|c|c|c|c|}
\hline $\begin{array}{l}\text { Nome } \\
\text { IA }\end{array}$ & $\begin{array}{l}\text { Fórmula } \\
\text { Molecular }\end{array}$ & CAS & Classe & $\begin{array}{c}\mathrm{MM}^{\mathrm{a}} \\
\left(\mathrm{g} \mathrm{mol}^{-1}\right)\end{array}$ & $\begin{array}{l}\text { Classificação } \\
\text { Toxicológica }\end{array}$ & $\begin{array}{l}\text { Solubilidade }^{\mathrm{b}} \\
\left(\mathrm{mg} \mathrm{L}^{-1}\right)\end{array}$ & $\begin{array}{c}\mathrm{Pv}^{\mathrm{c}} \\
(\mathrm{mPa})\end{array}$ & $\begin{array}{l}\text { Log } \\
\mathrm{K}_{\mathrm{ow}}\end{array}$ \\
\hline AZO & $\mathrm{C}_{22} \mathrm{H}_{17} \mathrm{~N}_{3} \mathrm{O}_{5}$ & $\begin{array}{c}131860- \\
33-8\end{array}$ & Fungicida & 403,39 & III & 6,7 & $\begin{array}{c}1,10 x \\
10^{-7}\end{array}$ & 2,5 \\
\hline DFZ & $\mathrm{C}_{19} \mathrm{H}_{17} \mathrm{Cl}_{2} \mathrm{~N}_{3} \mathrm{O}_{3}$ & $\begin{array}{c}119446- \\
68-3\end{array}$ & Fungicida & 406,26 & I & 15 & $\begin{array}{c}3,33 x \\
10^{-5}\end{array}$ & 4,36 \\
\hline IMD & $\mathrm{C}_{9} \mathrm{H}_{10} \mathrm{CIN}_{5} \mathrm{O}_{2}$ & $\begin{array}{c}138261- \\
41-3\end{array}$ & Inseticida & 255,66 & III & 610 & $4,0 \times 10^{-7}$ & 0,57 \\
\hline
\end{tabular}

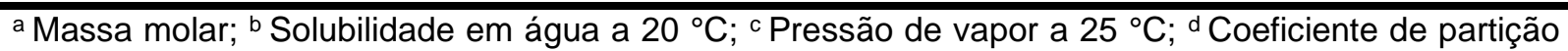
octanol-água em pH 7 a $20^{\circ} \mathrm{C}$.

Fonte: Adaptado de Andrade et al. (2015); Rodrigues et al. (2017); ANVISA (2019).

\subsubsection{Vias de contaminação e legislação vigente}

O livro "Primavera Silenciosa", de autoria da bióloga Rachel Louise Carson, lançado em 1962, apontou consequências a respeito do uso do inseticida DDT, que mais tarde viria a ser proibido em diversos países, e provocou questionamentos a respeito dos efeitos dos agrotóxicos à saúde humana e ao meio ambiente. A partir daí, houve aumento na preocupação por parte da comunidade científica, da sociedade civil e dos órgãos regulamentadores com respeito ao uso intensivo desses produtos na atividade agropecuária (DEZOTTI, 2008; CARNEIRO et al., 2015).

Com as pesquisas e o avanço das tecnologias de análise, os agrotóxicos podem ser vistos atualmente como compostos de preocupação emergente que, 
juntamente com outras substâncias naturais ou antropogênicas, tais como fármacos, produtos de cuidado pessoal e hormônios esteroides, causam efeitos adversos a diversos organismos, ainda que em baixas concentrações (RIBEIRO et al., 2015).

As vias de exposição do ser humano e do meio ambiente a esses compostos podem ser através da lavagem dos equipamentos de aspersão, dos resíduos presentes em alimentos ingeridos, pela ocorrência da lixiviação dos compostos no solo ou através dos efluentes gerados pela indústria, vindo a contaminar os corpos d'água.

A geração de efluentes contaminados a partir da lavagem de tomates pela agroindústria é um dos fatores de contaminação dos recursos hídricos. Antes do processamento e consequente produção da massa de tomate, entre outros produtos, os frutos recém-chegados das lavouras são descarregados pelos caminhões em esteiras, e água é usada para transportá-los do caminhão e lavar superficialmente os mesmos, como ilustra a Figura 4.

Figura 4 - Lavagem de tomates para processamento na agroindústria.
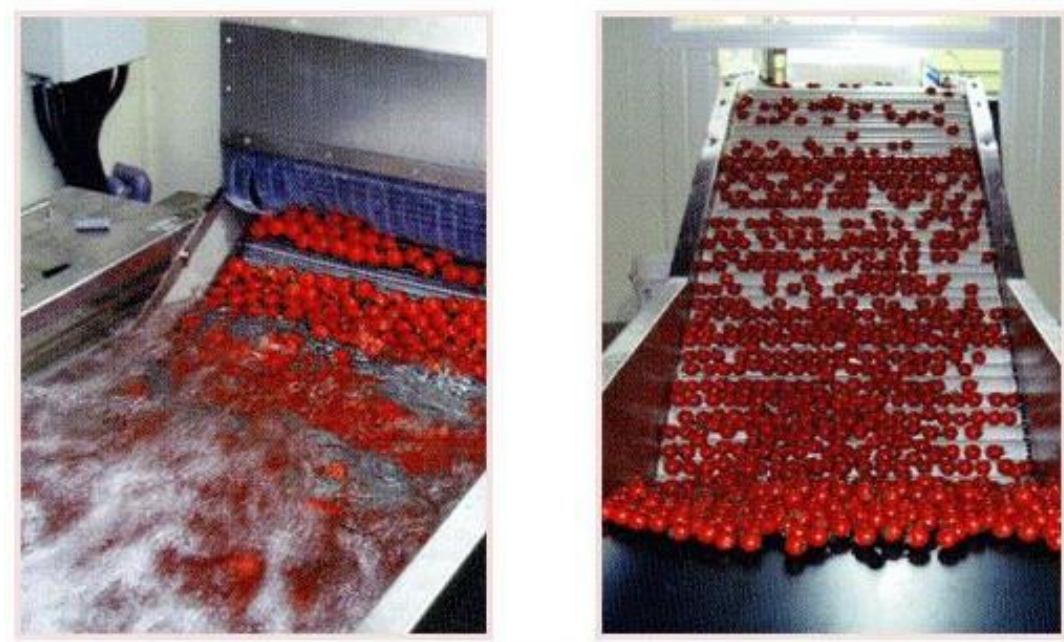

Fonte: Tropical Food Machinery (2019).

No Brasil, a Lei oㅜ 7.802, de 11 de julho de 1989, regulamentada pelo Decreto № 4.074 de 2002, estabelece que o controle dos agrotóxicos e seus componentes cabe a três órgãos federais, sendo eles o Ministério da Agricultura, Pecuária e Abastecimento (MAPA), o Instituto Brasileiro do Meio Ambiente e dos Recursos Naturais Renováveis (IBAMA) e a Agência Nacional de Vigilância Sanitária (ANVISA) (BRASIL, 1989). Esses órgãos são responsáveis por avaliar os produtos de acordo com sua eficiência agronômica, potencial toxicológico e potencial de periculosidade 
ao meio ambiente (PERES; MOREIRA, 2003).

O MAPA estabelece as Boas Práticas Agrícolas (BPA), que consistem em um conjunto de normas e recomendações que devem ser observadas pelos produtores durante o cultivo, aplicação dos agrotóxicos e demais atividades, visando o cuidado com a saúde humana e o meio ambiente. Segundo as BPA, o produtor deve observar as recomendações de aplicação e manuseio dos agrotóxicos, bem como respeitar o intervalo de segurança ou período de carência, que consiste no intervalo entre a aspersão do produto na cultura e a colheita (MAPA, 2017).

No entanto, ainda que o produtor respeite essas normas, estudos comprovam que os agrotóxicos aspergidos não são completamente absorvidos e metabolizados pelas plantas, permanecendo em concentrações residuais nos frutos. Durante a etapa de lavagem dos frutos anterior ao seu processamento na agroindústria, parte desses compostos é transferida para a fase aquosa. A Tabela 4 ilustra alguns dos estudos presentes na literatura relacionados à lavagem de tomates.

Tabela 4 - Estudos de lavagem de tomates.

\begin{tabular}{|c|c|c|c|c|c|c|}
\hline $\begin{array}{l}\text { Ingrediente } \\
\text { (s) ativo (s) }\end{array}$ & $\begin{array}{l}\text { Concentração } \\
\text { IA nos frutos } \\
\text { antes da } \\
\text { lavagem } \\
\left(\mathrm{mg} \mathrm{kg}^{-1}\right)\end{array}$ & $\begin{array}{c}\text { Concentração } \\
\text { IA nos frutos } \\
\text { após lavagem } \\
\left(\mathrm{mg} \mathrm{kg}^{-1}\right)\end{array}$ & $\begin{array}{l}\text { Concentração } \\
\text { IA na água de } \\
\text { lavagem } \\
\left(\mathrm{mg} \mathrm{L}^{-1}\right)\end{array}$ & $\begin{array}{c}\text { Quantidade } \\
\text { de frutos } \\
\text { lavados } \\
\text { (kg) }\end{array}$ & $\begin{array}{c}\text { Volume } \\
\text { de água } \\
\text { utilizado } \\
\text { na } \\
\text { lavagem } \\
\text { (L) }\end{array}$ & Referência \\
\hline Acetamiprido & 0,05 & 0,02 & 0,03 & \multirow{7}{*}{1} & \multirow[t]{7}{*}{$1-1$} & \multirow{7}{*}{$\begin{array}{l}\text { Andrade et al. } \\
\qquad(2015)\end{array}$} \\
\hline Azoxistrobina & 0,21 & 0,06 & 0,15 & & & \\
\hline Diflubenzuron & 0,54 & 0,14 & 0,40 & & & \\
\hline Dimetoato & 0,03 & 0,02 & 0,01 & & & \\
\hline Fipronil & 0,44 & 0,40 & 0,04 & & & \\
\hline Imidacloprido & 0,07 & 0,03 & 0,04 & & & \\
\hline Tiametoxam & 0,04 & 0,01 & 0,03 & & & \\
\hline Diclorvós & 3,6 & 2,5 & 0,11 & 0,1 & 1 & $\begin{array}{l}\text { Heshmati; } \\
\text { Nazemi } \\
(2017)\end{array}$ \\
\hline Metomil & 4,78 & 3,39 & 1,39 & \multirow{2}{*}{0,5} & \multirow{2}{*}{0,5} & \multirow{2}{*}{$\begin{array}{c}\text { Rasolonjatovo } \\
\text { et al. (2017) }\end{array}$} \\
\hline Acetamiprido & 0,50 & 0,30 & 0,20 & & & \\
\hline Azoxistrobina & 0,11 & 0,05 & Não estimado ${ }^{1}$ & \multirow{3}{*}{$\begin{array}{c}\text { Não } \\
\text { informado }\end{array}$} & \multirow{3}{*}{3} & \multirow{3}{*}{$\begin{array}{l}\text { Rodrigues et } \\
\text { al. (2017) }\end{array}$} \\
\hline Difenoconazol & 0,13 & 0,11 & Não estimado ${ }^{1}$ & & & \\
\hline Clorotalonil & 1,63 & 0,91 & Não estimado ${ }^{1}$ & & & \\
\hline Carbofurano & 0,14 & 0,01 & Não estimado ${ }^{1}$ & \multirow{4}{*}{$0,3-0,4$} & \multirow{4}{*}{$\begin{array}{c}\text { Não } \\
\text { informado }\end{array}$} & \multirow{4}{*}{$\begin{array}{c}\text { Wanwimolruk } \\
\text { et al. (2017) }\end{array}$} \\
\hline$\lambda$-Cialotrina & 0,05 & 0,02 & Não estimado ${ }^{1}$ & & & \\
\hline Fenobucarbe & 0,58 & 0,25 & Não estimado 1 & & & \\
\hline Isoprocarbe & 0,84 & 0,41 & Não estimado ${ }^{1}$ & & & \\
\hline
\end{tabular}

${ }^{1}$ Concentrações em água de lavagem indicados não puderam ser estimadas, por ausência de dados da quantidade de frutos lavados e/ou do volume de água utilizado na lavagem.

Fonte: Elaborada pela autora. 
Alimentarius, a ANVISA estabelece para cada IA um limite máximo de resíduos (LMR), que consiste na quantidade máxima de resíduos de agrotóxicos permitida nos alimentos consumidos pelos seres humanos, em decorrência da aplicação desses produtos na lavoura, dada por miligramas do composto por quilogramas de alimento.

Outro parâmetro estabelecido consiste na ingestão diária aceitável (IDA), parâmetro de segurança que estabelece, em miligramas do IA por peso corpóreo da pessoa em quilogramas, o máximo de ingestão permitida por dia, para que não ocorram danos à saúde. Para os compostos AZO, DFZ e IMD, os valores de LMR estabelecidos para o tomate são $0,5,0,1$, e $0,5 \mathrm{mg} \mathrm{kg}^{-1}$, respectivamente, enquanto os valores de IDA são 0,02, 0,6 e 0,05 $\mathrm{mg} \mathrm{kg}^{-1}$, respectivamente (ANVISA, 2019).

No que se refere às concentrações desses compostos na água, embora sejam estabelecidos alguns valores máximos permitidos (VMP) para alguns compostos na Portaria oㅡ 2.914, de 12 de dezembro de 2011 do Ministério da Saúde (MS), a legislação brasileira ainda não determina valores para os IA estudados neste trabalho, tanto para água de consumo humano (MS, 2011) quanto nos padrões de lançamento de efluentes (CONAMA, 2011). A União Europeia, por sua vez, adicionou o grupo químico dos neonicotinóides (incluindo o IMD) à lista de substâncias prioritárias a serem monitoradas na água, conforme a Diretriz 2008/105/CE.

\subsubsection{Toxicidade dos agrotóxicos}

Estando os agrotóxicos na lista de compostos de preocupação emergente, observa-se um aumento dos estudos investigando os efeitos dos mesmos à saúde do ser humano e ao meio ambiente, visando ao aumento de sua regulamentação e controle, bem como uma maior conscientização da população e dos órgãos públicos quanto ao seu uso.

Han et al. (2016) investigaram os efeitos toxicológicos da AZO, expondo machos e fêmeas da espécie dos peixe-zebra a concentrações de 1,0, 10 e $100 \mu \mathrm{g} \mathrm{L}$ 1 , e verificaram que houve indução do stress oxidativo nos rins da espécie e alterações no DNA, indicando que esse composto é genotóxico. Já Cao et al. (2019) investigaram os efeitos nos embriões dessa mesma espécie, quando os pais eram expostos a 2 , 20 e $200 \mu \mathrm{g} \mathrm{L}^{-1}$ de AZO durante 21 dias, constatando que esse IA pode afetar sua sobrevivência e desenvolvimento, assim como os genes envolvidos no sistema endócrino. A AZO também mostrou afetar a respiração mitocondrial, o crescimento 
das células e a proliferação de salmões jovens no estudo de Olvik et al. (2010).

Aragão et al. (2019) estudaram os efeitos citotóxicos e genotóxicos de fungicidas, dentre eles o DFZ nas células meristemáticas da alface (Lactuca sativa $L$.), concluindo que a exposição a esse IA afeta a multiplicação das células.

Ademais, Pan et al. (2017), ao variarem as concentrações de 0,01 a $0,5 \mu \mathrm{mol}$ $\mathrm{L}^{-1}$ do DFZ em células humanas HepG2, observaram a inibição da atividade enzimática do citocromo P450 3A4, importante enzima dos mamíferos responsável por oxidar toxinas, inativando-as para facilitar a eliminação pelo fígado ou intestino. Esses estudos indicaram o potencial do DFZ de atuar como perturbador endócrino.

Por sua vez, o composto IMD devido à sua alta solubilidade em água, possui grande potencial de contaminação de águas superficiais e exibe grande persistência nos solos aeróbios, sendo reportado com meia-vida nesse meio de até 365 dias, em estudos como o de Daam et al. (2013) e Barlett et al. (2019). Além disso, estudos como o de Cycon et al. (2013) e Pérez-lglesias et al. (2014) mostraram que a exposição contínua a esse IA pode afetar organismos aquáticos e anfíbios.

Silva et al. (2016) investigaram que a exposição a concentrações do IMD de 4,25 e $21,25 \mathrm{mg} \mathrm{L}^{-1}$ afetaram a atividade locomotora de abelhas, o que pode influenciar sua busca por alimentos e comprometer o funcionamento das colônias, contribuindo para sua drástica diminuição. $O$ efeito da exposição de abelhas a esse IA também foi verificado por outros autores, como Halm et al. (2006). Nos seres humanos, Kumar, Verma e Kumar (2013) relatam um caso de envenenamento de um trabalhador rural na Índia, que ao inalar acidentalmente o IA, sofreu problemas gastrointestinais e desconforto respiratório.

Como resultado de seu uso em larga escala, a presença dos IA estudados já foi verificada em concentrações residuais em águas superficiais brasileiras. A AZO e o DFZ foram detectados em amostras coletadas em rios do Estado de São Paulo em concentrações médias de 13,0 e 11,0 $\mathrm{ng} \mathrm{L}^{-1}$ (MONTAGNER et al., 2014), enquanto 0 IMD foi detectado em concentrações variando de 0,38 a 2,8 $\mu \mathrm{g} \mathrm{L}^{-1}$ em microbacias hidrográficas $(\mathrm{MBH})$ próximas a áreas de cultivo de fumo, em diferentes etapas dessa lavoura, conforme o estudo de Bortoluzzi et al. (2006). Resíduos do IMD também já foram detectados em vegetais (LIN et al., 2020) e até na urina humana (WANG et al., 2015). Visto que o mecanismo de ação dos pesticidas muitas vezes não se restringe somente aos organismo-alvo (HAN et al., 2016), é de extrema importância compreender os efeitos desses compostos em organismos vivos. 


\subsection{Processos Oxidativos Avançados}

Durante as últimas décadas, tem aumentado a preocupação com os poluentes orgânicos presentes em baixas concentrações e que podem causar danos à saúde e ao meio ambiente. Têm sido também propostos novos métodos que possam atingir uma remoção eficiente desses compostos persistentes nos efluentes (BANIC et al., 2014). Os métodos convencionais de tratamento incluem a adsorção em carvão ativado, coagulação, filtração, sedimentação, entre outros, que requerem etapas posteriores de recuperação/disposição e custos adicionais (RIBEIRO et al., 2015).

De acordo com Maurya et al. (2019), fungicidas do grupo triazol, tais como o DFZ, possuem alta estabilidade fotoquímica e baixa biodegradabilidade. Monsalvo et al. (2014) investigaram a biodegradabilidade de três pesticidas, dentre eles o IMD, em um reator biológico expandido de leito granular, e verificaram que esse composto não foi completamente removido decorridos cerca de 20 dias, enquanto Tišler et al. (2009) observaram que o IMD não é rapidamente biodegradado em ambientes aquáticos. Por sua vez, não foram encontrados estudos na literatura com relação à biodegradabilidade da AZO.

Como muitas vezes os processos de tratamento de efluente convencionais não são eficientes na remoção completa desses poluentes, os Processos Oxidativos Avançados (POA) têm chamado atenção por serem capazes de atingir a degradação completa desses compostos, ou transformá-los em compostos não tóxicos ou biodegradáveis (POYATOS et al., 2010; BETHI et al., 2016; AMETA; AMETA, 2018).

Os POA incluem diferentes sistemas de reação, entre os quais $\mathrm{UV} / \mathrm{O}_{3}$, $\mathrm{UVC} / \mathrm{H}_{2} \mathrm{O}_{2}$, Fenton, foto-Fenton, sonólise, fotocatálise, radiólise, entre outros. São processos capazes de gerar radicais hidroxila $\left(\mathrm{HO}^{\circ}\right)$, poderosos oxidantes $\left(\mathrm{E}^{0}=2,8 \mathrm{~V}\right.$ $\mathrm{EPH}$ em pH 0, e 1,95 V EPH, em pH 14), que reagem com a maioria dos compostos orgânicos com taxas de segunda ordem com constantes cinéticas de reação de $10^{8} \mathrm{a}$ $10^{10} \mathrm{~L} \mathrm{~mol}^{-1} \mathrm{~s}^{-1}$ e baixa seletividade. Além disso, são fáceis de serem produzidos e, em muitos casos, são capazes de mineralizar muitos contaminantes orgânicos, convertendo-os em dióxido de carbono $\left(\mathrm{CO}_{2}\right)$, água $\left(\mathrm{H}_{2} \mathrm{O}\right)$ e outros íons inorgânicos, de acordo com a reação global representada pela Equação 1. Os POA podem ser classificados em homogêneos e heterogêneos, de acordo com as fases envolvidas (OPPENLÄNDER, 2003; PARSONS, 2005; POYATOS et al., 2010; DENG; ZHAO, 2015; RIBEIRO et al., 2015; BETHI et al., 2016; AMETA; AMETA, 2018). 
POAs $\rightarrow \mathrm{HO} \cdot \stackrel{\text { poluentes }}{\longrightarrow} \mathrm{CO}_{2}+\mathrm{H}_{2} \mathrm{O}+$ íons inorgânicos

Além da completa mineralização dos poluentes orgânicos já mencionada, esses processos têm como vantagem a possibilidade de tratamento in situ, a não geração de lodo ou transferência de fase do poluente, a capacidade de tratamento de diferentes compostos simultaneamente, caminhos de reação não-seletivos, a fácil manutenção e a possibilidade de serem aplicados juntamente com outros processos como pré-tratamento (AMETA; AMETA, 2018). Estudos envolvendo a aplicação dos POA no tratamento dos IA são apresentados pela Tabela 5. 
Tabela 5 - Aplicação dos POA para tratamento dos IA estudados em meio aquoso.

\begin{tabular}{|c|c|c|c|c|c|}
\hline IA & POA utilizado & $\begin{array}{c}\text { Concentração } \\
\text { inicial do IA }\end{array}$ & Condições de processo & Resultados & Referência \\
\hline AZO & $\begin{array}{c}\text { Fotocatálise } \\
\mathrm{TiO}_{2}\end{array}$ & $15 \mathrm{mg} \mathrm{L}^{-1}$ & $\begin{array}{l}\text { - Lâmpada } 1500 \times \text { de xenônio, simulando a } \\
\text { - } \quad 5 \mathrm{~mL} \text { de de suspensão, contendo } 15 \mathrm{mg} \mathrm{L}^{-1} \\
\text { dos IA e } 200 \mathrm{mg} \mathrm{L}^{-1} \mathrm{TiO}_{2} \text {; } \\
\text { - Tempo de irradiação: } 120 \text { min. }\end{array}$ & $\begin{array}{l}\text { - } \quad \text { AZO é facilmente degradada e ocorre a } \\
\text { mineralização completa; } \\
\text { - } \quad \text { Análise dos caminhos de degradação e compostos } \\
\text { intermediários; } \\
\text { - Não informa as taxas de degradação; } \\
\text { - } \quad \text { Monitora TOC, evolução dos íons } \mathrm{NH}_{4}+\mathrm{e} \mathrm{NO}_{3} \text {. }\end{array}$ & Calza et al. (2006) \\
\hline AZO & $\begin{array}{l}\text { Fotocatálise } \\
\mathrm{ZnO} / \mathrm{Na}_{2} \mathrm{~S}_{2} \mathrm{O}_{8}\end{array}$ & $0,50 \mathrm{mg} \mathrm{L}^{-1}$ & 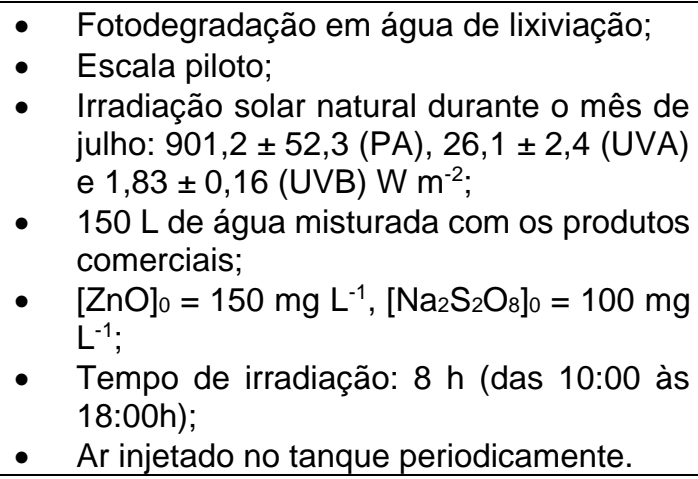 & $\begin{array}{l}\text { - A degradação dos IA estudados ocorre mais } \\
\text { lentamente na ausência do } \mathrm{ZnO} \text { (cerca de } 80 \% \text { da } \\
\text { [AZO] remanescente), e a adição do catalisador } \\
\text { sem a irradiação solar tem efeitos mínimos na } \\
\text { degradação dos compostos. } \mathrm{Na}_{2} \mathrm{~S}_{2} \mathrm{O}_{8} \text { reduz o } \\
\text { tempo de reação; } \\
\text { - Taxas de degradação da } \mathrm{AZO}: 0,6014 \pm 0,0460 \\
\text { - } \min ^{-1} \text { (fotocatálise) e } 0,0051 \pm 0,0011 \text { (fotólise); } \\
\text { - } \quad t_{1 / 2}=1,15 \text { min (fotocatálise) e } 135,9 \text { min (fotólise); } \\
\text { Mineralização completa após } 2 \mathrm{~h} \text {. }\end{array}$ & $\begin{array}{l}\text { Navarro et al. } \\
(2009)\end{array}$ \\
\hline AZO & Foto-Fenton & $\begin{array}{l}670 \mu \mathrm{g} \mathrm{L}^{-1} \text { (fotólise) } \\
\text { e } 0,5 \mathrm{mg} \mathrm{L}^{-1}\end{array}$ & $\begin{array}{ll}\text { - } & \text { Fotodegradação em água de lixiviação; } \\
\text { - } & \text { Escala piloto; } \\
\text { - } & \text { Irradiação solar natural durante o mês de } \\
& \text { setembro: } 950,2 \pm 30,6 \text { (VIS+NIR), } 23,6 \pm \\
& 2,1(\mathrm{UVA}) \text { e } 1,6 \pm 0,2 \text { (UVB), } 0,2 \pm 0,1 \mathrm{~W} \\
& \mathrm{~m}^{-2} ; \\
\text { - } & 150 \mathrm{~L} \text { de água misturada com os produtos } \\
& \text { comerciais; } \\
\text { - } & {\left[\mathrm{Fe}^{2+}\right]\left[\mathrm{H}_{2} \mathrm{O}_{2}\right]^{-1}=0,5 ;} \\
\text { - } & \mathrm{pH}=2,5-2,8 ; \\
\text { - } & \text { Tempo de irradiação: } 60 \text { minutos (entre } \\
& 12: 00 \text { e } 13: 00 h) ; \\
\text { - } & \text { Ar injetado no tanque periodicamente. }\end{array}$ & 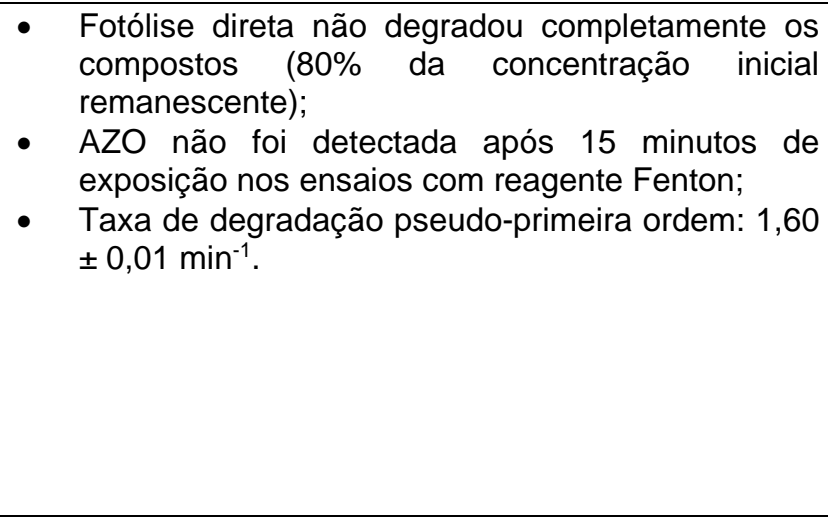 & $\begin{array}{c}\text { Navarro et al. } \\
(2011)\end{array}$ \\
\hline
\end{tabular}

Fonte: Elaborada pela autora. 
Tabela 5 (cont.) - Aplicação dos POA para tratamento dos IA estudados em meio aquoso.

\begin{tabular}{|c|c|c|c|c|c|}
\hline IA & POA utilizado & $\begin{array}{c}\text { Concentração inicial } \\
\text { do IA }\end{array}$ & Condições de processo & Resultados & Referência \\
\hline AZO & Fotocatálise $\mathrm{TiO}_{2}$ & $5 \mathrm{mg} \mathrm{L}^{-1}$ & $\begin{array}{ll}\text { - } & 320 \mathrm{~mL} \text { de água contaminada } \\
& \text { contendo diferentes compostos } \\
& \text { introduzida no reator; } \\
\text { - } & \text { Fluxo de ar: } 7,8 \mathrm{~mL} \mathrm{~s}^{-1} \\
& \text { (borbulhamento de ar ocorreu } \\
\text { durante } 1 \text { hora, na ausência de luz); } \\
\text { - } \quad \text { Lâmpada UVC (TUV } 30 \mathrm{~W} / \mathrm{G} 30 \mathrm{~TB} \text { ): } \lambda \\
\quad=365,404,435,491 \text { e } 546 \mathrm{~nm} ; \\
\text { - Área superficial do TiO }: 0,0879 \mathrm{~m}^{2} ; \\
\text { - } \quad \mathrm{K}=\text { superfície volume-1 }=255 \mathrm{~m}^{-1} ; \\
\text { - Temperatura: } 20 \text { a } 32 \circ \mathrm{C} ; \\
\text { - Tempo de irradiação: } 60 \text { minutos. }\end{array}$ & $\begin{array}{l}\text { - } \quad \text { Reator fotocatalítico foi desenvolvido para testar } \\
\text { remoção de pesticidas e fármacos na água; } \\
\text { - Adsorção da AZO no filme fino de } \mathrm{TiO}_{2} \text {, na } \\
\text { condição de pH entre 5,5 e } 6,5: 2 \pm 1 \% \text {; } \\
\text { - Taxa de degradação de pseudo-primeira ordem: } \\
5,1 \mathrm{~h}^{-1} \text { na ausência de } \mathrm{TiO}_{2} \text { ) e } 24,8 \mathrm{~h}^{-1} \text { (na } \\
\text { presença de } \mathrm{TiO}_{2} \text { ); } \\
\text { - } \\
\text { Na presença do } \mathrm{TiO}_{2} \text {, [AZO] estava abaixo dos } \\
\text { limites de detecção após } 20 \text { minutos de irradiação. }\end{array}$ & $\begin{array}{l}\text { Bessergenev } \\
\text { et al. (2017) }\end{array}$ \\
\hline DFZ & $\begin{array}{c}\text { Fotocatálise } \\
\text { homogênea } \\
\text { (Foto-Fenton, } \\
\text { Foto-Fenton-like) } \\
\text { e heterogênea } \\
\left(\mathrm{ZnO} \text { e } \mathrm{TiO}_{2}\right)\end{array}$ & $0,1 \mathrm{mg} \mathrm{L}^{-1}$ & 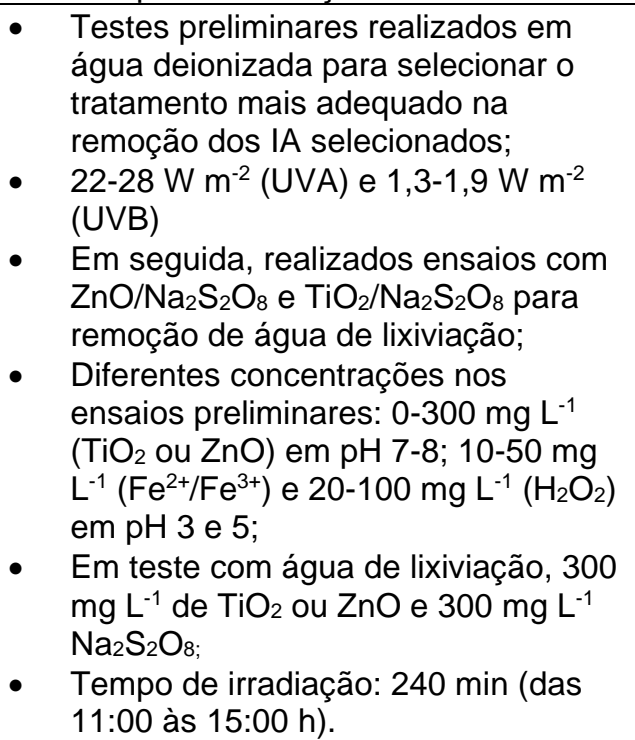 & 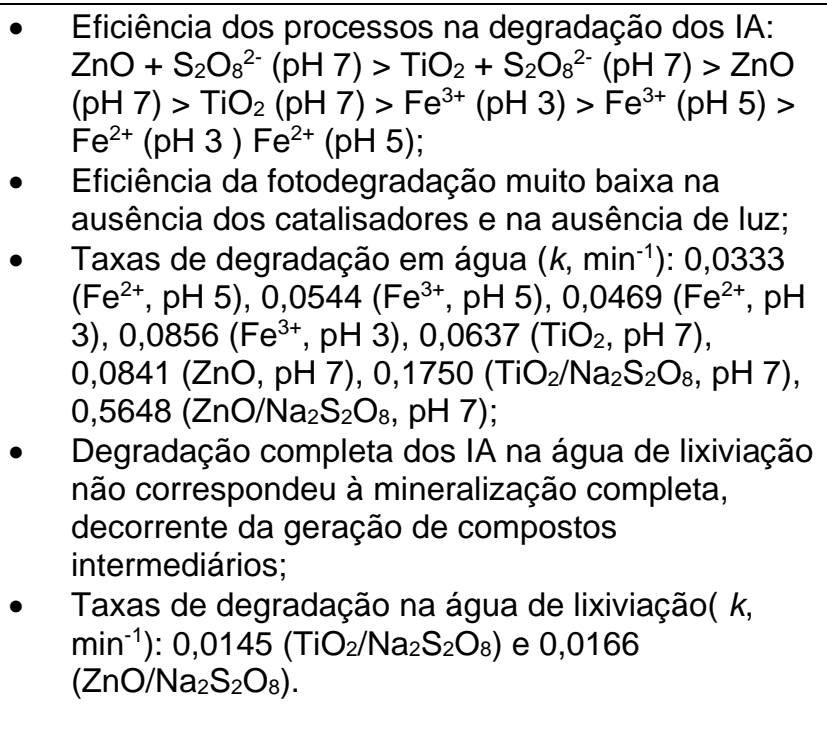 & $\begin{array}{l}\text { Aliste et al. } \\
(2020)\end{array}$ \\
\hline
\end{tabular}

Fonte: Elaborada pela autora. 
Tabela 5 (cont.) - Aplicação dos POA para tratamento dos IA estudados em meio aquoso.

\begin{tabular}{|c|c|c|c|c|c|}
\hline IA & POA utilizado & $\begin{array}{l}\text { Concentração } \\
\text { inicial do IA }\end{array}$ & Condições de processo & Resultados & Referência \\
\hline$\overline{D F Z}$ & $\begin{array}{l}\text { Fotocatálise } \\
\mathrm{TiO}_{2} / \mathrm{Na}_{2} \mathrm{~S}_{2} \mathrm{O}_{8}\end{array}$ & $0,18-0,26 \mathrm{mg} \mathrm{L}^{-1}$ & $\begin{array}{l}\text { - } \quad \text { Testes realizados em planta piloto; } \\
\text { - } \quad \text { Irradiação solar natural durante meses de setembro } \\
\text { e dezembro (7000 kJ m } \mathrm{m}^{-2} \text { de radiação UVA } \\
\text { acumulada); } \\
\text { - Ensaios realizados com os produtos comerciais em } \\
\text { efluente gerado nas fazendas a partir da lavagem } \\
\text { de tanques e containers durante vários dias; } \\
\text { - } \quad \text { Tempo de irradiação: } 10 \mathrm{~h}(\text { de } 9: 00 \text { às } 19: 00 \mathrm{~h}) ; \\
\text { - }\left[\mathrm{TiO}_{2}\right]_{0}=100-500 \mathrm{mg} \mathrm{L}^{-1} ;\left[\mathrm{Na}_{2} \mathrm{~S}_{2} \mathrm{O}_{8}\right]_{0}=300 \mathrm{mg} \mathrm{L}^{-1} \text {. }\end{array}$ & $\begin{array}{l}\text { Remoção: (15 a 4\%), } \\
\text { dependendo do tratamento } \\
\text { aplicado; } \\
\text { Taxas de degradação: } \\
\text { 0,382-0,513 }\left(10^{3} \mathrm{mg} \mathrm{L}^{-1} \mathrm{~kJ}^{-1}\right. \\
\left.\mathrm{m}^{2}\right) \text {. }\end{array}$ & $\begin{array}{l}\text { Garrido et } \\
\text { al. (2020) }\end{array}$ \\
\hline IMD & $\begin{array}{l}\text { Fotocatálise } \\
\text { heterogênea }\left(\mathrm{TiO}_{2}\right) \text {, } \\
\text { Fotólise } \mathrm{UV}_{254 \mathrm{~nm}} \\
\mathrm{UV}_{254 \mathrm{~nm}} / \mathrm{VUV} \text { e } \\
\text { gama-radiólise }\end{array}$ & $25,7 \mathrm{mg} \mathrm{L}^{-1}$ & $\begin{array}{l}\text { - Lâmpada UV e UV/VUV possuíam diâmetro interno } \\
20,5 \mathrm{~mm} \text { e comprimento } 307 \mathrm{~mm}, 15 \mathrm{~W} \text { (elétrico) e } \\
4,0 \mathrm{~W} \text { (output). Lâmpada UV emitindo em } 254 \mathrm{~nm} \text { e } \\
\text { lâmpada UV/VUV emitia também em } 185 \mathrm{~nm} \text {. Para } \\
\text { experimentos de fotocatálise, lâmpada UVA } \\
\text { emitindo na faixa de } 300-400 \mathrm{~nm}, \lambda_{\text {máx }}=365 \mathrm{~nm} \text {. } \\
\text { Fluxo de fótons: } 1,210^{-5} \text { molótons } \mathrm{S}^{-1} \text { (determinada } \\
\text { por actinometria com Ferrioxalato); } \\
\text { - }\left[\mathrm{TiO}_{2}\right]_{0}=1000 \mathrm{mg} \mathrm{L}^{-1} ; \\
\text { - Ensaios gama - radiólise: } 0,7 \mathrm{kGy} \mathrm{h}^{-1}\left(700 \mathrm{~J} \mathrm{~kg}^{-1} \mathrm{~h}^{-}\right. \\
\text {1). }\end{array}$ & 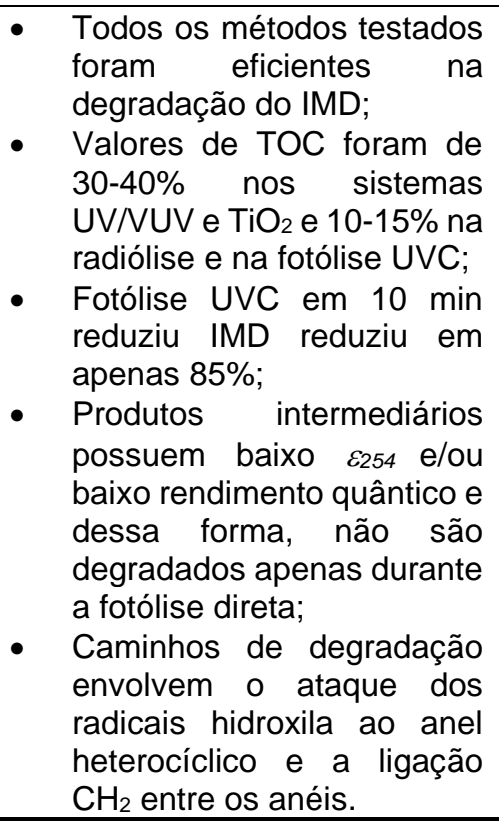 & $\begin{array}{c}\text { Rózsa et al. } \\
\text { (2019) }\end{array}$ \\
\hline
\end{tabular}

Fonte: Elaborada pela autora. 
Tabela 5 (cont.) - Aplicação dos POA para tratamento dos IA estudados em meio aquoso.

\begin{tabular}{|c|c|c|c|c|c|}
\hline IA & POA utilizado & $\begin{array}{c}\text { Concentração } \\
\text { inicial do IA }\end{array}$ & Condições de processo & Resultados & Referência \\
\hline IMD & $\mathrm{O}_{3}$ e $\mathrm{O}_{3} / \mathrm{UV}$ & $100-1000 \mu \mathrm{g} \mathrm{L}^{-1}$ & $\begin{array}{l}\text { - Três tipos de matrizes foram avaliados: água Milli-Q e } \\
\text { duas matrizes de esgoto após tratamento secundário; } \\
\text { - Temperatura: } 24 \pm 11^{\circ} \mathrm{C} \text {, Fluxo de ozônio: } 30 \mathrm{~L} \mathrm{~h}^{-1} \text {; } \\
\text { - } \quad \text { Variação da dose de ozônio }\left(600-1800 \mathrm{mg} \mathrm{h}^{-1}\right) \text {, da } \\
\text { concentração inicial do IMD e do pH }(6,25-8,25) ; \\
\text { - Lâmpada 10-W UV com emissão monocromática em } \\
\left.254 \mathrm{~nm} \text { (Intensidade: } 12,210^{-3} \mu \text { Einstein } \mathrm{cm}^{-2} \mathrm{~s}^{-1}\right) \text {; } \\
\text { - Tempo de irradiação: } 120 \text { minutos. }\end{array}$ & 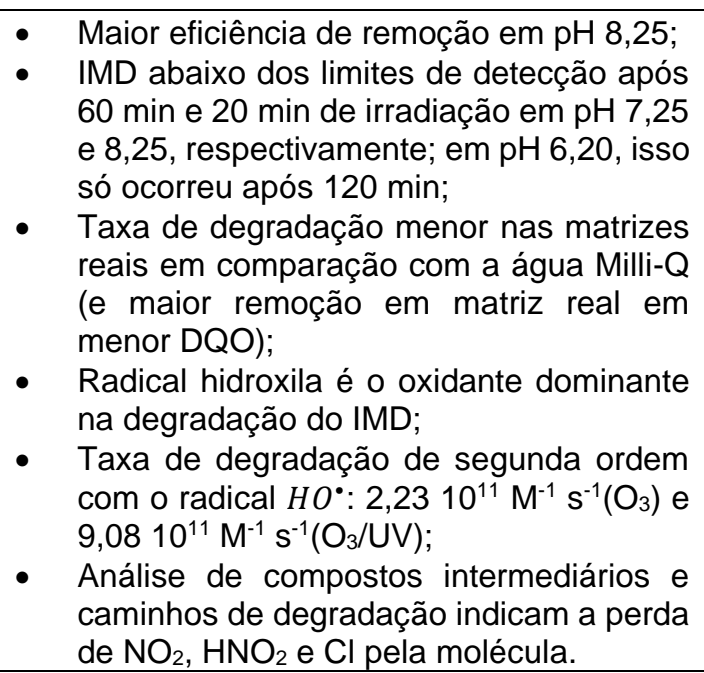 & $\begin{array}{l}\text { Baghirzade, } \\
\text { Yetis e Dilek } \\
(2020)\end{array}$ \\
\hline IMD & $\begin{array}{c}\text { Fotocatálise } \\
\text { (Percarbonato de } \\
\text { sódio - SPC) }\end{array}$ & $0,001 \mathrm{~mol} \mathrm{~L}^{-1}$ & $\begin{array}{ll}\text { - } & 500 \mathrm{~mL} \text { usado em todos os experimentos de } \\
& \text { degradação; } \\
\text { - } & \text { Tempo de irradiação: } 120 \text { minutos; } \\
\text { - } & \text { Fluxo: } 1 \mathrm{~mL} \mathrm{~min}^{-1} ; \\
\text { - } & \mathrm{pH}=2,0, \text { Temperatura }=25 \stackrel{\circ}{\circ} \mathrm{C} ; \\
\text { - } & {\left[\mathrm{Fe}^{2+}\right]_{0}=0,0025 \mathrm{~mol} \mathrm{~L}^{-1} ;} \\
\text { - } & {[\mathrm{SPC}]_{0}=0,06 \mathrm{~mol} \mathrm{~L}^{-1} \text {. }}\end{array}$ & $\begin{array}{l}\text { - } \quad \text { IMD é completamente removido nas } \\
\text { condições ótimas do processo; } \\
\text { Efeitos inibitórios de íons presentes na } \\
\text { degradação do IMD: } \mathrm{NO}^{2-}>\mathrm{PO}_{4}^{3-}>\mathrm{NH}^{4+} \\
>\mathrm{Cl}^{-}>\mathrm{NO}^{3-;} \\
\text { Máxima mineralização do IMD foi de } \\
38,1 \% \text { após } 2 \text { horas. }\end{array}$ & $\begin{array}{c}\text { Sablas et al. } \\
(2020)\end{array}$ \\
\hline
\end{tabular}

Fonte: Elaborada pela autora. 
A aplicação dos POA em larga escala ainda é limitada, uma vez que os processos físicos de geração das espécies reativas incorrem em custos muitas vezes elevados, sobretudo o custo operacional. Miklos et al. (2018) investigaram na literatura a viabilidade desses processos baseando-se em valores publicados para o parâmetro energia elétrica por ordem de grandeza de poluente removido por unidade de volume $\left(E_{E O}\right)$, que representa a energia elétrica em quilowatt-hora $(\mathrm{kWh})$ necessária para a degradação de um contaminante em uma ordem de grandeza presente em $1 \mathrm{~m}^{3}$ de água contaminada, e corresponde à maior parcela dos custos envolvidos (BOLTON et al., 1996).

Com base nos valores medianos dos dados publicados para esse parâmetro na literatura, Miklos et al. (2018) classificaram os POA em três grupos: processos que possuem $\mathrm{E}_{\mathrm{EO}}<1 \mathrm{kWh} \mathrm{m}^{-3}$, e que correspondem aos processos viáveis de aplicação industrial, sendo $\mathrm{O}_{3}, \mathrm{O}_{3} / \mathrm{H}_{2} \mathrm{O}_{2}, \mathrm{O}_{3} / \mathrm{UVC}, \mathrm{UVC} / \mathrm{H}_{2} \mathrm{O}_{2}$, UV/persulfato, $\mathrm{UV} / \mathrm{Cl}_{2}$ e feixe de elétrons; processos Foto-Fenton, plasma e eletroquímicos, que possuem $E_{E O}=1$ $100 \mathrm{kWh} \mathrm{m}^{-3}$, considerados de alto gasto energético, mas atrativos em determinados casos e potenciais para aplicação em larga escala; e processos com $\mathrm{E}_{\mathrm{EO}}>$ $100 \mathrm{kWh} \mathrm{m}^{-3}$, que correspondem a UV/fotocatálise, ultrassom e micro-ondas, não considerados energeticamente eficientes até o presente momento.

Além disso, Fast et al. (2017) realizaram um estudo comparativo dos processos oxidativos avançados na remoção de contaminantes de preocupação emergente baseando-se em parâmetros ambientais, de engenharia, sociais e econômicos. De acordo com o ranking estabelecido pelos autores, com pontuações variando de 1 a 5 , o processo $\mathrm{UVC} / \mathrm{H}_{2} \mathrm{O}_{2}$ apresentou pontuação geral 3,36, sendo vantajoso com relação aos processos $\mathrm{O}_{3}, \mathrm{O}_{3} / \mathrm{UVC}$, Fenton e fotocatálise utilizando $\mathrm{TiO}_{2}$ (com pontuações globais $3,30,3,08,2,89$ e 2,11, respectivamente), sobretudo no que se refere aos critérios de aceitação e facilidade de aplicação. Na realidade, de acordo com os autores, o processo UVC/ $\mathrm{H}_{2} \mathrm{O}_{2}$ é uma tecnologia já estabelecida, com baixo consumo energético e baixo impacto quanto a mudanças climáticas. Em todo caso, como observado por Katsoyannis, Canonica e Von Gunten (2011), a demanda energética do processo UVC/ $/ \mathrm{H}_{2} \mathrm{O}_{2}$ depende do caminho óptico da solução, da concentração do $\mathrm{H}_{2} \mathrm{O}_{2}$, da matriz aquosa e tipo do poluente.

Vislumbrando a aplicação para tratamento da água de lavagem de tomates em escala industrial, o foco principal deste trabalho é o processo $\mathrm{UVC} / \mathrm{H}_{2} \mathrm{O}_{2}$. 


\subsubsection{Fotólise direta}

Na fotólise direta, um poluente orgânico $(R X)$, capaz de absorver a radiação UV, pode ser degradado através de seu estado eletronicamente excitado (PARSONS, 2005). Esse estado excitado é altamente energético e pode ser desativado até um estado menos excitado (OPPENLÄNDER, 2003), que por sua vez pode ser desativado até o estado fundamental da molécula através de processos físicos radiativos (fluorescência e fosforescência) ou não radiativos (PARSONS, 2005). São possíveis reações químicas, a partir de estados excitados de moléculas de menor energia, segundo as reações dadas pelas Equações 2-7.

$$
\begin{aligned}
& R X+h v \rightarrow R X^{*} \\
& R X^{*} \rightarrow\left(R^{\bullet} \ldots \cdot X\right)_{\text {cage }} \rightarrow R^{\bullet}+\cdot X \\
& \left(R^{\bullet} \ldots \cdot X\right)_{\text {cage }} \rightarrow R X \\
& R X^{*} \rightarrow\left(R^{+} \ldots X^{-}\right)_{\text {cage }} \rightarrow R^{+}+X^{-} \\
& R X^{\bullet}+O_{2} \rightarrow R X^{+\bullet}+O_{2}^{-\bullet} \\
& R X^{*}+{ }^{3} O_{2} \rightarrow R X+{ }^{1} O_{2}
\end{aligned}
$$

A quebra homolítica das ligações formando radicais centrados no carbono $\left(R^{\bullet}\right)$ é a etapa de reação predominante, que ocorre seguida do aprisionamento (cage) das espécies reativas pelas moléculas do solvente (Equação 3). No entanto, a ocorrência da recombinação dos radicais é alta (Equação 4), o que explica valores baixos de rendimento quântico, e limita a aplicação industrial da fotólise direta. No entanto, os radicais formados podem escapar do aprisionamento do solvente e reagir com o oxigênio dissolvido, gerando radicais peroxil $\left(R O_{2}^{\circ}\right)$ e oxila $\left(R O^{\bullet}\right)$ e demais fotoprodutos. A transferência intramolecular de elétrons, resultando na quebra heterolítica também pode ocorrer no meio aquoso (Equação 5). Além disso, estados triplete excitados dos poluentes orgânicos podem interagir com o oxigênio dissolvido através de transferência de elétrons ou de energia, resultando em radicais catiônicos dos contaminantes e ânions radicais superóxido (Equação 6) ou em moléculas do contaminante no estado fundamental e oxigênio singlete (Equação 7), respectivamente (OPPENLÄNDER, 2003; PARSONS, 2005). 


\subsubsection{UVC/ $\mathrm{H}_{2} \mathrm{O}_{2}$}

A decomposição do peróxido de hidrogênio $\left(\mathrm{H}_{2} \mathrm{O}_{2}\right)\left(\varepsilon \mathrm{H} 2 \mathrm{O} 2,254 \mathrm{~nm}=19 \mathrm{~L} \mathrm{~mol}^{-1} \mathrm{~cm}^{-}\right.$ 1) (OPPENLÄNDER, 2003) pela irradiação ultravioleta (UVC) segue o mecanismo sugerido por Haber-Weiss (1932), gerando radicais hidroxila $\left(\mathrm{HO}^{\circ}\right)$ através da quebra fotolítica das ligações O-O (Equação 8, Ф но., $254 \mathrm{~nm}=0,98$ mol Einstein $^{-1}$ ). Os radicais gerados podem ser capturados por moléculas de $\mathrm{H}_{2} \mathrm{O}_{2}$, formando radicais hidroperoxila $\left(\mathrm{HO}_{2}^{*}\right)$ (Equação 9) e resultando em um complexo cíclico $\left(\mathrm{HOO}^{\bullet} \ldots \mathrm{H}_{2} \mathrm{O}_{2}\right)$, que sofre rearranjo através de transferências de elétrons gerando $\mathrm{H}_{2} \mathrm{O}, \mathrm{O}_{2}$ e $\mathrm{HO}^{\bullet}$ (Equação 10), esse último dando continuidade ao ciclo de propagação.

A energia necessária para a quebra homolítica da ligação entre os átomos de oxigênio nas moléculas de $\mathrm{H}_{2} \mathrm{O}_{2}$ é de $213 \mathrm{~kJ} \mathrm{~mol}^{-1}$. Na fase gasosa, os radicais gerados possuem excesso de energia translacional. Já na fase aquosa, apenas uma parte dos radicais formados consegue escapar para reagir com os poluentes de interesse, e uma grande maioria volta a se recombinar, o que caracteriza as etapas de terminação (Equações 11 a 13). Por outro lado, a oxidação dos compostos-alvo pelos radicais hidroxila envolve a abstração de hidrogênio e a adição eletrofílica a ligações insaturadas e anéis aromáticos, formando radicais orgânicos centrados no carbono, que por sua vez podem reagir com o oxigênio e formar radicais peroxila, resultando em rearranjos moleculares e/ou reações de eliminação, conduzindo a misturas complexas ou produtos de oxidação (OPPENLÄNDER, 2003; MIERZWA; RODRIGUES; TEIXEIRA, 2018).

$$
\begin{aligned}
& \mathrm{H}_{2} \mathrm{O}_{2}+\mathrm{hv} \rightarrow 2 \mathrm{HO}^{\bullet} \\
& \mathrm{H}_{2} \mathrm{O}_{2}+\mathrm{HO}^{\bullet} \rightarrow \mathrm{H}_{2} \mathrm{O}+\mathrm{HO}_{2}^{\bullet} \\
& \mathrm{HO}_{2}^{\bullet}+\mathrm{H}_{2} \mathrm{O}_{2} \rightarrow \mathrm{H}_{2} \mathrm{O}+\mathrm{O}_{2}+\mathrm{HO}^{\bullet} \\
& \mathrm{HO}^{\bullet}+\mathrm{HO}^{\bullet} \rightarrow \mathrm{H}_{2} \mathrm{O}_{2} \\
& \mathrm{HO}^{\bullet}+\mathrm{HO}_{2}^{\bullet} \rightarrow \mathrm{H}_{2} \mathrm{O}+\mathrm{O}_{2} \\
& \mathrm{HO}_{2}^{\bullet}+\mathrm{HO}_{2}^{\bullet} \rightarrow \mathrm{H}_{2} \mathrm{O}_{2}+\mathrm{O}_{2}
\end{aligned}
$$

Dentre as vantagens desse sistema em comparação com outros POA, podemse citar (TANG, 2004): (i) os poluentes orgânicos podem ser degradados tanto através da fotólise direta quando pelos radicais hidroxila; (ii) os microrganismos podem ser 
inativados pela radiação UVC, enquanto os radicais hidroxila são gerados de maneira eficiente (MIERZWA; RODRIGUES; TEIXEIRA, 2018); (iii) a alta solubilidade do $\mathrm{H}_{2} \mathrm{O}_{2}$ permite armazenamento de suas soluções, facilitando o manuseio, de forma que ele se mistura facilmente com o efluente a ser tratado, em comparação com a ozonização, em que a transferência do oxidante gasoso para a fase aquosa é limitada pela transferência de massa; (iv) não há geração de lodo (como no caso dos processos Fenton e Foto-Fenton) ou emissões de gases; (v) não são necessários processos complementares de separação ou descarte (como na fotocatálise utilizando $\mathrm{TiO}_{2}$ ); (vi) é um processo de simples operação e implantação.

A eficiência de produção dos radicais hidroxila depende da capacidade do $\mathrm{H}_{2} \mathrm{O}_{2}$ de absorver a radiação UV, e das características do fluido que irá ser submetido ao processo. Com relação à absorção do UVC pelo $\mathrm{H}_{2} \mathrm{O}_{2}$, pode-se dizer que quanto menor o comprimento de onda, maior a absorção de radiação, e maior o potencial de geração dos radicais hidroxila. Algumas propriedades físico-químicas do $\mathrm{H}_{2} \mathrm{O}_{2}$ se encontram apresentadas na Tabela 6.

Tabela 6 - Características físico-químicas de soluções de $\mathrm{H}_{2} \mathrm{O}_{2}$ a $25^{\circ} \mathrm{C}$.

\begin{tabular}{cccccc}
\hline Propriedade & \multicolumn{5}{c}{ Concentração $\mathrm{H}_{2} \mathbf{O}_{2}$ (\% mássica) } \\
\cline { 2 - 6 } & $\mathbf{3 0}$ & $\mathbf{3 5}$ & $\mathbf{5 0}$ & $\mathbf{7 0}$ & $\mathbf{9 0}$ \\
\hline Massa específica $\left(\mathrm{g} \mathrm{cm}^{-3}\right)$ & 1,1081 & 1,1282 & 1,1914 & 1,2839 & 1,3867 \\
Pressão parcial $(\mathrm{kPa})$ & - & 0,05 & 0,11 & 0,17 & 0,29 \\
$\mathrm{pH}$ & - & 4,6 & 4,3 & 4,4 & 5,1 \\
{$\left[\mathrm{H}_{2} \mathrm{O}_{2}\right]\left(\mathrm{mol} \mathrm{L}^{-1}\right)$} & 9,77 & 11,61 & 17,51 & 26,42 & 36,69 \\
{$\left[\mathrm{H}_{2} \mathrm{O}_{2}\right]\left(\mathrm{g} \mathrm{L}^{-1}\right)$} & 332,43 & 394,87 & 595,70 & 898,73 & 1248,03 \\
\hline
\end{tabular}

Fonte: Adaptado de Oppenländer (2003).

Outros fatores que podem influenciar a produção de radicais livres nesse processo é o tipo de fonte UVC utilizada, a emitância da lâmpada, o caminho óptico do meio reacional e as propriedades ópticas do efluente, como a absorção da radiação UVC pelos compostos presentes no meio (IKEHATA; EL-DIN, 2006; POYATOS et al., 2010).

$\mathrm{Na}$ literatura, os estudos envolvendo a aplicação do processo $\mathrm{UVC} / \mathrm{H}_{2} \mathrm{O}_{2}$ para a degradação do IMD ainda são escassos e não foram encontrados estudos para AZO e DFZ. A Tabela 7 apresenta os estudos encontrados, bem como alguns parâmetros investigados. 
Tabela 7 - Estudos envolvendo a degradação do IMD pelo processo UVC/ $\mathrm{H}_{2} \mathrm{O}_{2}$.

\begin{tabular}{|c|c|c|c|c|c|}
\hline IA & $\begin{array}{c}\text { Concentração } \\
\left(\mathrm{mg} \mathrm{L}^{-1}\right)\end{array}$ & $\begin{array}{c}\text { Objeto do } \\
\text { estudo }\end{array}$ & Condições de processo & Resultados & Referência \\
\hline IMD & 0,38 & $\begin{array}{l}\text { Comparação } \\
\text { entre diferentes } \\
\text { POA, } \\
\text { mineralização } \\
\text { dos compostos, } \\
\text { degradação do } \\
\text { IA e do produto } \\
\text { formulado. }\end{array}$ & $\begin{array}{l}\text { - } \quad \text { Reator } \\
\text { bancada; } \\
\text { - } \quad V_{\text {solução= }} \text { de } \mathrm{mL} \text {; } \\
\text { - } \quad \text { Profundidade da } \\
\text { solução: } 46 \mathrm{~mm} \\
\text { - } \quad \text { Intensidade } \quad \mathrm{UV} \text { : } \\
\text { 116,23 } \mathrm{mW} \mathrm{cm}^{-2} ; \\
\text { - } \\
\text { - } \quad \mathrm{V}\left(\mathrm{H}_{2} \mathrm{O}_{2}\right): 140 \mu \mathrm{L} ; \\
\end{array}$ & $\begin{array}{l}\text { - Eficiência } \\
\text { de remoção do IMD } \\
\text { de } 75 \% \text {; } \\
\text { - } \quad \text { Degradação } \\
\text { do IA e do produto } \\
\text { formulado ocorreu } \\
\text { de forma similar. }\end{array}$ & $\begin{array}{c}\text { Patil, Bote } \\
\text { e Gogate } \\
(2014)\end{array}$ \\
\hline IMD & 0,26 & $\begin{array}{l}\text { Influência de } \\
\text { matriz sintética e } \\
\text { real }\end{array}$ & 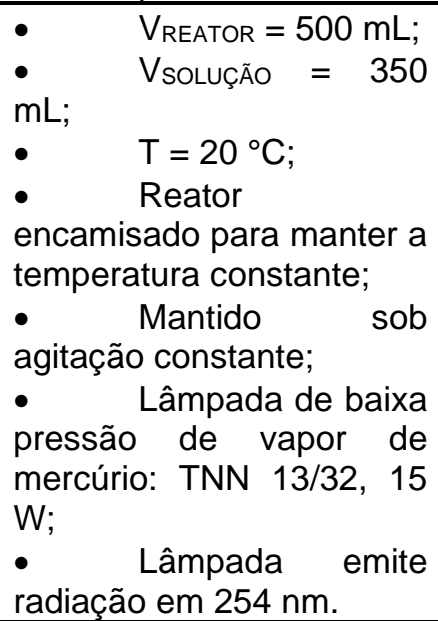 & $\begin{array}{l}\text { - Rendimento } \\
\text { quântico do IMD: } 48 \\
\times 10^{-3} \text { mol Einstein }{ }^{-1} ; \\
\text { de Presença } \\
\text { de partículas } \\
\text { dissolvidas na } \\
\text { matriz real diminui a } \\
\text { taxa de degradação } \\
\text { dos compostos. }\end{array}$ & $\begin{array}{c}\text { Acero et al. } \\
(2019)\end{array}$ \\
\hline IMD & 0,20 & $\begin{array}{l}\begin{array}{l}\text { Comparar } \\
\text { eficiência }\end{array} \\
\text { processo do } \\
\text { UVC } / \mathrm{Cl}_{2} \text { com o } \\
\text { processo } \\
\text { UVC } / \mathrm{H}_{2} \mathrm{O}_{2} \text { na } \\
\text { remoção de } \\
\text { contaminantes } \\
\text { de preocupação } \\
\text { emergente em } \\
\text { diferentes } \\
\text { matrizes reais; }\end{array}$ & 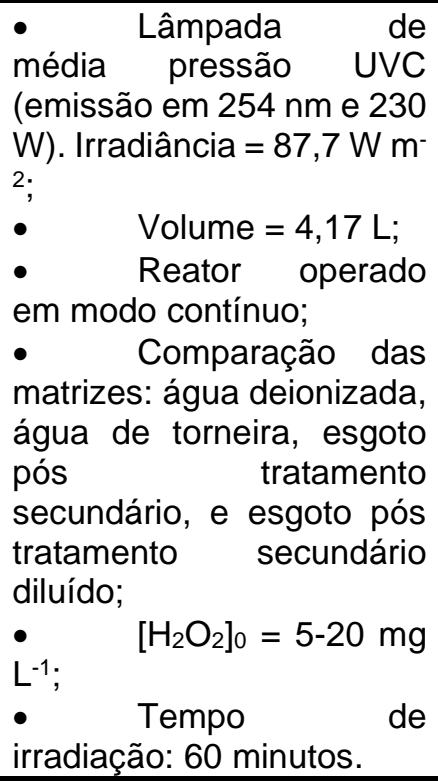 & $\begin{array}{l}\text { - } \mathrm{UVC}^{-} \mathrm{Cl}_{2} \text { foi } \\
\text { mais efetivo do que } \\
0 \quad \mathrm{UVC} / \mathrm{H}_{2} \mathrm{O}_{2} \\
\text { degradação dos } \\
\text { compostos em água } \\
\text { de torneira; } \\
\text { - No entanto, } \\
\text { para tratamento de } \\
\text { água de esgoto } \\
\text { secundário, } \\
\text { UVC/H} \mathrm{H}_{2} \\
\text { mostrou se } \\
\text { eficiente (remoção } \\
\text { superior a } 82 \%) ; \\
\text { direta foi importante } \\
\text { na degradação do } \\
\text { IMD. }\end{array}$ & $\begin{array}{l}\text { Cerreta et } \\
\text { al. (2019) }\end{array}$ \\
\hline
\end{tabular}

Fonte: Elaborada pela autora. 



\section{MATERIAIS E MÉTODOS}

\subsection{Reagentes}

Os reagentes empregados nesse trabalho, bem como sua pureza, composição e procedência são apresentados na Tabela 8.

Tabela 8 - Reagentes e produtos comerciais utilizados neste trabalho.

\begin{tabular}{ccc}
\hline Composto & Pureza/Composição & Procedência \\
\hline Azoxistrobina (AZO) & P.A. & Sigma-Aldrich \\
Difenoconazol (DFZ) & P.A. & Sigma-Aldrich \\
Imidacloprido (IMD) & P.A. & Sigma-Aldrich \\
Amistar Top ${ }^{\circledR}$ & AZO $\left(200 \mathrm{~g} \mathrm{~L}^{-1}, 20 \% \mathrm{~m} / \mathrm{v}\right), \mathrm{DFZ}\left(125 \mathrm{~g} \mathrm{~L}^{-1}, 12,5 \% \mathrm{~m} / \mathrm{v}\right)$ & Syngenta \\
Provado $200 \mathrm{SC}^{\circledR}$ & $\mathrm{IMD}\left(200 \mathrm{~g} \mathrm{~L}^{-1}, 20 \% \mathrm{~m} / \mathrm{v}\right)$ & Bayer \\
Acetonitrila & $\mathrm{HPLC}$ & Merck \\
$\mathrm{H}_{2} \mathrm{O}_{2}$ & $30 \% \mathrm{v} / \mathrm{v}$ & Labsynth \\
$\mathrm{Metanol}$ & $\mathrm{HPLC}$ & Merck \\
$\mathrm{HCl}$ & $37 \% \mathrm{v} / \mathrm{v}$ & Vetec \\
\hline
\end{tabular}

Fonte: Elaborado pela autora.

Todas as soluções foram preparadas utilizando água deionizada (18.2 $\mathrm{M} \Omega \mathrm{cm}$ ), produzida através de sistema Milli-Q ${ }^{\circledR}$ Direct-Q (Merck Millipore).

\subsection{Estimativa da concentração dos IA na calda dos produtos comerciais e na água de lavagem dos tomates}

Os três IA estudados foram escolhidos considerando quais os principais compostos aplicados nas culturas de tomate no Brasil e as informações a respeito dos produtos comerciais utilizados no controle de pragas para a cultura de tomate, fornecidas pela agroindústria. Dessa forma, os dois produtos comerciais selecionados para uso nos procedimentos experimentais foram o Amistar Top ${ }^{\circledR}$, da Syngenta ${ }^{\circledR}$, contendo em sua formulação AZO e DFZ, e Provado 200 SC $^{\circledR}$, da Bayer ${ }^{\circledR}$, que contém IMD.

Para estabelecer as concentrações de trabalho, foram realizados os seguintes cálculos para estimar as concentrações dos IA nas caldas aplicadas na cultura, desconsiderando a adição de adjuvantes (por exemplo, surfactantes) à mistura, e na água de lavagem dos tomates durante as etapas de seu processamento.

De acordo com as informações dos fabricantes, as concentrações dos ingredientes ativos no produto comercial Amistar Top ${ }^{\circledR}$ é de $200 \mathrm{~g} \mathrm{~L}^{-1}$ para AZO e 125 
$\mathrm{g} \mathrm{L}^{-1}$ para DFZ, enquanto no produto comercial Provado $200 \mathrm{SC}^{\circledR}$ é de e $200 \mathrm{~g} \mathrm{~L}^{-1}$ para IMD. Supondo a ocorrência de uma aplicação por aspersão da calda dos agrotóxicos no cultivo, a dose máxima de produto comercial (em mililitros por litro de calda) recomendada por hectare para a cultura de tomate é de $0,40 \mathrm{~mL} \mathrm{~L}^{-1}$ para o Amistar Top $^{\circledR}$ e $0,35 \mathrm{~mL} \mathrm{~L}^{-1}$ para o Provado $200 \mathrm{SC}^{\circledR}$. As Equações 14-16 indicam as concentrações desses compostos (em miligramas por litro) estimadas para 1 litro de calda preparada.

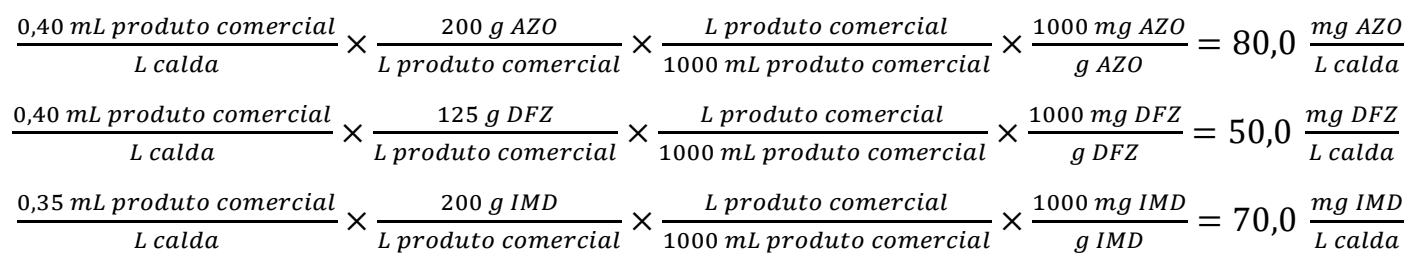

A partir de dados fornecidos pela Empresa de Assistência Técnica e Extensão Rural do Estado de Minas Gerais (EMATER-MG) quanto ao rendimento médio dos tomateiros por hectare (aproximadamente $80000 \mathrm{~kg}$ tomate por hectare), e dado que devem ser aspergidos $1000 \mathrm{~L}$ de calda (conforme recomendado na bula dos produtos comerciais), a Equação 17 apresenta a quantidade de calda aspergida por quilograma de fruto, considerando a ocorrência de uma aspersão homogênea.

$\frac{1000 \mathrm{~L} \mathrm{calda}}{\mathrm{ha}} \times \frac{\mathrm{ha}}{80.000 \mathrm{~kg} \text { tomate }}=0,0125 \frac{\mathrm{L} \mathrm{calda}}{\mathrm{kg} \text { tomate }}$

Partindo desse valor, sabendo que a agroindústria reutiliza a água da lavagem dos frutos dez vezes e que a proporção na lavagem é de 3 litros por quilograma, a concentração nominal esperada para os compostos (em $\mathrm{mg} \mathrm{L}^{-1}$ ) na água de lavagem (aqui denominada água de lavagem sintética) é dada pelas equações a seguir, supondo que os compostos fiquem retidos na casca dos frutos após a aplicação das caldas, e fossem totalmente removidos durante a lavagem (Equações 18 a 20).

$$
\begin{aligned}
& \frac{0,0125 \mathrm{~L} \text { calda }}{\mathrm{kg} \text { tomate }} \times \frac{80 \mathrm{mg} \mathrm{AZO}}{\mathrm{L} \mathrm{calda}} \times \frac{\mathrm{kg} \text { tomate }}{3,0 \mathrm{~L} \text { água }} \times 10 \cong 3,0 \frac{\mathrm{mg} \mathrm{AZO}}{\mathrm{L} \text { água }} \\
& \frac{0,0125 \mathrm{~L} \text { calda }}{k g \text { tomate }} \times \frac{50 \mathrm{mg} \mathrm{DFZ}}{\mathrm{L} \text { calda }} \times \frac{\mathrm{kg} \text { tomate }}{3,0 \mathrm{~L} \text { água }} \times 10 \cong 2,0 \frac{\mathrm{mg} \mathrm{DFZ}}{\mathrm{L} \text { água }} \\
& \frac{0,0125 \mathrm{~L} \text { calda }}{\mathrm{kg} \text { tomate }} \times \frac{70 \mathrm{mg} \text { IMD }}{\mathrm{L} \text { calda }} \times \frac{\mathrm{kg} \text { tomate }}{3,0 \mathrm{~L} \text { água }} \times 10 \cong 3,0 \frac{\mathrm{mg} \text { IMD }}{\mathrm{L} \text { água }}
\end{aligned}
$$


As concentrações nominais dos IA na água de lavagem sintética podem ser consideradas sobrestimadas. Além disso, durante a aplicação dos agrotóxicos na cultura, o produtor pode realizar a mistura da calda preparada a partir dos produtos formulados com os adjuvantes, tais como surfactantes, de forma a reduzir a tensão superficial do líquido e promover maior cobertura na superfície das plantas. Todavia, para o sistema modelo avaliado neste trabalho, as soluções foram preparadas apenas com as caldas contendo os ingredientes ativos selecionados, de forma a investigar sua remoção pelo processo $\mathrm{UVC} / \mathrm{H}_{2} \mathrm{O}_{2}$.

\subsection{Obtenção do espectro de absorção UV-visível dos IA}

Para melhor compreender como os IA absorvem a radiação UV-visível, foi realizado um experimento para obtenção dos coeficientes de absorção molar decádicos $\left(\varepsilon_{\lambda}\right)$ dos compostos no intervalo 200-800 nm.

À vista disso, foram preparadas soluções estoque na concentração de $80 \mathrm{mg}$ $\mathrm{L}^{-1}$ para cada composto através da diluição dos padrões analíticos em água Milli- ${ }^{\circledR}$ à temperatura ambiente. Na sequência, as soluções estoque foram diluídas e geradas cinco soluções de trabalho nas concentrações $0,8,1,2,1,6,2,0$ e 4,0 $\mathrm{mg} \mathrm{L}^{-1}$ (ou seja 1,98-9,92 $\mu \mathrm{mol} \mathrm{L}^{-1}$ para AZO; e 1,97-9,85 $\mu \mathrm{mol} \mathrm{L}^{-1}$ DFZ) e 0,63, 0,99, 1,27, 1,64 e 3,35 $\mathrm{mg} \mathrm{L}^{-1}\left(2,46-13,1 \mu \mathrm{mol} \mathrm{L} \mathrm{L}^{-1} \mathrm{IMD}\right)$. A absorbância decádica $\left(A_{10}\right)$ de cada solução com concentração molar $(c)$ foi medida em função do comprimento de onda utilizando um espectrofotômetro UV/VIS Varian Cary 50 e cubeta de quartzo com caminho óptico ( $(\ell)$ de $1 \mathrm{~cm}$. Os valores de $\varepsilon \lambda$ foram obtidos para cada IA e comprimento de onda através da inclinação das retas nos gráficos $A_{10, \lambda} \times C$, conforme a lei de Beer-Lambert-Bourger (Equação 21) (SKOOG; HOLLER; CROUCH, 2017).

$\varepsilon_{\lambda}=\frac{A_{10, \lambda}}{c l}$

\subsection{Avaliação da estabilidade dos IA na água de lavagem sintética}

Dada a importância dos fatores abióticos no comportamento dos compostos presentes em água (LIU et al., 2007), foi realizado teste de hidrólise para os IA estudados com o intuito de verificar sua estabilidade na ausência de luz na água de 
lavagem sintética. Para tanto, $100 \mathrm{~mL}$ de solução foram distribuídos em dois erlenmeyers ( $50 \mathrm{~mL}$ em cada) de cor âmbar, para obter os resultados em duplicata. $O$ $\mathrm{pH}$ inicial das soluções foi medido e em seguida os erlenmeyers foram colocados sob agitação de $100 \mathrm{rpm}$ e à temperatura de aproximadamente $25^{\circ} \mathrm{C}$ em incubadora, durante 72 horas.

Durante 0 teste foram retiradas alíquotas de $1 \mathrm{~mL}$ dos erlenmenyers nos tempos $0,5,10,15,30,45,60,120,240,360$ minutos, 24,48 e 72 horas, e injetadas no cromatógrafo Shimadzu UFLC LC $20 \mathrm{AD}$ para monitorar a concentração dos compostos.

\subsection{Fotodegradação dos IA utilizando água de lavagem sintética: fotólise direta e UVC $/ \mathrm{H}_{2} \mathrm{O}_{2}$}

\subsection{1 Água de lavagem sintética}

Os testes de degradação por fotólise direta e $\mathrm{UVC} / \mathrm{H}_{2} \mathrm{O}_{2}$ foram realizados utilizando a água de lavagem de tomates sintética, preparada a partir da diluição e mistura das caldas dos produtos comerciais Amistar Top ${ }^{\circledR}$ e Provado 200 SC $^{\circledR}$, simulando a concentração esperada dos IA na água de lavagem da agroindústria, contendo 3,0, 2,0 e 3,0 $\mathrm{mg} \mathrm{L}^{-1}$ de AZO, DFZ e IMD respectivamente.

\subsubsection{Reator fotoquímico}

Foi utilizado gabinete fotoquímico de bancada, com capacidade para até quatro lâmpadas UVC (Philips TUV 8W/G8TS) emitindo na faixa de comprimento de onda entre 251-257 nm $\left(\lambda_{\text {máx }}=254 \mathrm{~nm}\right)$. A Tabela 9 apresenta as irradiâncias para 1, 2, 3 e 4 lâmpadas medidas utilizando um espectroradiômetro (Luzchem, SPR-4002) posicionado a $15 \mathrm{~cm}$ sob as lâmpadas. Essa distância foi estabelecida considerando as dimensões internas do gabinete fechado e o espaço disponível para o equipamento necessário. Um béquer encamisado ( $\varnothing_{\text {interno }}=7 \mathrm{~cm}$ ), com capacidade para $250 \mathrm{~mL}$, foi preenchido com $150 \mathrm{~mL}$ de solução cuja superfície se encontrava a uma distância de $15 \mathrm{~cm}$ das lâmpadas e um banho termostático (Neslab, Modelo RTE-211) foi utilizado para manter a temperatura do líquido constante em $21^{\circ} \mathrm{C}$. A solução foi agitada continuamente por meio de um agitador magnético (Fisatom, Modelo 752), de 
forma a manter sua homogeneidade. A Figura 5 mostra uma representação esquemática do equipamento empregado nos ensaios.

Tabela 9 - Número de lâmpadas UVC e respectivas irradiâncias à distância de $15 \mathrm{~cm}$ (superfície do líquido).

\begin{tabular}{cc}
\hline Número de lâmpadas & Irradiância $\left(\mathbf{W ~ m}^{-2}\right)$ \\
\hline 1 & 6,2 \\
2 & 15,0 \\
3 & 21,8 \\
4 & 28,6 \\
\hline
\end{tabular}

Fonte: Elaborado pela autora.

Figura 5 - Equipamento empregado nos ensaios de degradação.

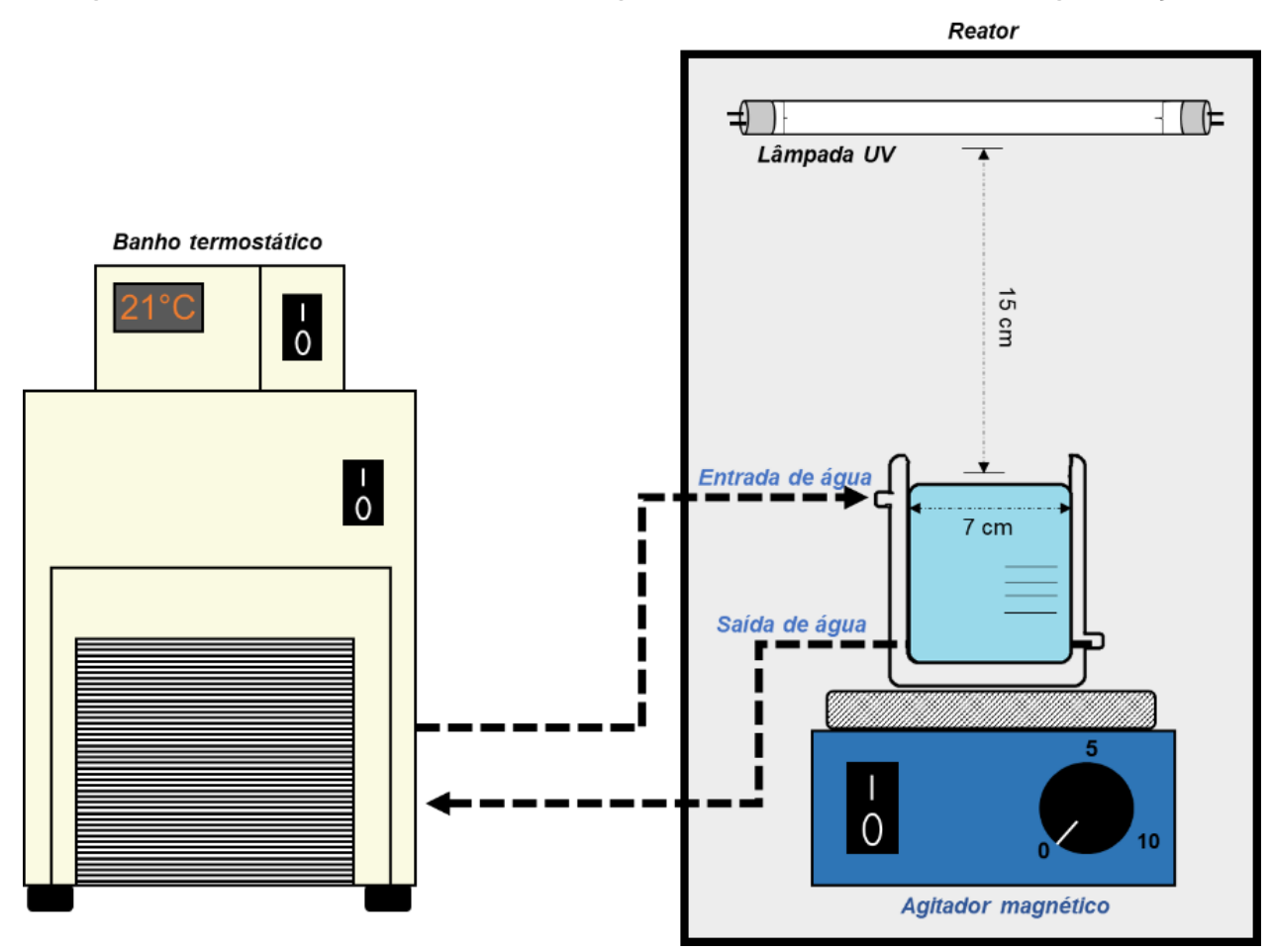

Fonte: Elaborado pela autora.

\subsubsection{Determinação do rendimento quântico da fotólise dos IA}

O rendimento quântico $(\Phi)$ é um parâmetro de extrema importância que permite avaliar a eficiência de um processo fotoquímico. Dado um composto $P$, o rendimento quântico da fotólise pode ser definido como a razão entre o número de mols do composto que foram consumidos durante a fotólise e o número de mols de fótons que foram absorvidos pelo composto (BRAUN; MAURETTE; OLIVEROS, 1991; PARSONS, 2005), como expresso pela Equação 22. 
$\Phi_{P, \lambda}=\frac{\text { número total de mols de } P \text { consumido }}{\text { número total de mols de fótons absorvidos }}$

A taxa de fotólise no UVC $\left(\lambda_{\max }=254 \mathrm{~nm}\right)$ é dada pela Equação 23, em que $E_{\mathrm{p}, 0}$ representa a taxa específica de fótons incidentes (mol fótons $\mathrm{L}^{-1} \mathrm{~s}^{-1}$ ); $C$, a concentração molar do composto $\left(\mathrm{mol} \mathrm{L}^{-1}\right) ; \alpha_{254 \mathrm{~nm}}$, o coeficiente de absorção desconsiderando a espécie $\mathrm{P}\left(\mathrm{cm}^{-1}\right) ; \varepsilon_{P, 254 \mathrm{~nm}}$, o coeficiente de absorção molar da espécie $\mathrm{P}\left(\mathrm{L} \mathrm{mol}^{-1} \mathrm{~cm}^{-1}\right)$ no comprimento de onda de $254 \mathrm{~nm}$ e $l_{\text {reator }}$, o caminho óptico de propagação da radiação no reator fotoquímico, que para o sistema utilizado corresponde à altura dos $150 \mathrm{~mL}$ de líquido no reator $(4,5 \mathrm{~cm})$.

$$
-r_{i, 254 \mathrm{~nm}}=\Phi_{i, 254 \mathrm{~nm}} E_{p, 0} \frac{\varepsilon_{i, 254 \mathrm{~nm}} C_{i}}{\alpha_{254 \mathrm{~nm}}+\varepsilon_{i, 254 \mathrm{~nm}} C_{i}}\left(1-10^{\left.-\left(\alpha_{254 \mathrm{~nm}}+\varepsilon_{i, 254 \mathrm{~nm}} C_{i}\right) l_{\text {reator }}\right)}\right.
$$

De acordo com a lei de Beer-Lambert-Bourguer, a absorbância total da solução (Abs) em 254 nm é dada pela Equação 24, em que $l$ corresponde ao caminho óptico da cubeta para medição no espectrofotômetro $(1 \mathrm{~cm})$.

$$
A b s_{254 n m}=\left(\alpha_{254 n m}+\varepsilon_{i, 254 n m} C_{i}\right) l
$$

Sendo assim, para os IA estudados, tem-se que a taxa de fotólise no UVC ( $\lambda_{\max }$ $=254 \mathrm{~nm}$ ) dada pelas Equações 25 a 27 :

$$
\begin{aligned}
& -r_{A Z O}=\Phi_{A Z O, 254 n m} E_{p, 0} \frac{\varepsilon_{A Z O, 254 n m} C_{A Z O} l}{A b s_{254 \mathrm{~nm}}}\left(1-10^{\left.-\frac{A b s_{254 n m}}{l} l_{\text {reator }}\right)}\right. \\
& -r_{D F Z}=\Phi_{D F Z, 254 n m} E_{p, 0} \frac{\varepsilon_{D F Z, 254 n m} C_{D F Z} l}{A b s_{254 \mathrm{~nm}}}\left(1-10^{\left.-\frac{A b s_{254 \mathrm{~nm}}}{l} l_{\text {reator }}\right)}\right. \\
& -r_{I M D}=\Phi_{I M D, 254 n m} E_{p, 0} \frac{\varepsilon_{I M D, 254 n m} C_{I M D} l}{A b s_{254 \mathrm{~nm}}}\left(1-10^{\left.-\frac{A b s_{254 \mathrm{~nm}}}{l} l_{\text {reator }}\right)}\right.
\end{aligned}
$$

Para cálculo do rendimento quântico dos $I A$, foram realizados experimentos de fotólise direta utilizando soluções dos compostos individualmente, nas concentrações nominais esperadas para a água de lavagem $\left(3,0,2,0\right.$ ou $3,0 \mathrm{mg} \mathrm{L}^{-1}$ para $A Z O$, DFZ e IMD, respectivamente). As soluções foram irradiadas durante 15 minutos, para irradiâncias de 15,0, 21,8 e 28,6 $\mathrm{W} \mathrm{m}^{-2}$, e alíquotas foram retiradas em 0, 0,25, 0,50, 0,75, 1,0, 2,0, 5,0, 10,0 e 15,0 minutos e medidas suas respectivas absorbâncias em 
254 nm utilizando espectrofotômetro UV/VIS Varian Cary 50. Os valores numéricos encontrados foram substituídos nas Equações 25 a 27 para cálculo das taxas de reação e na equação de balanço molar para cada IA no reator batelada (Equação 28). O rendimento quântico para os IA foi estimado através de um modelo matemático desenvolvido no software MATLAB 2015a, utilizando o conjunto das três condições experimentais aplicadas para cada IA.

$$
\frac{d C}{d t}=r_{i}
$$

O modelo emprega a minimização de uma função objetivo $(f o)$, dada pela Equação 29, que representa a soma dos quadrados das diferenças entre a concentração de cada IA calculada e a concentração experimental. Para a resolução matemática em MATLAB, foi utilizada a ferramenta solver de mínimos quadrados lsnonlin para ajuste de curvas não lineares. Adicionalmente, o algoritmo de otimização executado seguiu o método Levenberg-Marquardt e para solução das equações diferenciais ordinárias (EDO), foi aplicada a rotina ode15s.

$f o=\sum\left([A Z O, D F Z \text { ou IMD }]_{\text {calculada }}-[A Z O, D F Z \text { ou IMD }]_{\text {experimental }}\right)^{2}$

A minimização da função $(f o$ ) está sujeita às equações $24,25,26,27,28$ e $\Phi_{A Z O 254 n m}>0, \Phi_{D F Z, 254 n m}>0, \Phi_{I M D, 254 n m}>0$.

\subsubsection{Fotólise direta e ensaios $\mathrm{UVC} / \mathrm{H}_{2} \mathrm{O}_{2}$}

Para os ensaios na ausência de $\mathrm{H}_{2} \mathrm{O}_{2}, 150 \mathrm{~mL}$ da solução sintética contendo os três IA (AZO, DFZ e IMD) foi irradiada em 15,0, 21,8 e 28,6 W m² durante 15 minutos. Alíquotas de $1 \mathrm{~mL}$ foram retiradas em 0,0,25, 0,50, 0,75, 1, 2, 5, 10 e 15 minutos e analisadas em HPLC.

No caso do UVC/ $\mathrm{H}_{2} \mathrm{O}_{2}$, os experimentos foram realizados durante 15 minutos, usando $150 \mathrm{~mL}$ da solução sintética contendo os três IA variando a concentração inicial de $\mathrm{H}_{2} \mathrm{O}_{2}$ e a irradiância UVC. A solução $30 \%$ (v/v) de peróxido de hidrogênio foi adicionada no tempo zero para obter o valor desejado de $\left[\mathrm{H}_{2} \mathrm{O}_{2}\right]_{0}$. Alíquotas de $1 \mathrm{~mL}$ foram retiradas em $0,0,25,0,50,0,75,1,2,5,10$ e 15 minutos e diluídas com $100 \mu \mathrm{L}$ 
de metanol para capturar os radicais hidroxila e interromper a reação, de acordo com a metodologia aplicada por Lastre-Acosta et al. (2019), sendo em seguida analisadas em HPLC.

Os experimentos foram conduzidos seguindo um projeto experimental Doehlert sequencial, combinado com a análise de superfície de resposta, objetivando explorar os efeitos da concentração inicial de $\mathrm{H}_{2} \mathrm{O}_{2}$ e da irradiância na degradação dos IA, bem como obter a melhor condição experimental em termos da maior taxa de degradação de cada composto, dada pela taxa específica de degradação de pseudo-primeira ordem. Esse projeto experimental foi proposto inicialmente por Doehlert em 1970 (NOVAES et al., 2017) e possui as seguintes vantagens: requer poucos experimentos para atingir o ponto ótimo, demandando consequentemente uma menor quantidade de insumos; permite mapear o domínio experimental de modo uniforme e eficiente; oferece possibilidade de extensão do domínio experimental através da adição ou deslocamento do projeto, o que viabiliza o uso de dados de experimentos prévios (CALDAS et al., 2012; SENA et al., 2012).

Uma matriz experimental Doehlert com duas variáveis foi usada, sendo $x_{1}$ correspondente à concentração inicial de $\mathrm{H}_{2} \mathrm{O}_{2}$ e $x_{2}$, à irradiância. A Tabela 10 ilustra as condições experimentais para a matriz base (Experimentos 1 a 9, Figura 6), composta de sete experimentos e duas replicatas da condição do ponto central, com $\left[\mathrm{H}_{2} \mathrm{O}_{2}\right]$ o variando de 24,9 a 99,5 $\mathrm{mg} \mathrm{L}^{-1}$, o que corresponde a 1-4 vezes a proporção estequiométrica necessária para ocorrer a mineralização completa dos IA presentes na água de lavagem sintética. Os valores de irradiância (Euvc) foram avaliados na faixa de 15,0 a 28,6 W m-2 (2 a 4 lâmpadas Philips TUV 8W/G8TS).

A fim de explorar os efeitos da $\left[\mathrm{H}_{2} \mathrm{O}_{2}\right]$ o na degradação dos $I A$, o projeto foi deslocado ao longo do eixo de $x_{1}$ no domínio experimental, para maiores e menores dosagens de oxidante. Para tanto, foram adicionados inicialmente três experimentos (Experimentos 10 a 12), com $\left[\mathrm{H}_{2} \mathrm{O}_{2}\right.$ ] variando de 118,2 a $136,8 \mathrm{mg} \mathrm{L}^{-1}$, o que corresponde a 4,75 e 5,50 vezes a proporção estequiométrica, respectivamente; e em seguida, uma segunda matriz experimental foi construída (Experimentos 13 a 18), com $\left[\mathrm{H}_{2} \mathrm{O}_{2}\right]$ o variando de 12,4 a $37,3 \mathrm{mg} \mathrm{L}^{-1}$, o que corresponde a 0,5 e 1,5 vezes a proporção estequiométrica, respectivamente (Figura 6). 
Tabela 10 - Condições experimentais usadas nos ensaios de $\mathrm{UVC} / \mathrm{H}_{2} \mathrm{O}_{2}$ seguindo a matriz experimental Doehlert para duas variáveis.

\begin{tabular}{|c|c|c|c|c|}
\hline \multirow{2}{*}{ Experimento } & \multicolumn{2}{|c|}{$\begin{array}{c}\text { Valores } \\
\text { codificados }\end{array}$} & \multicolumn{2}{|c|}{ Valores reais experimentais } \\
\hline & $C_{1}$ & $C_{2}$ & $\begin{array}{c}x_{1},\left[\mathrm{H}_{2} \mathrm{O}_{2}\right]_{0} \\
\left(\mathrm{mg} \mathrm{L}^{-1}\right)\end{array}$ & $\begin{array}{c}x_{2} \text {, irradiância, } \\
E_{U v c}\left(\mathrm{~W} \mathrm{~m}^{-2}\right)\end{array}$ \\
\hline 1 & 0 & 0 & 62,2 & 21,8 \\
\hline 2 & 0 & 0 & 62,2 & 21,8 \\
\hline 3 & 0 & 0 & 62,2 & 21,8 \\
\hline 4 & 1,0 & 0 & 99,5 & 21,8 \\
\hline 5 & 0,500 & 0,866 & 80,9 & 28,6 \\
\hline 6 & $-1,0$ & 0 & 24,9 & 21,8 \\
\hline 7 & $-0,500$ & $-0,866$ & 43,5 & 15,0 \\
\hline 8 & 0,500 & $-0,866$ & 80,9 & 15,0 \\
\hline 9 & $-0,500$ & 0,866 & 43,5 & 28,6 \\
\hline 10 & 1,500 & 0,866 & 118,2 & 28,6 \\
\hline 11 & 1,500 & $-0,866$ & 118,2 & 15,0 \\
\hline 12 & 2,0 & 0 & 136,8 & 21,8 \\
\hline 13 & $-0,667$ & 0 & 37,3 & 21,8 \\
\hline 14 & $-0,833$ & 0,866 & 31,1 & 28,6 \\
\hline 15 & $-1,333$ & 0 & 12,4 & 21,8 \\
\hline 16 & $-1,167$ & $-0,866$ & 18,9 & 15,0 \\
\hline 17 & $-0,833$ & $-0,866$ & 31,1 & 15,0 \\
\hline 18 & $-1,167$ & 0,866 & 18,7 & 28,6 \\
\hline
\end{tabular}

Figura 6 - Matrizes Doehlert usadas nos experimentos $\mathrm{UVC} / \mathrm{H}_{2} \mathrm{O}_{2}$.

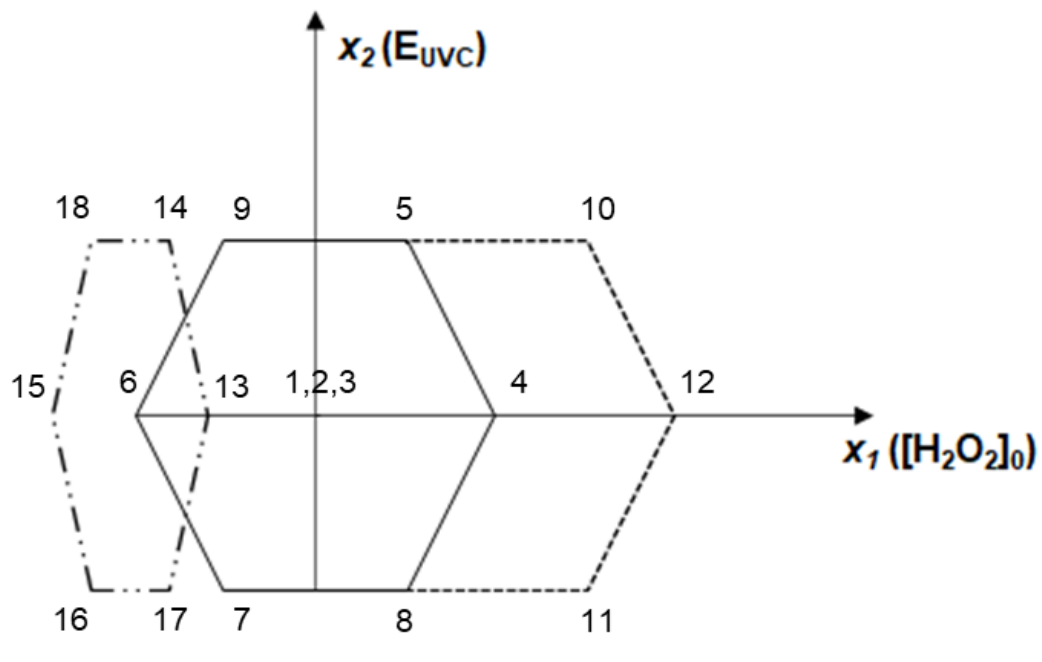

Fonte: Elaborado pela autora.

A Tabela 10 apresenta os valores reais e codificados usados nos ensaios de UVC/ $/ \mathrm{H}_{2} \mathrm{O}_{2}$, que são relacionados através da Equação 30 , em que $C_{i}$ e $x_{i}$, correspondem aos valores codificados e reais da variável $i$, respectivamente; $x_{i}^{0}$ se refere às condições no ponto central da matriz experimental base; $\Delta x_{i}$ é o passo de variação e $\alpha$ corresponde ao valor codificado limite para cada variável (FERREIRA et al., 2004). 


$$
C_{i}=\left\{\frac{x_{i}-x_{i}^{0}}{\Delta x_{i}}\right\} \alpha
$$

Para análise de dados e obtenção das superfícies de resposta, foi empregado o software STATGRAPHICS Plus ${ }^{\circledR}$, versão 5.0 (Statgraphics Technologies Inc.).

\subsection{Tratamento $\mathrm{UVC} / \mathrm{H}_{2} \mathrm{O}_{2}$ das matrizes reais}

\subsubsection{Coleta e caracterização físico-química da matriz real}

Com o intuito de avaliar o desempenho do processo $\mathrm{UVC} / \mathrm{H}_{2} \mathrm{O}_{2}$ em matrizes reais, foram coletadas amostras de água de lavagem de tomates em dois pontos em uma indústria (Figura 7): (i) durante o descarregamento dos caminhões contendo os frutos recém-colhidos, o que é feito com o auxílio de jatos de água (pré-lavagem); e (ii) na etapa final de lavagem, que ocorre em esteiras transportadoras, anteriormente à etapa de seleção dos frutos e processamento de produtos alimentícios (esteira de lavagem).

Figura 7 - Pontos de coleta da água de lavagem de tomate na agroindústria. À esquerda: descarregamento dos caminhões contendo frutos recém-colhidos, com o auxílio jatos de água (pré-lavagem). À direita: Etapa final de lavagem realizada nas

esteiras transportadoras, anterior à seleção dos frutos para processamento $e$ produção de produtos alimentícios (esteira de lavagem).

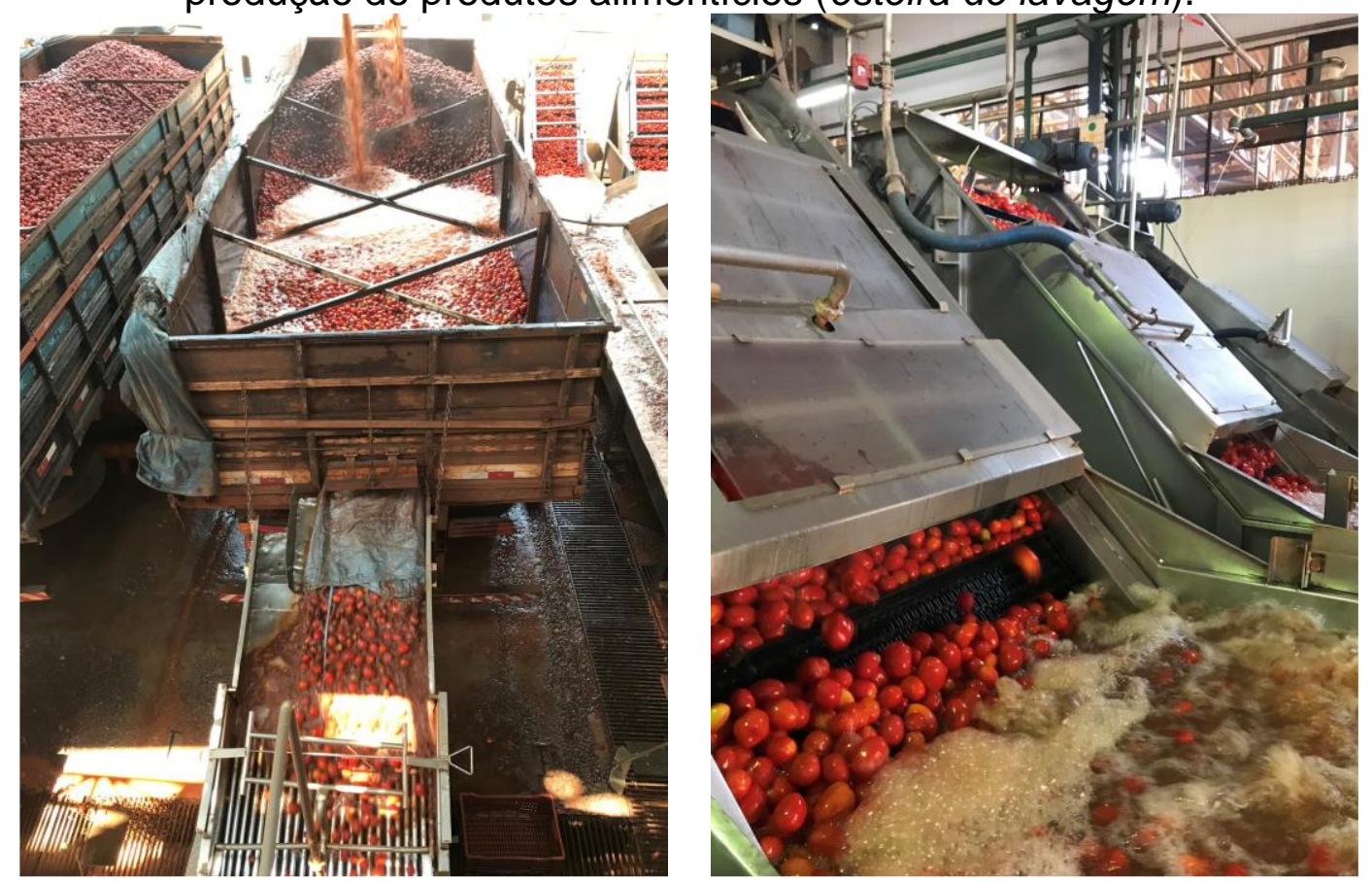

Fonte: Fotografia da autora. 
As amostras foram armazenadas em frascos à temperatura de $-4{ }^{\circ} \mathrm{C}$ até a realização dos ensaios de caracterização e UVC/ $\mathrm{H}_{2} \mathrm{O}_{2}$. Os parâmetros físico-químicos avaliados na caracterização das matrizes reais foram: $\mathrm{pH}$, temperatura, condutividade, absorbância em 254 nm, carbono orgânico total (TOC) e série de sólidos. As análises foram realizadas nos laboratórios do Centro Internacional de Referência em Reúso de Água (CIRRA) e do Grupo de Pesquisa em Processos Oxidativos (AdOx) do CESQ/PQI-EPUSP, em conformidade com o Standard Methods for the Examination of Water and Wastewater (APHA, 2017). Para análise de TOC, as matrizes foram previamente filtradas utilizando filtro de membranas PVDF de $0,45 \mu \mathrm{m}$ e em seguida analisadas no equipamento Shimadzu TOC-L.

\subsubsection{Aplicação do processo $\mathrm{UVC} / \mathrm{H}_{2} \mathrm{O}_{2}$ em matrizes reais}

Para aplicação do tratamento $\mathrm{UVC} / \mathrm{H}_{2} \mathrm{O}_{2}$, as matrizes reais coletadas foram dopadas com os produtos comerciais Amistar Top ${ }^{\circledR}$ e Provado $200 \mathrm{SC}^{\circledR}$ para obter as concentrações nominais dos IA $\left(3,0,2,0\right.$ e $3,0 \mathrm{mg} \mathrm{L}^{-1}$ para AZO, DFZ e IMD, respectivamente). As matrizes foram irradiadas durante 15 minutos, nas condições ótimas experimentais de $\left[\mathrm{H}_{2} \mathrm{O}_{2}\right]_{0}$ e irradiância obtidas a partir da análise de superfície de resposta para ensaios da matriz Doehlert usando a matriz sintética. Alíquotas de 1 $\mathrm{mL}$ foram retiradas em $0,0,25,0,50,0,75,1,2,5,10$ e 15 minutos, diluídas com 100 $\mu \mathrm{L}$ de metanol, filtradas utilizando filtro de membranas PVDF de $0,45 \mu \mathrm{m}$ e analisadas em HPLC.

\subsection{Métodos analíticos}

Durante o cultivo de tomates, o produtor pode realizar a aspersão dos dois produtos comerciais selecionados simultaneamente para a prevenção e remediação de diversas pragas que afetam a lavoura com diferentes condições climáticas decorrentes das estações do ano. Dessa forma, com a lavagem dos frutos, os três IA estudados podem ocorrer juntos em mistura, sendo necessário estabelecer um método analítico capaz de separá-los e identificá-los de maneira satisfatória, e que permita monitorar o decaimento de sua concentração durante os ensaios de degradação por POA.

Para esse fim, foi utilizado um cromatógrafo Shimadzu UFLC LC 20AD, 
acoplado ao detector UV-visível Shimadzu SPD 20A e coluna Luna C18 $(250 \times 4,60$ $\mathrm{mm}, 5 \mu \mathrm{m}$ diâmetro interno).

Inicialmente foram feitos testes com os compostos puros (padrão SigmaAldrich), uma vez que na formulação dos produtos comerciais existem outros ingredientes que poderiam influenciar a identificação dos picos. Baseando nos métodos desenvolvidos por Tsochatzis et al. (2011), Al-Rimawi (2016) e Yaqub et al. (2017), foram realizadas corridas utilizando diferentes composições e proporções de fase móvel, bem como utilizando os métodos isocrático e gradiente. Os compostos AZO e DFZ foram identificados no comprimento de onda 254 nm e o IMD em 270 nm, seguindo informações encontradas na literatura e recomendações do fornecedor dos padrões analíticos.

Utilizando vazão de $1 \mathrm{~mL} \mathrm{~min}^{-1}$, temperatura do forno $40^{\circ} \mathrm{C}$ e volume de injeção de $100 \mu \mathrm{L}$, as fases capazes de eluir efetivamente os IA foram água Milli- $\mathrm{Q}^{\circledR}(\mathrm{A})$ e acetonitrila grau HPLC $(B)$, sendo que o método gradiente permitiu a separação em menor tempo de corrida (18 minutos). A Tabela 11 indica as condições do método e variação das proporções de B durante o tempo de corrida estabelecido.

\begin{tabular}{|c|c|}
\hline Tempo de corrida (min) & Concentração de B (\%) \\
\hline 0 & 50 \\
\hline 3 & 50 \\
\hline 12 & 80 \\
\hline 14 & 80 \\
\hline 14,5 & 50 \\
\hline 18 & 50 \\
\hline
\end{tabular}

Fonte: Elaborada pela autora.

Uma vez separados e identificados os compostos, foram preparadas soluções dos compostos puros nas concentrações 16,0, 14,0, 12,0, 10,0, 8,0, 6,0, 4,0, 2,0, 1,0, 0,50, 0,30 e 0,10 $\mathrm{mg} \mathrm{L}^{-1}$ e construídas suas respectivas curvas de calibração, que permitem relacionar a área dos picos com suas concentrações (Anexo A1).

Em seguida, o mesmo método foi testado para os compostos presentes nos produtos comerciais, e não foi observada influência dos demais ingredientes presentes em formulação. Assim, foram preparadas soluções a partir das caldas preparadas com os produtos comerciais, contendo as concentrações 16,0, 8,0, 4,0, 2,0, 1,2, 0,80, 0,40 $\mathrm{mg} \mathrm{L}^{-1}$ para AZO, 10,0 5,0, 2,5, 1,25, 0,75, 0,50, 0,25 $\mathrm{mg} \mathrm{L}^{-1}$ para DFZ e de $14,0,7,0,3,5,1,75,1,05,0,70,0,35 \mathrm{mg} \mathrm{L}^{-1}$ para IMD, e construídas suas 
respectivas curvas de calibração (Anexo A2). O método foi validado através da linearidade das retas, e dos parâmetros limite de detecção (LD) e limite de quantificação (LQ) das curvas, calculados através das Equações 31 e 32 (RIBANI et al., 2004). Os parâmetros obtidos para as curvas de calibração são apresentados na Tabela 12.

$$
\begin{aligned}
& L D=\frac{\text { coeficiente linear }}{\text { coeficiente angular }} \times 3,3 \\
& L Q=\frac{\text { coeficiente linear }}{\text { coeficiente angular }} \times 10
\end{aligned}
$$

Tabela 12 - Resultados dos parâmetros de validação analíticos das curvas de calibração dos compostos (AZO, DFZ e IMD) em padrão analítico e nos produtos comerciais em HPLC. A: área da curva; [C]: concentração do composto $\left(\mathrm{mg} \mathrm{L}^{-1}\right) ; R^{2}$ :

\begin{tabular}{|c|c|c|c|c|c|}
\hline \multicolumn{6}{|c|}{ Produtos Padrão Sigma } \\
\hline IA & Equação & $R^{2}$ & $\begin{array}{l}\text { Tempo de } \\
\text { Retenção } \\
\text { (min) }\end{array}$ & LD $\left(\mathrm{mg} \mathrm{L}^{-1}\right)$ & LQ $\left(\mathrm{mg} \mathrm{L}^{-1}\right)$ \\
\hline AZO & $A=28796[C]+4106,3$ & 0,996 & 10,388 & 0,382 & 0,763 \\
\hline DFZ & $A=4950,9[C]-2167,3$ & 0,987 & 13,276 & 0,276 & 0,552 \\
\hline IMD & $A=167603[C]+15055$ & 1,000 & 3,816 & 0,069 & 0,139 \\
\hline \multicolumn{6}{|c|}{ Produtos comerciais } \\
\hline IA & Equação & $R^{2}$ & $\begin{array}{l}\text { Tempo de } \\
\text { Retenção } \\
\text { (min) }\end{array}$ & LD $\left(\mathrm{mg} \mathrm{L}^{-1}\right)$ & LQ $\left(\mathrm{mg} \mathrm{L}^{-1}\right)$ \\
\hline AZO (AM) & $A=75201[C]+48108$ & 0,996 & 10,301 & 0,166 & 0,331 \\
\hline DFZ (AM) & $A=21443[C]+8570,3$ & 0,988 & 13,241 & 0,199 & 0,397 \\
\hline $\operatorname{IMD}(\mathrm{P})$ & $A=235553[C]+32305$ & 1,000 & 3,815 & 0,128 & 0,255 \\
\hline
\end{tabular}
coeficiente de determinação; AM: Amistar Top ${ }^{\circledR}$; P: Provado 200 SC $^{\circledR}$.

Fonte: Resultados da autora.

\subsection{Ensaios de citotoxicidade e genotoxicidade com Allium cepa}

A avaliação da citotoxicidade e genotoxicidade foi realizada utilizando o organismo Allium cepa, de acordo com a metodologia proposta por Fiskesjö (1985).

Para tal, bulbos de cebola cultivados organicamente e sem exposição prévia a agrotóxicos foram colocados para germinar em água durante 72 horas, sem exposição direta à luz solar. Após o crescimento, as raízes foram expostas em duplicata à água de torneira (controle negativo) e às soluções individuais dos IA em padrão analítico nas concentrações nominais da água de lavagem sintética, antes e após o tratamento nas mesmas condições indicadas pela matriz Doehlert, durante 48 horas e à temperatura ambiente, com a finalidade de analisar os efeitos isolados dos IA e de 
seus produtos de degradação. Em seguida, a raízes foram coletadas e hidrolisadas utilizando solução $1,0 \mathrm{~mol} \mathrm{~L}^{-1}$ de $\mathrm{HCl}$ a $60^{\circ} \mathrm{C}$, durante 10 minutos.

Lâminas para análise foram preparadas com as células meristemáticas das raízes, que foram coradas com kit Panótico Rápido ${ }^{\circledR}$ (Laborclin) e observadas em microscópio óptico (Zeiss Axio Scope A1). Qualitativamente, os efeitos genotóxicos estão associados a alterações tais como micronúcleos, células binucleadas e brotos nucleares, enquanto os efeitos citotóxicos podem ser quantificados através da análise de alterações mitóticas, considerando as etapas da divisão celular (prófase, metáfase, anáfase e telófase). $O$ índice mitótico (IM) pode ser calculado como a razão entre 0 número de células observadas em quaisquer fases de divisão celular (NCD) e o número total de células analisadas (NCT), com a contagem até 100 células por amostra, de acordo com a Equação 33:

$I M(\%)=\frac{N C D}{N C T} \times 100$

Esse procedimento foi repetido para as matrizes reais coletadas e dopadas com os produtos comerciais Amistar Top ${ }^{\circledR}$ e Provado $200 \mathrm{SC}^{\circledR}$, antes e após o tratamento $\mathrm{UVC} / \mathrm{H}_{2} \mathrm{O}_{2}$ nas condições de $\left[\mathrm{H}_{2} \mathrm{O}_{2}\right]_{0}$ e Euvc indicadas pela matriz Doehlert. A Figura 8 mostra uma representação esquemática do procedimento.

Figura 8 - Representação esquemática dos ensaios de citotoxicidade e genotoxicidade com Allium cepa.

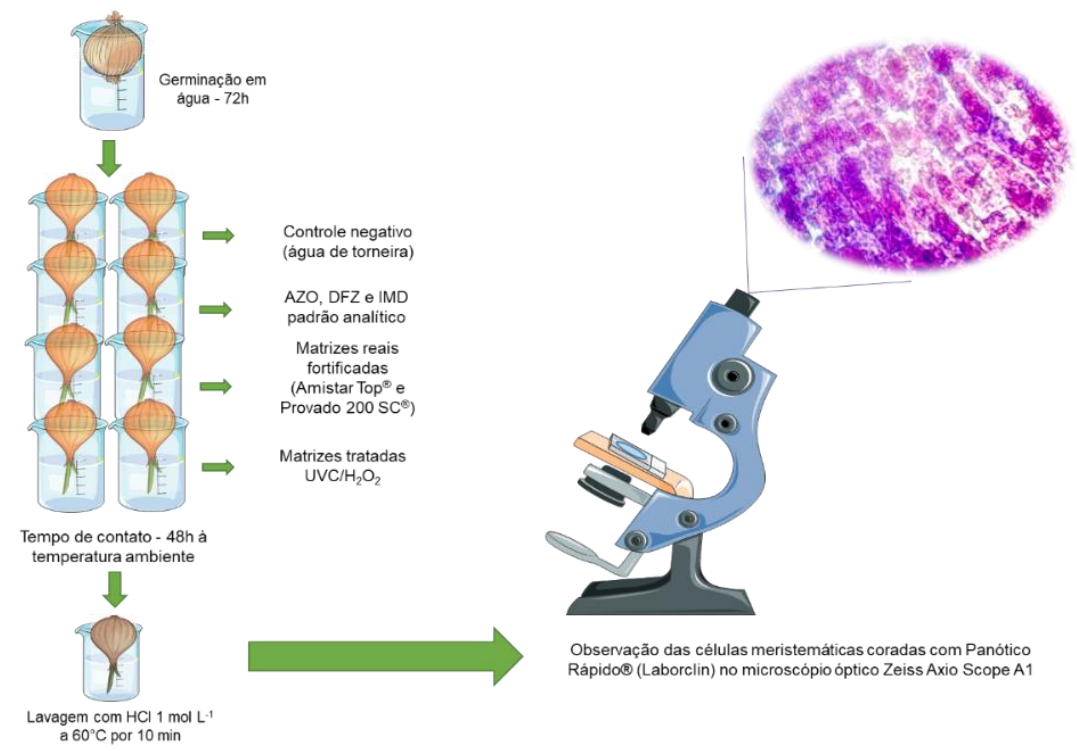

Fonte: Elaborado pela autora. 


\section{RESULTADOS E DISCUSSÃO}

\subsection{Espectros de absorção dos ingredientes ativos}

O coeficiente de absorção molar $(\varepsilon \lambda)$ é uma propriedade física fundamental de uma substância pura capaz de absorver radiação UV-visível, que mede a probabilidade da interação entre os fótons e as moléculas da substância resultar em um evento de absorção da luz, em determinado comprimento de onda (PARSONS, 2005). Em outras palavras, o coeficiente de absorção molar mede a probabilidade de ocorrência de uma transição eletrônica a partir da absorção da radiação UV-visível por um composto.

A partir da varredura das soluções dos IA em espectrofotômetro, foram obtidos os valores para a absorbância decádica $\left(A_{10}\right)$ dos compostos em cada comprimento de onda. De acordo com a lei de Beer-Lambert-Bourguer (Equação 21) e considerando um feixe de radiação monocromática, a absorbância decádica em uma solução líquida isotrópica para um dado comprimento de onda é proporcional ao produto $c l$, em que $c$ corresponde à concentração molar da espécie absorvedora (em mol L-1); l é caminho óptico da solução, atravessado pela radiação UV-visível $(\mathrm{em} \mathrm{cm})$; e a constante de proporcionalidade corresponde ao coeficiente de absorção molar decádico, $\varepsilon_{\lambda}$ (OPPENLÄNDER, 2003). A partir da inclinação das retas em gráficos de $A_{10, \lambda} \times c$ para cada comprimento de onda $\lambda$, foram obtidos os coeficientes de absorção $\varepsilon \lambda$ e o espectro de absorção para cada pesticida (Figura 9). 
Figura 9 - Espectros de absorção molar para AZO, DFZ e IMD.

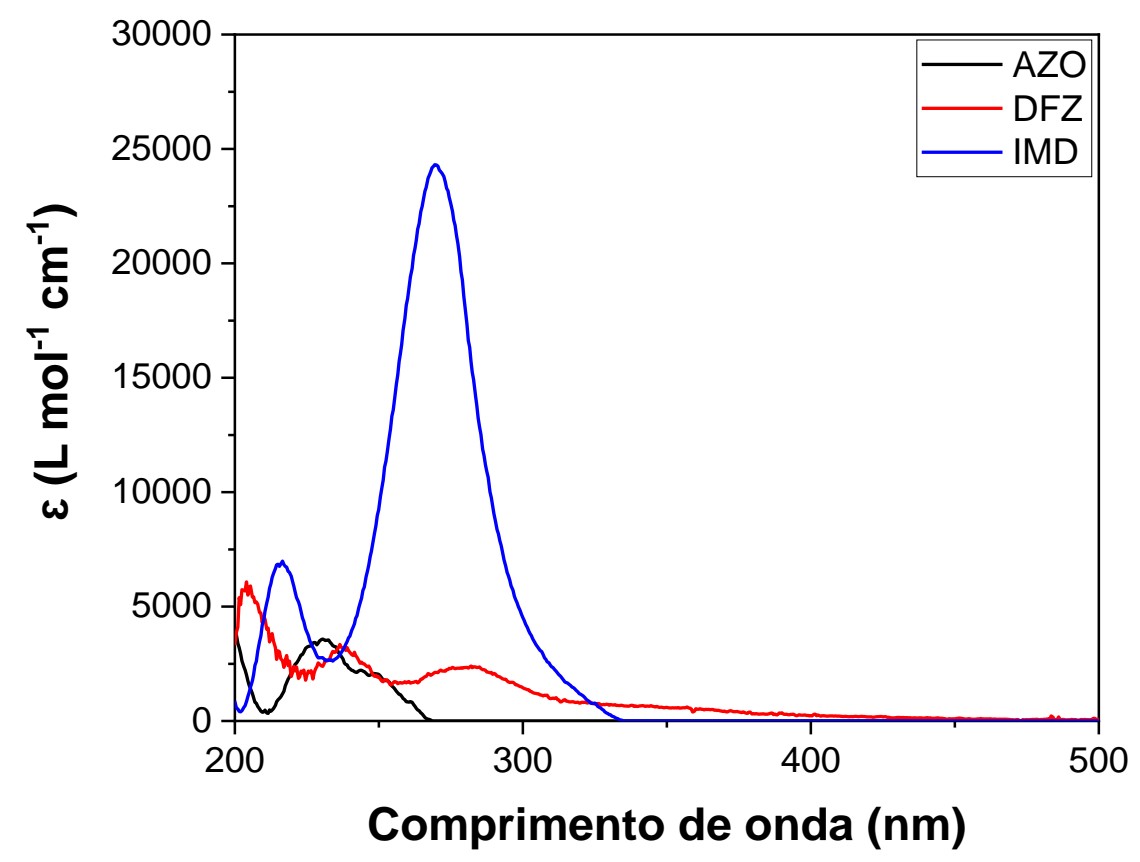

Fonte: Resultados da autora.

Analisando os espectros no intervalo de comprimento de onda do UVC (200$300 \mathrm{~nm}$ ), tem-se que o valor máximo de $\varepsilon$ para o IMD ocorre no comprimento de onda de $272 \mathrm{~nm}$. Dado que as fontes radiantes empregadas no reator fotoquímico de bancada emitem na faixa de comprimento de onda entre $251-257 \mathrm{~nm}\left(\lambda_{\operatorname{máx}}=254 \mathrm{~nm}\right)$, os valores de $\varepsilon$ para AZO, DFZ e IMD são, respectivamente, 1572, 1701 e $12817 \mathrm{~L}$ $\mathrm{mol}^{-1} \mathrm{~cm}^{-1}$. Como os valores de $\varepsilon$ dos IA para esse comprimento são superiores a 1000 $\mathrm{L} \mathrm{mol}^{-1} \mathrm{~cm}^{-1}$, a probabilidade de ocorrência de absorção e transições eletrônicas é alta para esses compostos. No entanto, ainda que os IA apresentem valores de $\varepsilon$ elevados no UVC, a ocorrência de reações fotoquímicas advindas da absorção da radiação depende da sobreposição do espectro de $\varepsilon \lambda$ e do seu espectro ativo, determinado através do rendimento quântico $\left(\Phi_{\lambda}\right)$ da fotólise direta, estimado neste trabalho para cada composto. Finalmente, cabe observar que para $\mathrm{H}_{2} \mathrm{O}_{2}$ tem-se $\varepsilon 254=19,6 \mathrm{~L} \mathrm{~mol}^{-1}$ $\mathrm{cm}^{-1}$, muito inferior aos coeficientes de absorção dos pesticidas, de modo que se espera forte competição entre as moléculas de peróxido de hidrogênio e dos pesticidas quanto à absorção dos fótons na região de emissão das lâmpadas, particularmente no início da degradação pelo processo $\mathrm{UVC} / \mathrm{H}_{2} \mathrm{O}_{2}$, em que as concentrações dos IA são elevadas. 


\subsection{Estabilidade dos compostos em água}

Experimentos de hidrólise foram realizados para verificar a estabilidade dos IA na ausência de luz. $\mathrm{O}$ pH inicial médio das soluções foi de 7,5 e não foi controlado, simulando uma condição real de aplicação nos frutos e ocorrência da lavagem pela agroindústria. Após 72 horas em incubadora sob agitação e temperatura constantes $\left(25^{\circ} \mathrm{C}\right.$ ), foram obtidos os perfis ilustrados pela Figura 10 para IMD, AZO e DFZ presentes na água de lavagem sintética.

Figura 10 - Variação da concentração de AZO, DFZ e IMD na solução sintética após 72 horas.

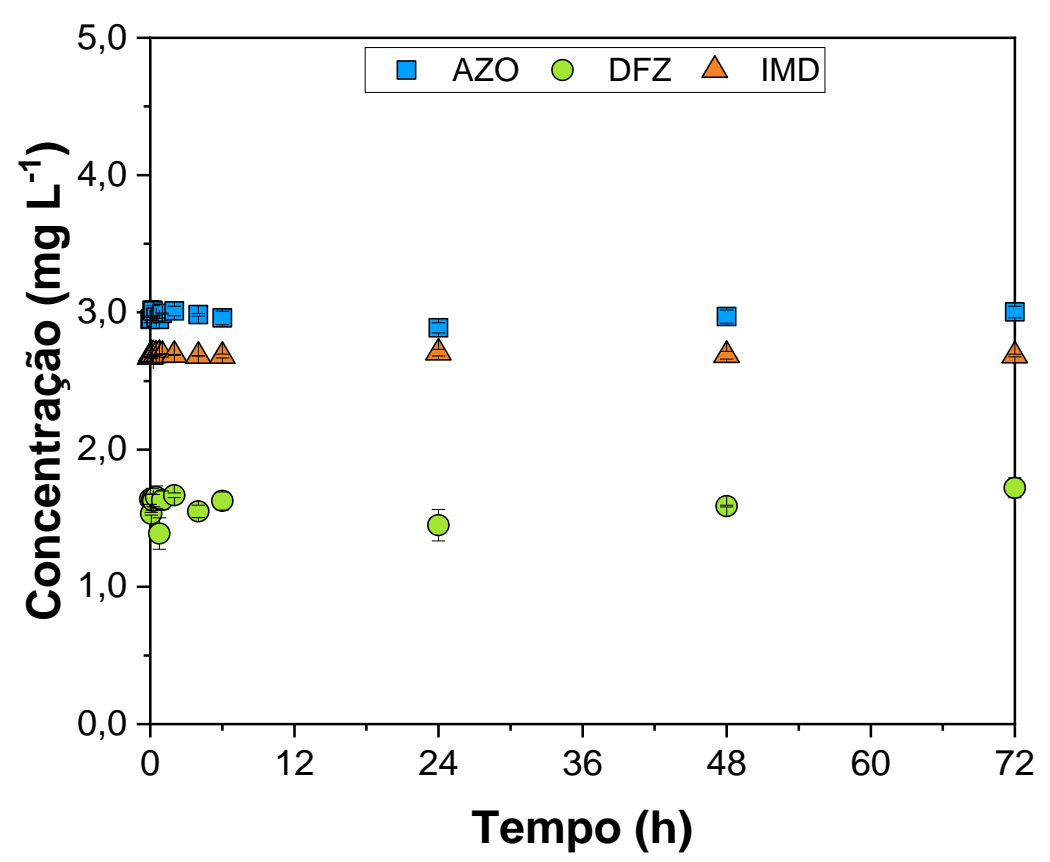

Fonte: Resultados da autora.

O comportamento das curvas de concentração em função do tempo e a estabilidade dos compostos indicam que a degradação dos IA deve ocorrer apenas a partir da interação com a radiação UVC (fotólise direta) e com os radicais hidroxila (processo UVC/ $\mathrm{H}_{2} \mathrm{O}_{2}$ ) durante os experimentos. Comportamento semelhante foi observado para a AZO e IMD em estudos de Boudina et al. (2007) e Todey, Fallon e Arnold (2018), respectivamente. Segundo esses autores, a AZO é estável numa faixa de temperatura entre 25 e $50^{\circ} \mathrm{C}$ e valores de pH entre 5,0 e 9,0, e o IMD é estável em $\mathrm{pH}$ ácido e neutro, hidrolisando apenas a partir de pH 9,0. Não foram encontrados 
estudos na literatura que investigaram a estabilidade do DFZ.

\subsection{Fotólise direta no UVC}

A fotólise direta dos IA na região do UVC foi investigada para o reator batelada para diferentes irradiâncias (Euvc). Os resultados da degradação da AZO, DFZ e IMD são apresentados na Figura 11.

Figura 11 - Decaimento da concentração relativa de AZO, DFZ e IMD com o tempo para a fotólise direta, para $E u v c=15,0 \mathrm{~W} \mathrm{~m}^{-2}(\square), 21,8 \mathrm{~W} \mathrm{~m}^{-2}(\circ)$ e 28,6 W m $\mathrm{W}^{-2}(\triangle)$.

Experimentos realizados com a água de lavagem sintética contendo os três ingredientes ativos: $[A Z O]_{0}=2,83 \pm 0,06 \mathrm{mg} \mathrm{L}^{-1} ;[\mathrm{DFZ}]_{0}=1,54 \pm 0,03 \mathrm{mg} \mathrm{L}^{-1} ;[\mathrm{IMD}]_{0}$ $=2,74 \pm 0,01 \mathrm{mg} \mathrm{L}^{-1}$. Experimentos realizados em triplicata, sendo os erros percentuais médios iguais a 1,8\% (AZO), 1,1\% (DFZ) e 2,8\% (IMD).
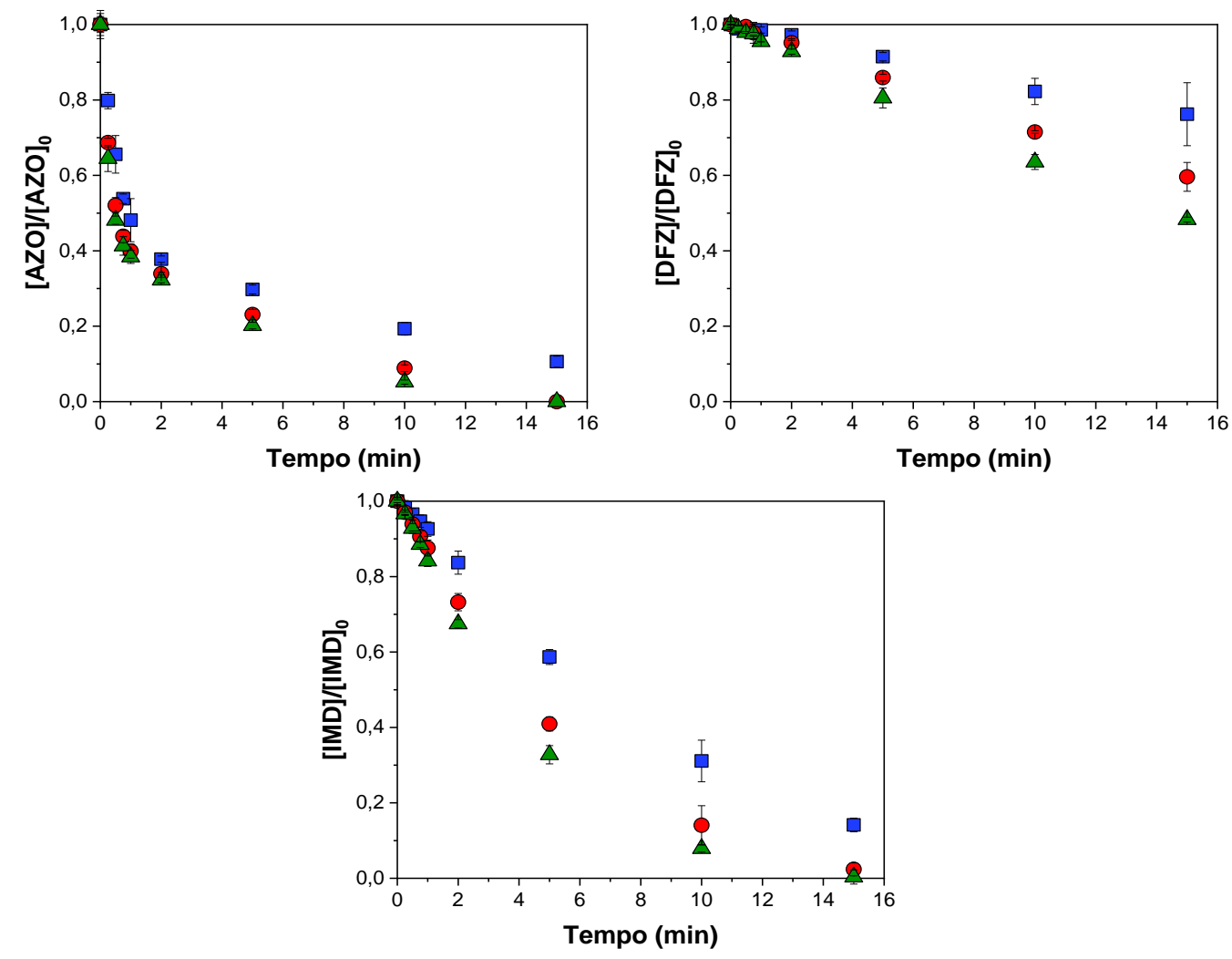

Fonte: Resultados da autora.

É possível observar a ocorrência de degradação acentuada de AZO logo nos primeiros minutos, em todas as condições de irradiação. A fotólise direta usando 15,0 W $\mathrm{m}^{-2}$ foi capaz de remover $89,4 \%$ desse pesticida após os 15 minutos de ensaio, resultando em concentrações abaixo do limite de detecção. O DFZ se mostrou mais resistente à fotólise e não foi completamente degradado (remoção máxima obtida de 
$51,7 \%$ após 15 minutos, na condição de Euvc $=28,6 \mathrm{~W} \mathrm{~m}^{-2}$ ). As taxas específicas de pseudo-primeira ordem ( $k^{\prime}$ ) para os IA aumentaram com o aumento da irradiância para os três compostos, variando da faixa de $0,128-0,249 \mathrm{~s}^{-1}$ (AZO), 0,019-0,048 s-1 (DFZ) e 0,129-0,266 s-1 (IMD), como ilustra a Tabela 13; seus respectivos coeficientes de determinação foram satisfatoriamente altos, com $R^{2}$ variando entre $0,895-0,928$ (AZO), 0,986-0,997 (DFZ) e 0,981-0,995 (IMD).

Tabela 13 - Constantes de pseudo-primeira ordem ( $k^{\prime}$ ) para AZO, DFZ e IMD em diferentes condições de irradiância.

\begin{tabular}{|c|c|c|c|}
\hline $\begin{array}{l}\text { Irradiância } \\
\left(E_{\mathrm{Uvc}}\right) \\
\left(\mathrm{W} \mathrm{m}^{-2}\right)\end{array}$ & $k_{A Z O}^{\prime}\left(s^{-1}\right)$ & $k_{\text {DFZ }}^{\prime}\left(\mathbf{s}^{-1}\right)$ & $k_{\text {IMD }}^{\prime}\left(s^{-1}\right)$ \\
\hline $\begin{array}{l}15,0 \\
21,8 \\
28,6\end{array}$ & $\begin{array}{l}0,128 \pm 0,002\left(R^{2}=0,902\right) \\
0,202 \pm 0,003\left(R^{2}=0,895\right) \\
0,249 \pm 0,004\left(R^{2}=0,928\right)\end{array}$ & $\begin{array}{l}0,019 \pm 0,004\left(R^{2}=0,986\right) \\
0,035 \pm 0,002\left(R^{2}=0,996\right) \\
0,048 \pm 0,001\left(R^{2}=0,997\right)\end{array}$ & $\begin{array}{l}0,129 \pm 0,004\left(R^{2}=0,995\right) \\
0,240 \pm 0,016\left(R^{2}=0,981\right) \\
0,266 \pm 0,022\left(R^{2}=0,994\right)\end{array}$ \\
\hline
\end{tabular}

Fonte: Resultados da autora.

O rendimento quântico $(\Phi)$ dos IA foi estimado com auxílio do software MATLAB a partir dos dados experimentais obtidos para o decaimento das concentrações dos IA com o tempo, conforme procedimento apresentado na seção 4.5.3, considerando a absorção de cada composto para o UVC e as condições de irradiação em cada caso.

Sabendo que a absorção da radiação de um composto em dado comprimento de onda é proporcional ao produto de seu coeficiente molar de absorção $(\varepsilon)$ e de sua concentração molar, c ( $\mathrm{mol} \mathrm{L}^{-1}$ ) e que a ocorrência de uma reação fotoquímica seguida da irradiação depende da sobreposição dos espectros de absorção $\left(\varepsilon_{\lambda}\right)$ e de ativação $\left(\Phi_{\lambda}\right)$ (BRAUN; MAURETTE; OLIVEROS, 1991), para a radiação UVC emitida pelas lâmpadas, se compararmos a AZO $\left(\varepsilon\right.$ AZO $\left.=1572 \mathrm{~L} \mathrm{~mol}^{-1} \mathrm{~cm}^{-1}\right)$ e o DFZ $(\varepsilon \mathrm{DFZ}=1701 \mathrm{~L}$ $\mathrm{mol}^{-1} \mathrm{~cm}^{-1}$ ), pode-se atribuir o baixo valor para a fotólise do DFZ ao produto $\varepsilon \times c$ observado para esse composto no tempo zero $\left(0,011\right.$ e $0,006 \mathrm{~cm}^{-1}$ para AZO e DFZ, respectivamente) e ao seu baixo rendimento quântico da fotólise $(\Phi \mathrm{DFZ}=0,028 \mathrm{~mol}$ Einstein $\left.^{-1}\right)$. No caso do IMD, esse composto apresenta o maior coeficiente de absorção molar dentre os três pesticidas $\left(\varepsilon \mathrm{IMD}=12817 \mathrm{~L} \mathrm{~mol}^{-1} \mathrm{~cm}^{-1}\right)$ e o maior valor inicial de $\varepsilon \times c\left(0,135 \mathrm{~cm}^{-1}\right)$; no entanto o valor estimado para seu rendimento quântico é relativamente baixo ( $\left.\Phi \mathrm{IMD}=0,061 \mathrm{~mol}^{\text {Einstein }}{ }^{-1}\right)$. Consequentemente, os valores de $K^{\prime}$ IMD são maiores do que os de $K^{\prime}$ DFZ, mas similares aos valores de $k^{\prime}$ AzO. O maior rendimento quântico obtido para a fotólise na região de 251-257 nm foi para a AZO 
$\left(\Phi\right.$ AzO $\left.=0,572 \mathrm{~mol}^{\text {Einstein }}{ }^{-1}\right)$, que é uma ordem de grandeza superior aos valores encontrados para o DFZ e IMD.

Boudina et al. (2007) sugerem que a fototransformação da AZO, em soluções aquosas em comprimentos de onda superiores a $290 \mathrm{~nm}$ envolvem múltiplos caminhos de reação paralelos, incluindo foto isomerização, foto-hidrólise dos grupos éster metílico e nitrila, quebra da ligação do grupo acrilato, quebra fotohidrolítica do éter entre os anéis aromáticos gerando fenol e a quebra oxidativa da ligação dupla do grupo acrilato. Zheng et al. (2004) estudaram a fotólise direta do IMD em solução aquosa a $254 \mathrm{~nm}$, observando a formação de $\mathrm{CO}_{2}, \mathrm{Cl}^{-}$e $\mathrm{NO}_{3}{ }^{-}$, esse último ocorrendo a partir da formação de $\mathrm{NH}_{4}{ }^{+}$e $\mathrm{NO}_{2}{ }^{-}$. Por sua vez, de acordo com Todey, Fallon e Arnold (2018), a ureia foi identificada como o produto mais comum formado a partir da hidrólise e fotólise de inseticidas do grupo dos neonicotinóides, dentre eles o IMD.

\subsection{Processo UVC/ $\mathrm{H}_{2} \mathrm{O}_{2}$}

A influência da irradiância (Euvc) e da concentração inicial de peróxido de hidrogênio $\left(\left[\mathrm{H}_{2} \mathrm{O}_{2}\right]\right.$ ) na degradação da AZO, DFZ e IMD foi investigada através dos experimentos realizados segundo a matriz Doehlert (Tabela 10 e Figura 6). Em comparação com os ensaios da fotólise direta, houve remoção total para os pesticidas, com concentrações abaixo dos limites de detecção para os primeiros dez minutos de irradiação para a maioria das condições (Figuras 12-17). 
Figura 12 - Decaimento das concentrações relativas de AZO, DFZ e IMD com o tempo para processo $\mathrm{UVC} / \mathrm{H}_{2} \mathrm{O}_{2}$. Experimentos 7 (घ) e 8 (०), usando $15,0 \mathrm{~W} \mathrm{~m}^{-2}$ (matriz Doehlert, experimentos 1-9). Experimentos realizados com água de lavagem sintética contendo os três ingredientes ativos. [AZO $]_{0}=(2,60 \pm 0,04) \mathrm{mg} \mathrm{L}^{-1} ;$ [DFZ] $0=$ $(1,72 \pm 0,05) \mathrm{mg} \mathrm{L}^{-1} ;[\mathrm{IMD}]_{0}=(2,55 \pm 0,01) \mathrm{mg} \mathrm{L}^{-1}$.
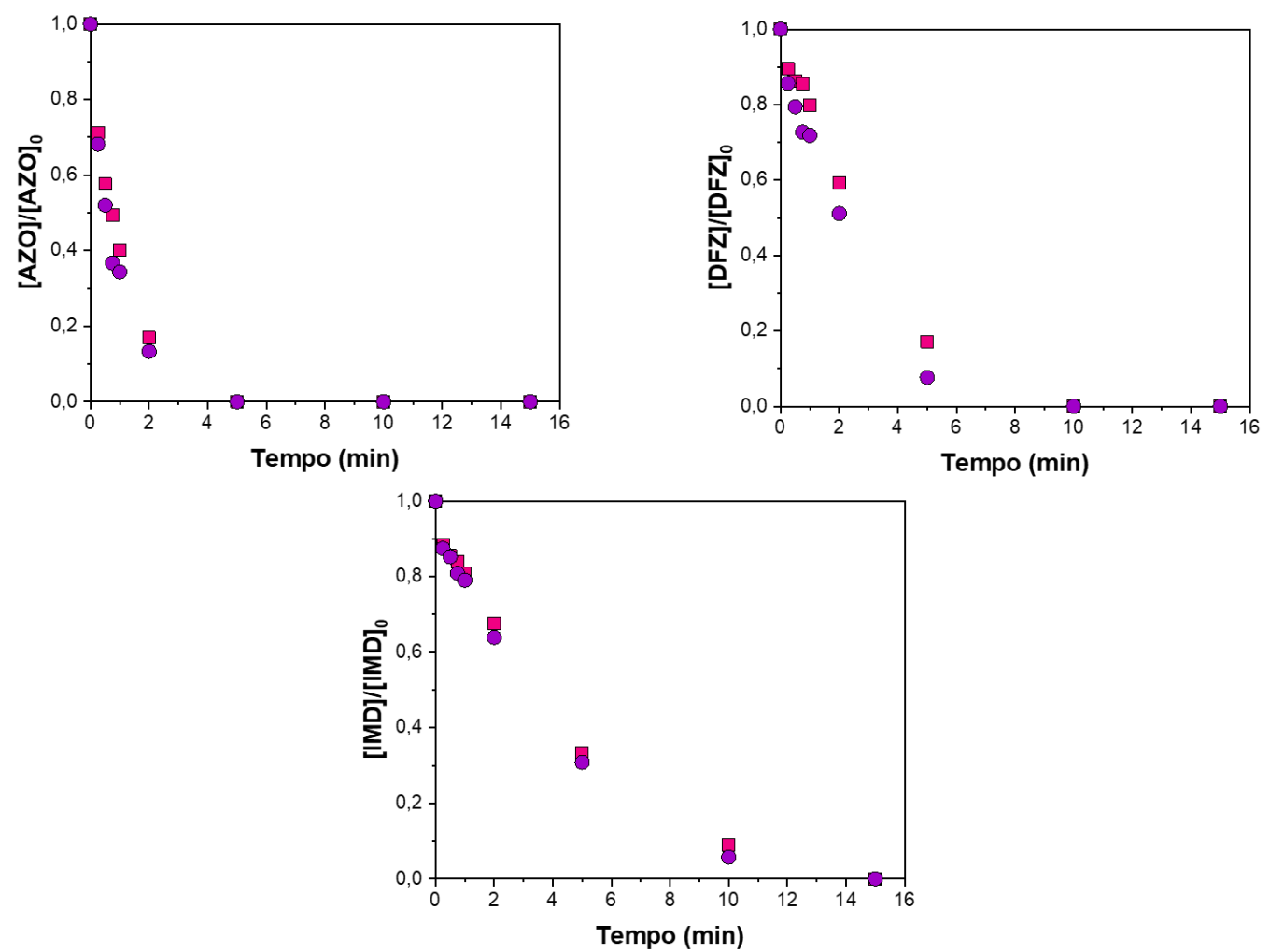

Fonte: Resultados da autora. 
Figura 13 - Decaimento das concentrações relativas de AZO, DFZ e IMD com o tempo para processo $\mathrm{UVC} / \mathrm{H}_{2} \mathrm{O}_{2}$. Experimentos 6 (घ) e 4 (॰), usando 21,8 $\mathrm{W} \mathrm{m}^{-2}$ (matriz Doehlert, experimentos 1-9). Experimentos realizados com água de lavagem sintética contendo os três ingredientes ativos. [AZO $]_{0}=(2,60 \pm 0,04) \mathrm{mg} \mathrm{L}^{-1} ;[\mathrm{DFZ}]_{0}=$ $(1,72 \pm 0,05) \mathrm{mg} \mathrm{L}^{-1} ;[\mathrm{IMD}]_{0}=(2,55 \pm 0,01) \mathrm{mg} \mathrm{L}^{-1}$.
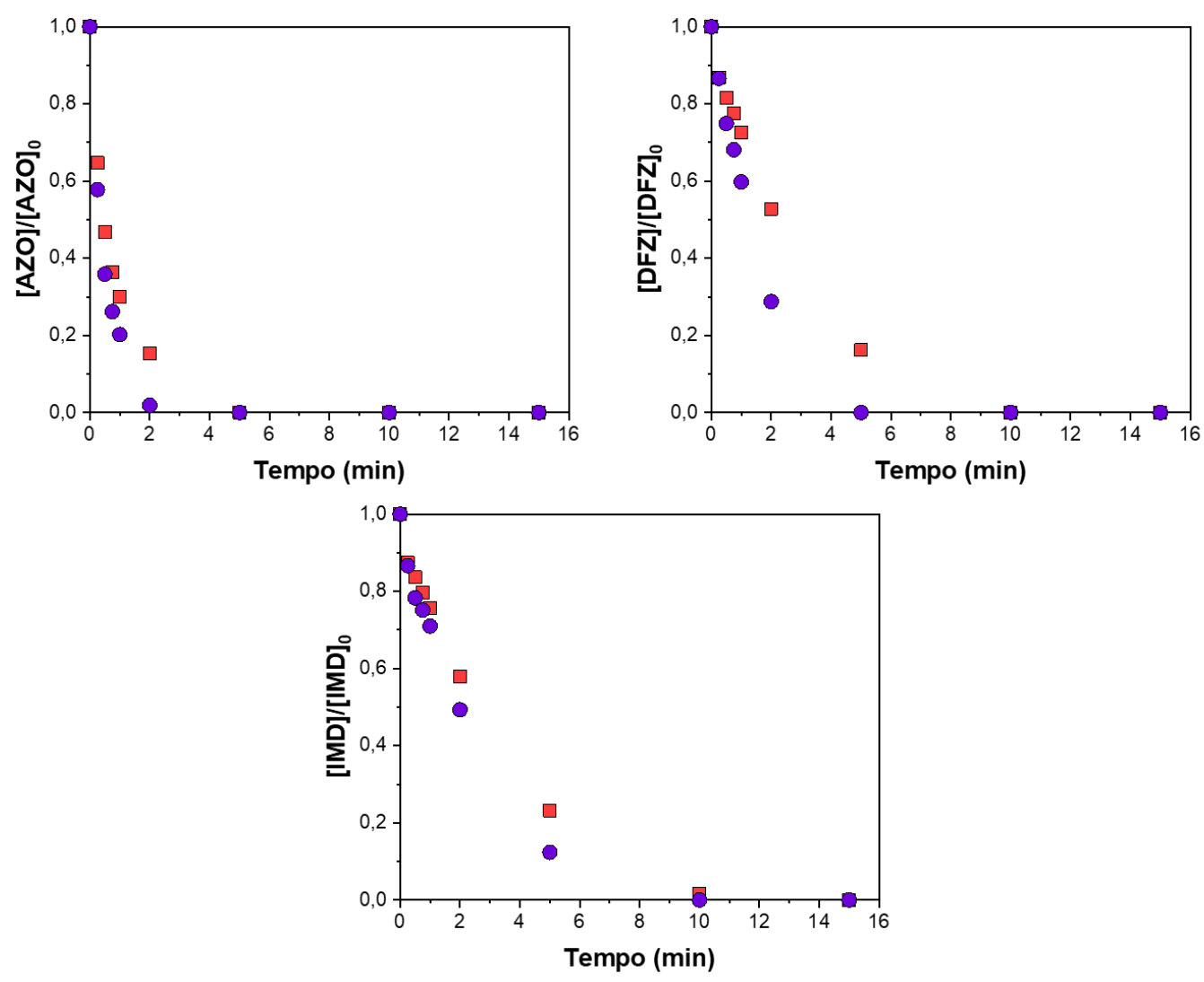

Fonte: Resultados da autora. 
Figura 14 - Decaimento das concentrações relativas de AZO, DFZ e IMD com o tempo para processo $\mathrm{UVC} / \mathrm{H}_{2} \mathrm{O}_{2}$. Experimentos 9 () e 5 (०), usando $28,6 \mathrm{~W} \mathrm{~m}^{-2}$ (matriz Doehlert, experimentos 1-9). Experimentos realizados com água de lavagem sintética contendo os três ingredientes ativos. [AZO $]_{0}=(2,60 \pm 0,04) \mathrm{mg} \mathrm{L}^{-1} ;$ [DFZ] $0=$ $(1,72 \pm 0,05) \mathrm{mg} \mathrm{L}^{-1} ;[\mathrm{IMD}]_{0}=(2,55 \pm 0,01) \mathrm{mg} \mathrm{L}^{-1}$.
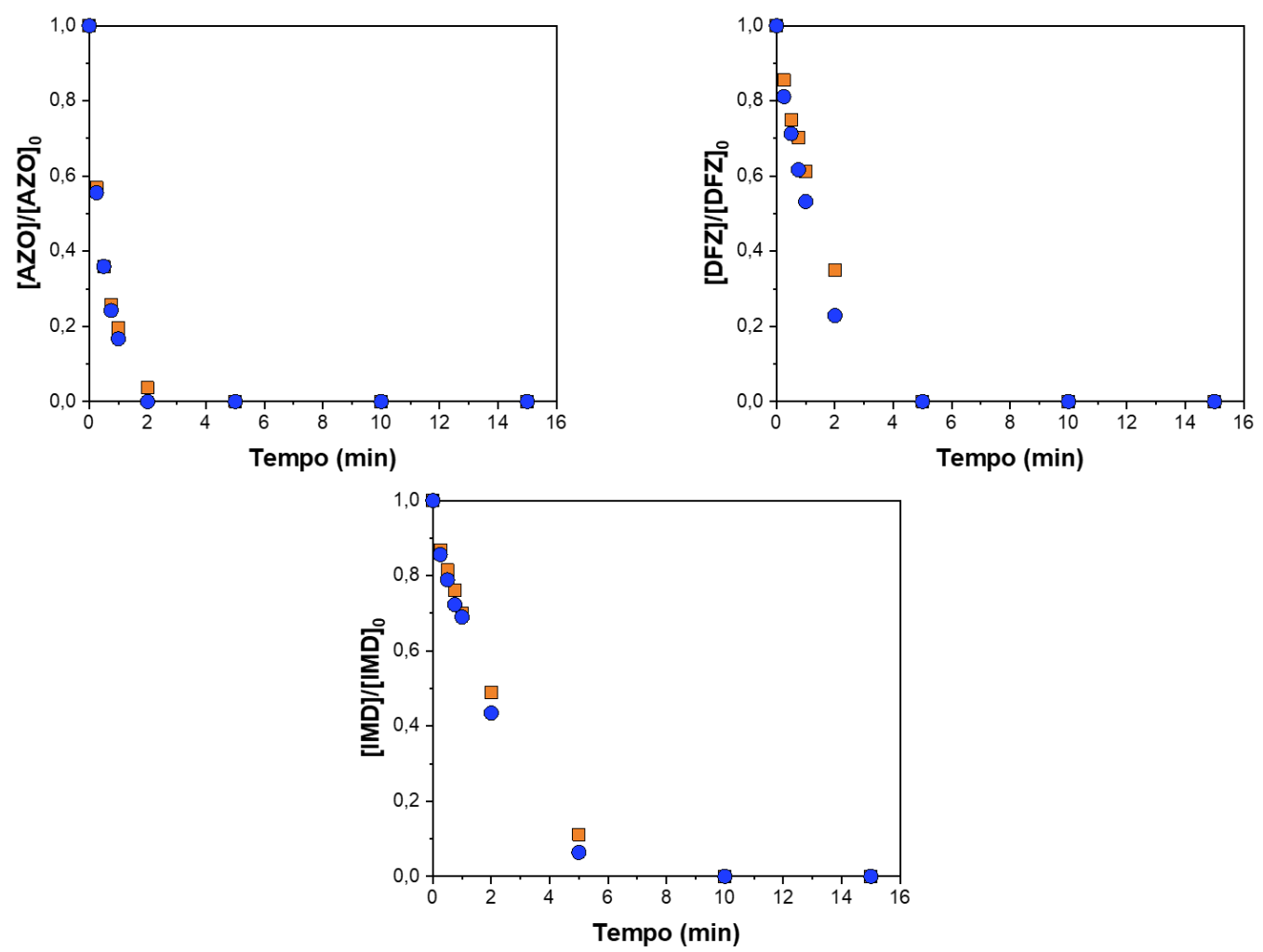

Fonte: Resultados da autora. 
Figura 15 - Decaimento das concentrações relativas de AZO, DFZ e IMD com o tempo para processo $\mathrm{UVC} / \mathrm{H}_{2} \mathrm{O}_{2}$. Experimentos 1 (口), 2 (o) e $3(\triangle)$, usando 21,8 W $\mathrm{m}^{-2}$ (matriz Doehlert, experimentos 1-9). Experimentos realizados com água de lavagem sintética contendo os três ingredientes ativos. $[A Z O]_{0}=(2,60 \pm 0,04) \mathrm{mg} \mathrm{L}^{-1}$; $[D F Z]_{0}=(1,72 \pm 0,05) \mathrm{mg} \mathrm{L}^{-1} ;[\mathrm{IMD}]_{0}=(2,55 \pm 0,01) \mathrm{mg} \mathrm{L}^{-1}$.
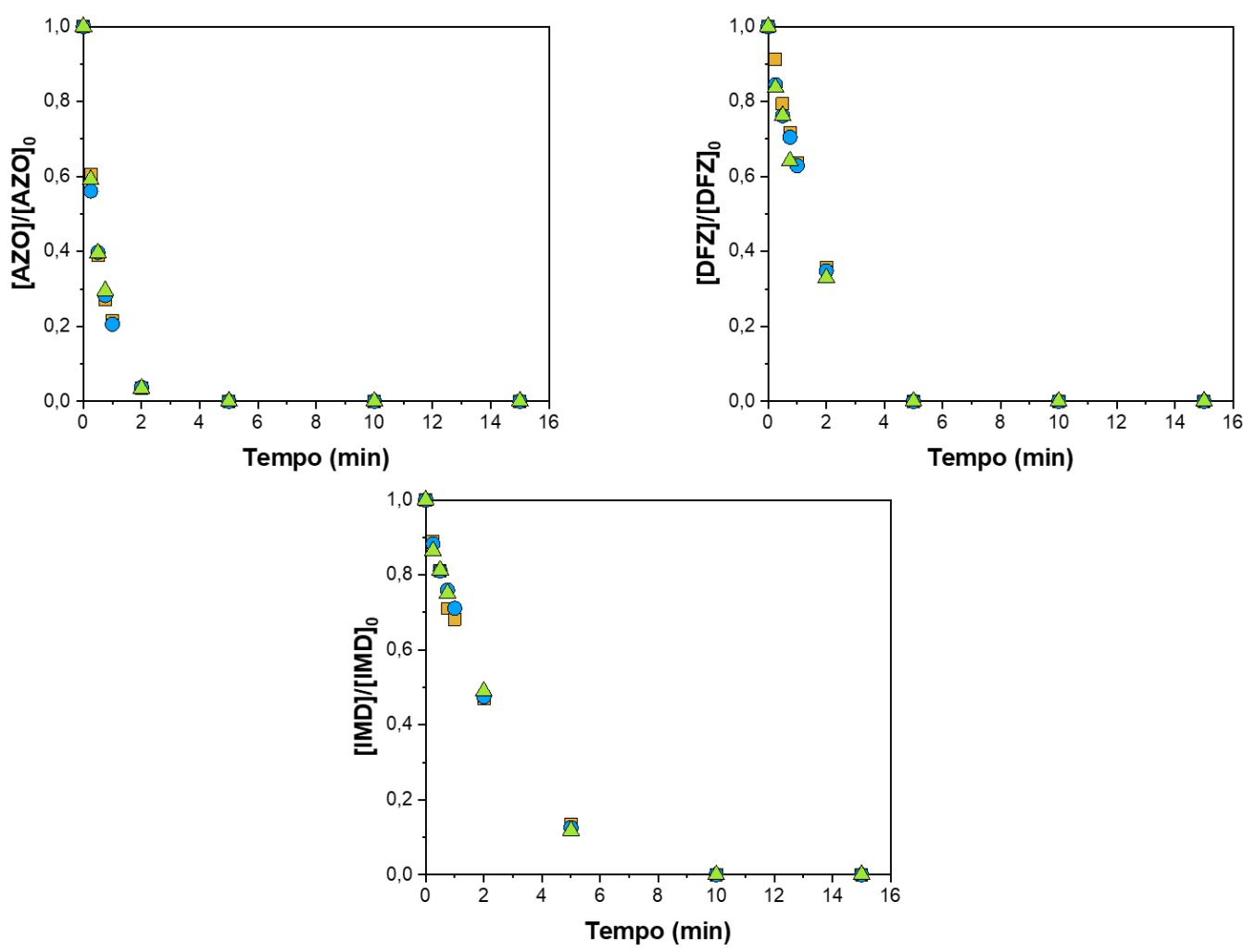

Fonte: Resultados da autora. 
Figura 16 - Decaimento das concentrações relativas de AZO, DFZ e IMD com o tempo para processo $\mathrm{UVC} / \mathrm{H}_{2} \mathrm{O}_{2}$. Experimentos 10 (口), 11 (o) e $12(\triangle)$ (matriz Doehlert, experimentos 10-12). Experimentos realizados com água de lavagem sintética contendo os três ingredientes ativos. $[A Z O]_{0}=(2,60 \pm 0,04) \mathrm{mg} \mathrm{L}^{-1} ;[\mathrm{DFZ}]_{0}=$ $(1,72 \pm 0,05) \mathrm{mg} \mathrm{L}^{-1} ;[\mathrm{IMD}] \mathrm{o}=(2,55 \pm 0,01) \mathrm{mg} \mathrm{L}^{-1}$.
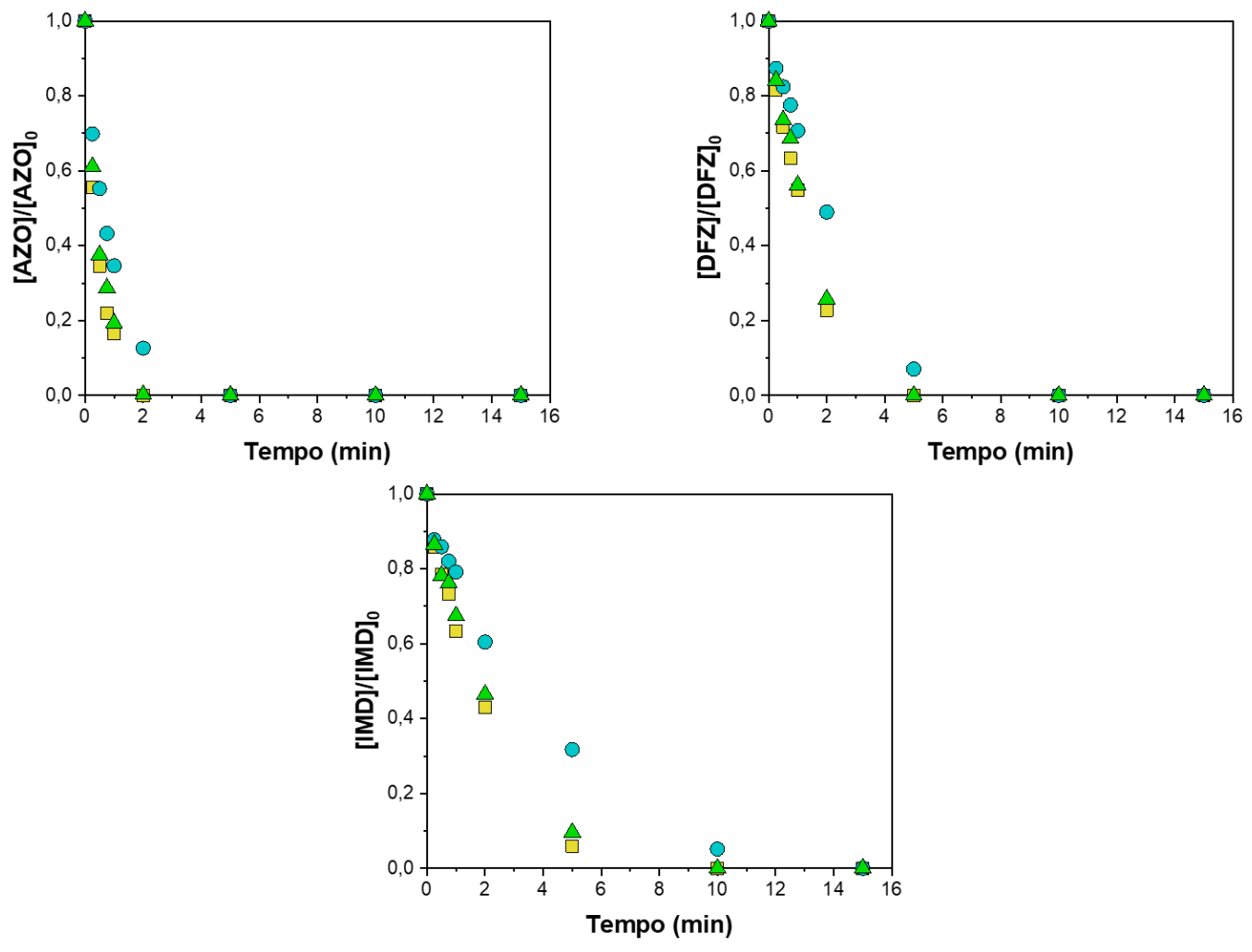

Fonte: Resultados da autora. 
Figura 17 - Decaimento das concentrações relativas de AZO, DFZ e IMD com o tempo para processo UVC/ $\mathrm{H}_{2} \mathrm{O}_{2}$. Experimentos $13(\square), 14(\bullet), 15(\triangle), 16(\nabla), 17(\diamond)$ e $18(\triangleleft)$ (matriz Doehlert, experimentos 13-18). Experimentos realizados com água de lavagem sintética contendo os três ingredientes ativos. $[A Z O]_{0}=(2,60 \pm 0,04) \mathrm{mg}$

$\mathrm{L}^{-1} ;[\mathrm{DFZ}]_{0}=(1,72 \pm 0,05) \mathrm{mg} \mathrm{L}^{-1} ;[\mathrm{IMD}]_{0}=(2,55 \pm 0,01) \mathrm{mg} \mathrm{L}^{-1}$.
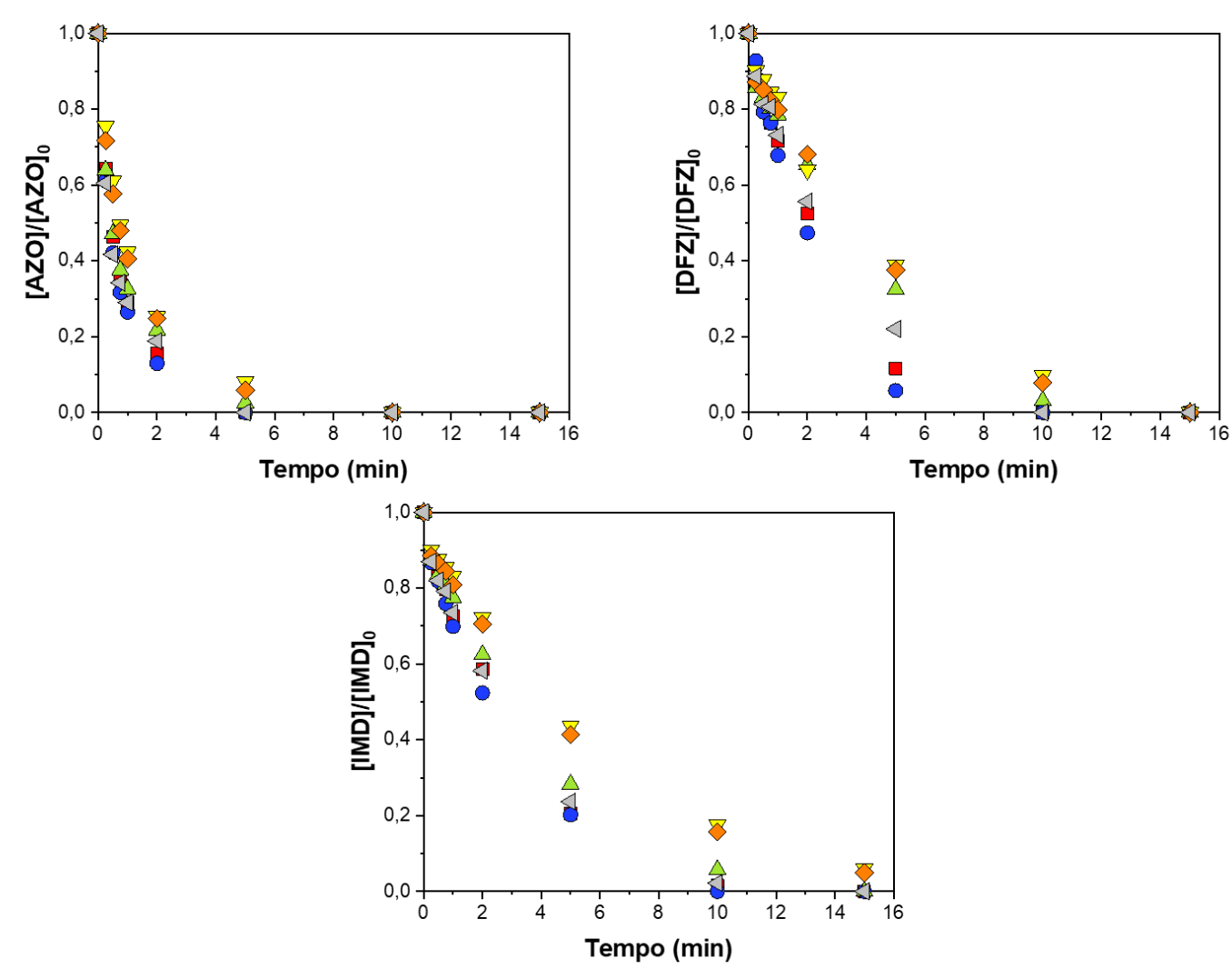

Fonte: Resultados da autora.

Tendo em vista que todas as configurações de processo exploradas atingiram 100\% de remoção dos IA após 15 minutos de irradiação, os efeitos da variação da $\left[\mathrm{H}_{2} \mathrm{O}_{2}\right] 0$ e Euvc foram mais bem avaliados em termos das taxas específicas de degradação de pseudo-primeira ordem $(k)$.

Como esperado, a degradação dos IA ocorreu mais rapidamente com o aumento da concentração de oxidante (para Euvc constante) e da irradiância (para $\left[\mathrm{H}_{2} \mathrm{O}_{2}\right] 0$ mantida constante), como pode ser verificado para as taxas de degradação de pseudo-primeira ordem $k_{A Z O}, k_{D F Z}$ e $k_{I M D}$, que variaram entre $0,475-2,998 \mathrm{~s}^{-1}, 0,226$ $0,726 \mathrm{~s}^{-1}$ e $0,182-0,562 \mathrm{~s}^{-1}$, respectivamente (Figura 18 e Tabela 14). Os coeficientes de determinação $\left(R^{2}\right)$ para os valores de $k$ variaram na faixa de 0,871-0,998 (AZO), 0,965-0,998 (DFZ) and 0,963-0,999 (IMD) (Tabela 14), enquanto o erro experimental, estimado a partir das três repetições na condição do ponto central (Experimentos $1 \mathrm{a}$ 3) foi de apenas 3,0\% (AZO), 2,2\% (DFZ) e 2,5\% (IMD), indicando boa 
reprodutibilidade dos experimentos $\mathrm{UVC} / \mathrm{H}_{2} \mathrm{O}_{2}$.

Tabela 14 - Valores obtidos para as taxas de degradação de pseudo-primeira ordem para cada IA nos experimentos $\mathrm{UVC} / \mathrm{H}_{2} \mathrm{O}_{2}$ e respectivos coeficientes de determinação $\left(R^{2}\right)$. Experimentos realizados conforme o planejamento Doehlert (Tabela 10 e Figura 6).

\begin{tabular}{cccc}
\hline \multirow{2}{*}{ Experimento } & \multicolumn{3}{c}{ Respostas } \\
\cline { 2 - 4 } & $\boldsymbol{k}_{\text {AZO }}\left(\mathbf{s}^{-1}\right)$ & $\boldsymbol{k}_{\text {DFZ }}\left(\mathbf{s}^{-1}\right)$ & $\boldsymbol{k}_{\text {MD }}\left(\mathbf{s}^{-1}\right)$ \\
\hline $\mathbf{1}$ & $1,648\left(R^{2}=0,995\right)$ & $0,520\left(R^{2}=0,995\right)$ & $0,397\left(R^{2}=0,999\right)$ \\
$\mathbf{2}$ & $1,599\left(R^{2}=0,996\right)$ & $0,513\left(R^{2}=0,991\right)$ & $0,412\left(R^{2}=0,997\right)$ \\
$\mathbf{3}$ & $1,659\left(R^{2}=0,998\right)$ & $0,549\left(R^{2}=0,998\right)$ & $0,423\left(R^{2}=0,994\right)$ \\
$\mathbf{4}$ & $1,940\left(R^{2}=0,986\right)$ & $0,617\left(R^{2}=0,989\right)$ & $0,412\left(R^{2}=0,993\right)$ \\
$\mathbf{5}$ & $1,764\left(R^{2}=0,991\right)$ & $0,725\left(R^{2}=0,991\right)$ & $0,548\left(R^{2}=0,987\right)$ \\
$\mathbf{6}$ & $0,898\left(R^{2}=0,966\right)$ & $0,360\left(R^{2}=0,979\right)$ & $0,441\left(R^{2}=0,969\right)$ \\
$\mathbf{7}$ & $0,857\left(R^{2}=0,994\right)$ & $0,352\left(R^{2}=0,984\right)$ & $0,236\left(R^{2}=0,995\right)$ \\
$\mathbf{8}$ & $0,974\left(R^{2}=0,982\right)$ & $0,507\left(R^{2}=0,976\right)$ & $0,277\left(R^{2}=0,990\right)$ \\
$\mathbf{9}$ & $1,608\left(R^{2}=0,994\right)$ & $0,515\left(R^{2}=0,994\right)$ & $0,435\left(R^{2}=0,992\right)$ \\
\hline $\mathbf{1 0}$ & $1,806\left(R^{2}=0,986\right)$ & $0,726\left(R^{2}=0,986\right)$ & $0,562\left(R^{2}=0,988\right)$ \\
$\mathbf{1 1}$ & $1,010\left(R^{2}=0,997\right)$ & $0,530\left(R^{2}=0,980\right)$ & $0,287\left(R^{2}=0,986\right)$ \\
$\mathbf{1 2}$ & $2,998\left(R^{2}=0,933\right)$ & $0,671\left(R^{2}=0,985\right)$ & $0,465\left(R^{2}=0,992\right)$ \\
\hline $\mathbf{1 3}$ & $0,888\left(R^{2}=0,944\right)$ & $0,425\left(R^{2}=0,988\right)$ & $0,409\left(R^{2}=0,963\right)$ \\
$\mathbf{1 4}$ & $0,970\left(R^{2}=0,943\right)$ & $0,572\left(R^{2}=0,981\right)$ & $0,312\left(R^{2}=0,999\right)$ \\
$\mathbf{1 5}$ & $0,679\left(R^{2}=0,980\right)$ & $0,331\left(R^{2}=0,965\right)$ & $0,280\left(R^{2}=0,995\right)$ \\
$\mathbf{1 6}$ & $0,475\left(R^{2}=0,966\right)$ & $0,226\left(R^{2}=0,990\right)$ & $0,182\left(R^{2}=0,996\right)$ \\
$\mathbf{1 7}$ & $0,535\left(R^{2}=0,981\right)$ & $0,244\left(R^{2}=0,983\right)$ & $0,194\left(R^{2}=0,996\right)$ \\
$\mathbf{1 8}$ & $0,770\left(R^{2}=0,871\right)$ & $0,297\left(R^{2}=0,997\right)$ & $0,369\left(R^{2}=0,984\right)$ \\
\hline
\end{tabular}

Fonte: Resultados da autora.

Os valores de $k$ obtidos foram superiores para a $\mathrm{AZO}$, para ambos os processos de fotólise e UVC/ $\mathrm{H}_{2} \mathrm{O}_{2}$, em todas as irradiâncias estudadas (Figura 18 e Tabela 14). Além disso, pode-se perceber que $k_{A z O}$ aumentou continuamente com o aumento da concentração inicial de peróxido de hidrogênio, atingindo valores praticamente constantes de 1,0 s $\mathrm{s}^{-1}\left(\left[\mathrm{H}_{2} \mathrm{O}_{2}\right] 0=80,9 \mathrm{mg} \mathrm{L}^{-1}\right.$, Euvc $\left.=15,0 \mathrm{~W} \mathrm{~m}^{-2}\right), 1,9 \mathrm{~s}^{-1}\left(\left[\mathrm{H}_{2} \mathrm{O}_{2}\right]_{0}=99,5\right.$ $\mathrm{mg} \mathrm{L}^{-1}$, Euvc $\left.=21,8 \mathrm{~W} \mathrm{~m}^{-2}\right)$ e 1,8 $\mathrm{s}^{-1}\left(\left[\mathrm{H}_{2} \mathrm{O}_{2}\right] 0=80,9 \mathrm{mg} \mathrm{L}^{-1}\right.$, Euvc $\left.=28,6 \mathrm{~W} \mathrm{~m}^{-2}\right)$; para Euvc $=21,8 \mathrm{~W} \mathrm{~m}^{-2}$, o aumento posterior de $\left[\mathrm{H}_{2} \mathrm{O}_{2}\right]_{0}$ para $136,8 \mathrm{mg} \mathrm{L}^{-1}$ resultou em um aumento de cerca de 55\% de $k_{A Z Z}$. Em contrapartida, os valores de $k_{D F Z}$ e $k_{\text {IMD }}$ foram próximos um do outro, particularmente para baixos valores $\left[\mathrm{H}_{2} \mathrm{O}_{2}\right]_{0}$ e/ou Euvc; os maiores valores encontrados foram de aproximadamente $0,73 \mathrm{~s}^{-1}$ e $0,55 \mathrm{~s}^{-1}$, respectivamente, para $\left[\mathrm{H}_{2} \mathrm{O}_{2}\right]_{0}=118,2 \mathrm{mg} \mathrm{L}^{-1}$ e Euvc $=28,6 \mathrm{~W} \mathrm{~m}^{-2}$. 
Figura 18 - Taxas de degradação de pseudo-primeira ordem para experimentos UVC/ $/ \mathrm{H}_{2} \mathrm{O}_{2}$ da matriz Doehlert e de fotólise direta UVC $\left(\left[\mathrm{H}_{2} \mathrm{O}_{2}\right] 0=0\right)$, realizados em diferentes condições de $\left[\mathrm{H}_{2} \mathrm{O}_{2}\right]_{0}$ e Euvc. (a) $15,0 \mathrm{~W} \mathrm{~m}^{-2}$, (b) $21,8 \mathrm{~W} \mathrm{~m}^{-2}$ e (c) $28,6 \mathrm{~W}$ $\mathrm{m}^{-2}$.

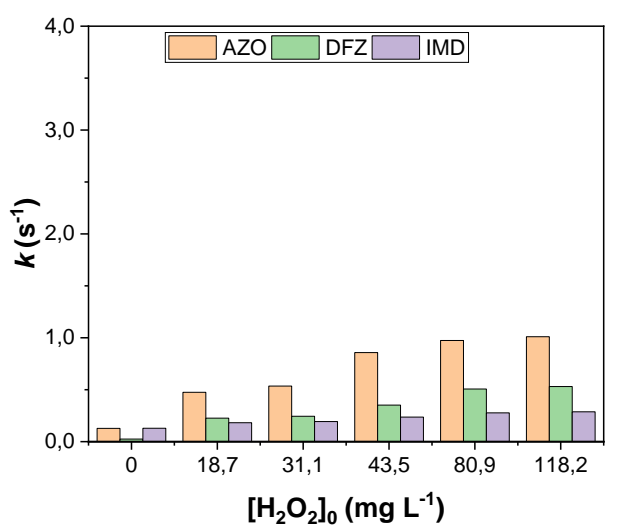

(a)

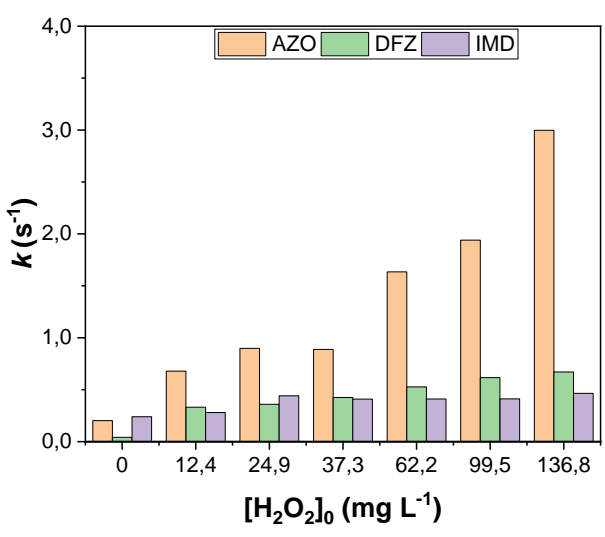

(b)

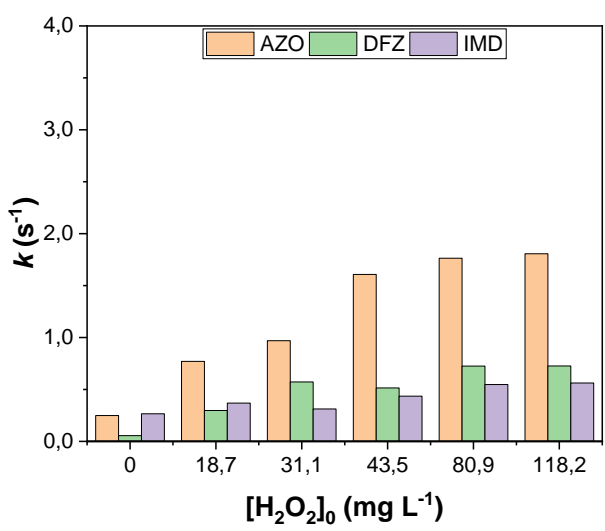

(c)

Fonte: Resultados da autora.

Finalmente, os resultados também sugerem que a contribuição da fotólise direta na taxa de degradação dos pesticidas durante o processo $\mathrm{UVC} / \mathrm{H}_{2} \mathrm{O}_{2}$ seguiu a ordem IMD > AZO > DFZ. Isso pode ser previsto, uma vez que há competição entre as moléculas de $\mathrm{H}_{2} \mathrm{O}_{2}$ e as moléculas dos IA pelos fótons incidentes, dado que esses compostos apresentam valores do coeficiente de absorção molar muito superiores ao exibido pelo $\mathrm{H}_{2} \mathrm{O}_{2}$ na mesma faixa de comprimento de onda (251-257 nm). De fato, se a absorção dos compostos intermediários desconhecidos formados na degradação for negligenciada, a fração da radiação UVC que é absorvida pelos pesticidas no início do tratamento estará em torno de $13-61 \%$ (AZO), 7-46\% (DFZ) e $64-95 \%$ (IMD) (dependendo da $\left[\mathrm{H}_{2} \mathrm{O}_{2}\right]_{0}$ ), o que varia com o tempo, à medida que suas concentrações, assim com a concentração de $\mathrm{H}_{2} \mathrm{O}_{2}$ diminuem. No entanto, é importante mencionar que o papel da fotólise direta durante o processo $\mathrm{UVC} / \mathrm{H}_{2} \mathrm{O}_{2}$ para cada composto, 
particularmente no que se refere às condições experimentais em que a concentração inicial de $\mathrm{H}_{2} \mathrm{O}_{2}$ é baixa, está intimamente ligada às suas propriedades particulares de absorção e aos seus respectivos valores de rendimento quântico.

A literatura registra algumas informações importantes com relação à degradação dos IA estudados por POA. Baghirzade, Yetis e Dilek (2020) observaram que o IMD é resistente à degradação pelo $\mathrm{O}_{3}$, mas indiretamente degradado pelos radicais hidroxila formados em meio básico, o que envolve a perda de $\mathrm{NO}_{2}, \mathrm{HNO}_{2} \mathrm{e}$ $\mathrm{Cl}^{-}$pela molécula. Já Fiorenza et al. (2020) estudaram a degradação do IMD em água pelos processos de fotocatálise, Fenton e Foto-Fenton, e descobriram que sua degradação é caracterizada pela formação de produtos tais como aminas e cloropiridina. Ainda, segundo os autores, o mecanismo de degradação do IMD envolve a quebra das ligações entre $\mathrm{C}-\mathrm{N}$ e $\mathrm{N}-\mathrm{N}$, seguida da formação de moléculas simples como $\mathrm{CO}_{2}, \mathrm{NO}_{x}, \mathrm{H}_{2} \mathrm{O}$ e $\mathrm{ClO}_{2}$. Navarro et al. (2011) investigaram a remoção de dez pesticidas de água de lixiviação, dentre eles a AZO, utilizando tratamento Foto-Fenton e irradiação natural solar em uma planta piloto. No estudo desses autores, foram levantadas hipóteses com relação às reações envolvendo o radical hidroxila e os poluentes alvo, através da abstração de hidrogênio das ligações $\mathrm{C}-\mathrm{H}, \mathrm{N}-\mathrm{H}$ ou $\mathrm{O}-\mathrm{H}$ e da adição do $\mathrm{HO}^{\bullet}$ à ligação dupla entre átomos de carbono ou nos anéis aromáticos. Além disso, segundo os autores uma vez que a AZO contém nitrogênio em sua molécula, os autores sugerem que pode haver a formação de $\mathrm{HNO}_{3}$ e $\mathrm{NH}_{4}^{+}$durante a degradação. Calza et al. (2006) verificaram a ocorrência de caminhos de degradação concomitantes para esse IA, em estudos envolvendo a transformação de diferentes fungicidas através da fotocatálise com $\mathrm{TiO}_{2}$. Nesse caso, o mecanismo de degradação da AZO envolveu a hidroxilação do anel cianofenil, oxidação dos grupos metílicos e a quebra do grupo éter entre os anéis cianofenil e pirimidinil. Por fim, Pushkareva e Zenkevich (2019) estudaram a oxidação eletroquímica do DFZ e identificaram produtos de transformação advindos da substituição do cloreto no anel aromático e dos átomos de hidrogênio ligado a átomos de carbono por grupos hidroxila, ou adição de oxigênio à molécula.

A análise estatística a partir dos valores obtidos de $k_{A Z O}, k_{D F Z}$ e $k_{I M D}$ foi realizada considerando inicialmente os experimentos 1-9 da Matriz Doehlert. A análise de variância (ANOVA) e os gráficos de Pareto para os resultados do processo $U V C / \mathrm{H}_{2} \mathrm{O}_{2}$ indicam que, para o AZO e o DFZ, apenas os efeitos lineares positivos de $x_{1}\left(\left[\mathrm{H}_{2} \mathrm{O}_{2}\right] 0\right)$ e de $x_{2}$ (Euvc) se mostraram estatisticamente significativos para um nível de confiança 
de 95\% (Tabelas 15-16 e Figuras 19-20), enquanto para o IMD, apenas o efeito linear de Euvc foi significativo (Tabela 17 e Figura 21). Portanto, apesar dos valores satisfatórios de $R^{2}$ para a AZO, DFZ e IMD $\left(R^{2}=0,782,0,947\right.$ e 0,815, respectivamente), a análise estatística indicou que apenas os experimentos base do projeto não foram capazes de identificar nenhum efeito quadrático para as variáveis independentes no domínio experimental estudado.

Tabela 15 - Análise de variância (ANOVA) para kAzo (processo UVC/ $\mathrm{H}_{2} \mathrm{O}_{2}$, matriz Doehlert, experimentos 1-9).

\begin{tabular}{cccccc}
\hline Fator & $\mathbf{S Q}^{\mathbf{a}}$ & $\mathbf{g l}^{\mathbf{a}}$ & $\mathbf{M Q}^{\mathbf{a}}$ & $\boldsymbol{F}$ & Valor de $^{\mathbf{b}}$ \\
\hline$x_{1}:\left[\mathrm{H}_{2} \mathrm{O}_{2}\right]_{0}$ & 0,462561 & 1 & 0,462561 & 9,44 & 0,0219 \\
$x_{2}:$ Euvc & 0,594133 & 1 & 0,594133 & 12,12 & 0,0131 \\
Erro puro & 0,294048 & 6 & 0,049008 & & \\
\hline SQ Total & 1,35074 & 8 & & & \\
\hline
\end{tabular}

a $\mathrm{SQ}=$ soma dos quadrados; $\mathrm{gl}=$ graus de liberdade; $\mathrm{MQ}=$ média dos quadrados. ${ }^{\mathrm{b}} \alpha=0,05$.

Fonte: Resultados da autora.

Tabela 16 - Análise de variância (ANOVA) para $k_{D F Z}$ (processo $\mathrm{UVC} / \mathrm{H}_{2} \mathrm{O}_{2}$, matriz Doehlert, experimentos 1-9).

\begin{tabular}{cccccc}
\hline Fator & $\mathbf{S Q}^{\mathbf{a}}$ & $\mathbf{g}^{\mathbf{a}}$ & $\mathbf{M Q}^{\mathbf{a}}$ & $\boldsymbol{F}$ & Valor de $\mathbf{p}^{\mathbf{b}}$ \\
\hline $\mathbf{x}_{1}:\left[\mathrm{H}_{2} \mathrm{O}_{2}\right]_{0}$ & 0,0643428 & 1 & 0,0643428 & 69,09 & 0,0002 \\
$\mathbf{X}_{2}:$ Euvc & 0,0362331 & 1 & 0,0362331 & 38,91 & 0,0008 \\
Erro puro & 0,00558775 & 6 & 0,000931292 & & \\
\hline SQ Total & 0,106164 & 8 & & & \\
\hline
\end{tabular}

${ }^{a} \mathrm{SQ}=$ soma dos quadrados; $\mathrm{gl}=$ graus de liberdade; $\mathrm{MQ}=$ média dos quadrados. ${ }^{\mathrm{b}} \alpha=0,05$.

Fonte: Resultados da autora.

Tabela 17 - Análise de variância (ANOVA) para kıMD (processo UVC/ $\mathrm{H}_{2} \mathrm{O}_{2}$, matriz Doehlert, experimentos 1-9).

\begin{tabular}{cccccc}
\hline Fator & $\mathbf{S Q}^{\mathbf{a}}$ & $\mathbf{g l}^{\mathbf{a}}$ & $\mathbf{M Q}^{\mathbf{a}}$ & $\boldsymbol{F}$ & Valor de $^{\mathbf{b}}$ \\
\hline$X_{2}$ : Euvc & 0,0550372 & 1 & 0,0550372 & 30,89 & 0,0009 \\
Erro puro & 0,0124712 & 7 & 0,00178161 & & \\
\hline SQ Total & 0,0675084 & 8 & & & \\
\hline
\end{tabular}

${ }^{\mathrm{a}} \mathrm{SQ}=$ soma dos quadrados; $\mathrm{gl}=$ graus de liberdade; $\mathrm{MQ}=$ média dos quadrados. ${ }^{\mathrm{b}} \alpha=0,05$.

Fonte: Resultados da autora. 
Figura 19 - Gráfico de Pareto para $k_{A Z O}$ (processo UVC/ $/ \mathrm{H}_{2} \mathrm{O}_{2}$, experimentos 1-9).

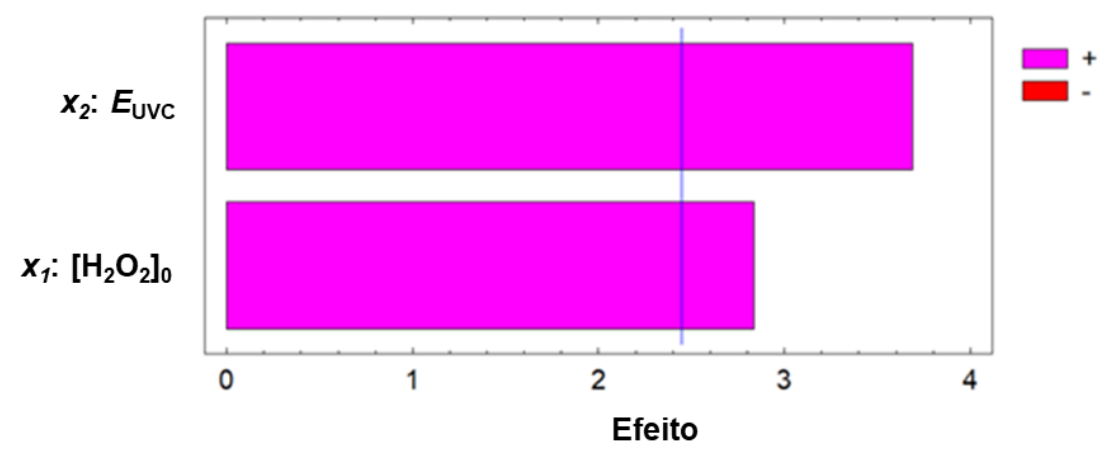

Fonte: Resultados da autora.

Figura 20 - Gráfico de Pareto para $k_{D F Z}$ (processo UVC/ $/ \mathrm{H}_{2} \mathrm{O}_{2}$, experimentos 1-9).

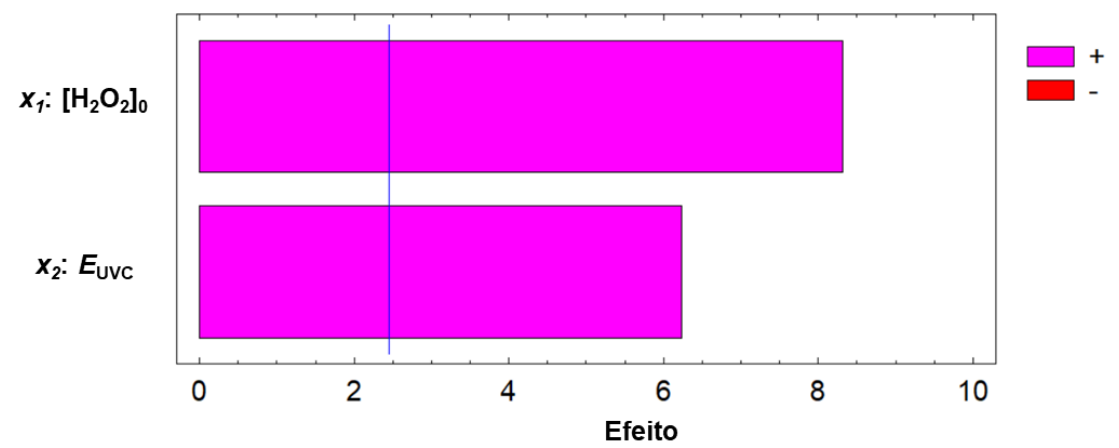

Fonte: Resultados da autora.

Figura 21 - Gráfico de Pareto para $k_{M D D}$ (processo $U V C / \mathrm{H}_{2} \mathrm{O}_{2}$, experimentos 1-9).

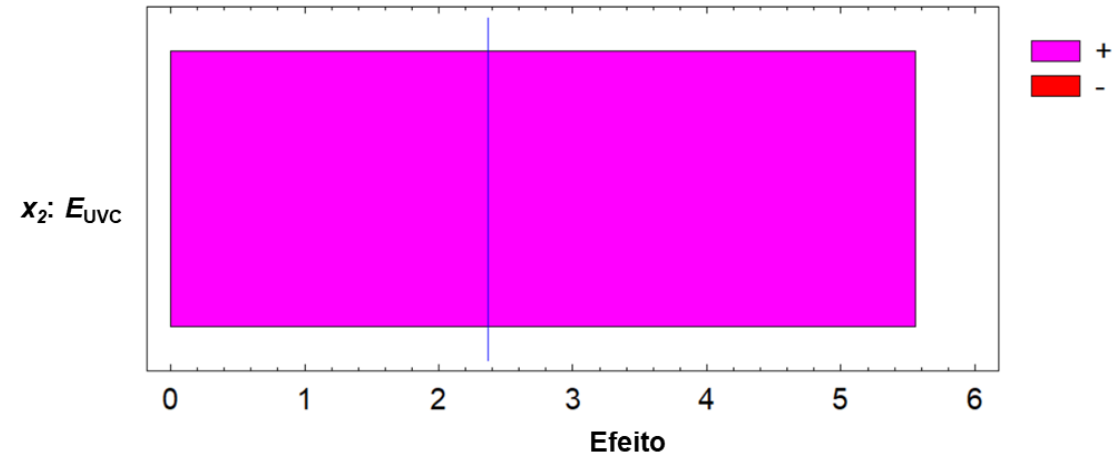

Fonte: Resultados da autora.

Dessa maneira, foram incluídos experimentos adicionais, variando a concentração inicial de $\mathrm{H}_{2} \mathrm{O}_{2}$ (Tabela 10 e Figura 6). Os resultados são indicados na Tabela 14 e Figura 18. Considerando todos os experimentos realizados, a ANOVA (Tabelas 18-20) e os gráficos de Pareto (Figuras 22-24) indicam efeitos positivos para ambas as variáveis de processo nas taxas de degradação para os três pesticidas. 
Tabela 18 - Análise de variância (ANOVA) para kAzo (processo UVC/ $\mathrm{H}_{2} \mathrm{O}_{2}$, experimentos 1-18).

\begin{tabular}{cccccc}
\hline Fator & $\mathbf{S Q}^{\mathbf{a}}$ & $\mathbf{g l}^{\mathbf{a}}$ & $\mathbf{M Q}^{\mathbf{a}}$ & $\boldsymbol{F}$ & Valor de $^{\mathbf{b}}$ \\
\hline$X_{1}:\left[\mathrm{H}_{2} \mathrm{O}_{2}\right]_{0}$ & 3,8584 & 1 & 3,8584 & 44,81 & 0,0000 \\
$X_{2}:$ Euvc & 0,941876 & 1 & 0,941876 & 10,94 & 0,0052 \\
$X_{2}{ }^{2}$ & 0,764035 & 1 & 0,764035 & 8,87 & 0,0100 \\
Erro puro & 1,20544 & 14 & 0,0861028 & & \\
\hline SQ Total & 6,95347 & 17 & & & \\
\hline
\end{tabular}

a $S Q=$ soma dos quadrados; $g \mathrm{l}=$ graus de liberdade; $\mathrm{MQ}=$ média dos quadrados. ${ }^{\mathrm{b}} \alpha=0,05$.

Fonte: Resultados da autora.

Tabela 19 - Análise de variância (ANOVA) para kDFz (processo UVC/ $\mathrm{H}_{2} \mathrm{O}_{2}$, experimentos 1-18).

\begin{tabular}{cccccc}
\hline Fator & $\mathbf{S Q}^{\mathbf{a}}$ & $\mathbf{g l}^{\mathbf{a}}$ & $\mathbf{M Q}^{\mathbf{a}}$ & $\boldsymbol{F}$ & Valor de $^{\mathbf{b}}$ \\
\hline$x_{1}:\left[\mathrm{H}_{2} \mathrm{O}_{2}\right]_{0}$ & 0,219162 & 1 & 0,219162 & 97,80 & 0,0000 \\
$x_{2}:$ Euvc & 0,09516 & 1 & 0,09516 & 42,46 & 0,0000 \\
$x_{1}{ }^{2}$ & 0,0232346 & 1 & 0,0232346 & 10,37 & 0,0062 \\
Erro puro & 0,031374 & 14 & 0,002241 & & \\
\hline SQ Total & 0,406305 & 17 & & & \\
\hline
\end{tabular}

a $S Q=$ soma dos quadrados; $g \mathrm{l}=$ graus de liberdade; $\mathrm{MQ}=$ média dos quadrados. ${ }^{\mathrm{b}} \alpha=0,05$.

Fonte: Resultados da autora.

Tabela 20 - Análise de variância (ANOVA) para kIMD (processo UVC/ $\mathrm{H}_{2} \mathrm{O}_{2}$, experimentos 1-18).

\begin{tabular}{cccccc}
\hline Fator & $\mathbf{S Q}^{\mathbf{a}}$ & $\mathbf{g l}^{\mathbf{a}}$ & $\mathbf{M Q}^{\mathbf{a}}$ & $\boldsymbol{F}$ & Valor de $^{\mathbf{b}}$ \\
\hline$X_{1}:\left[\mathrm{H}_{2} \mathrm{O}_{2}\right]_{0}$ & 0,0436956 & 1 & 0,0436956 & 17,90 & 0,0008 \\
$X_{2}:$ Euvc & 0,109893 & 1 & 0,109893 & 45,03 & 0,0000 \\
$X_{2}{ }^{2}$ & 0,015767 & 1 & 0,015767 & 6,46 & 0,0235 \\
Erro puro & 0,0341698 & 14 & 0,0024407 & & \\
\hline SQ Total & 0,206306 & 17 & & & \\
\hline
\end{tabular}

a $S Q=$ soma dos quadrados; $g \mathrm{l}=$ graus de liberdade; $\mathrm{MQ}=$ média dos quadrados. ${ }^{\mathrm{b}} \alpha=0,05$.

Fonte: Resultados da autora.

Figura 22 - Gráfico de Pareto para $k_{A Z O}$ (processo UVC/ $\mathrm{H}_{2} \mathrm{O}_{2}$, experimentos 1-18).

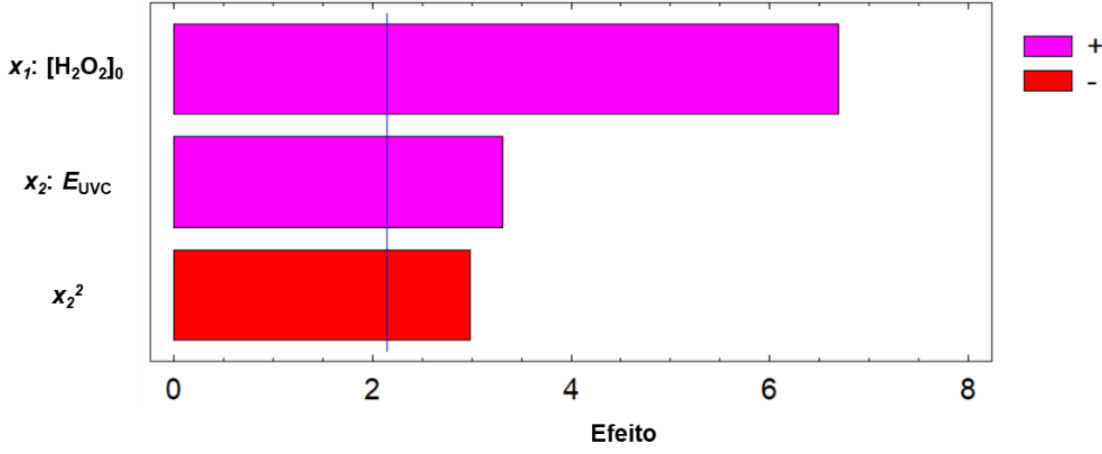

Fonte: Resultados da autora. 
Figura 23 - Gráfico de Pareto para $k_{D F Z}$ (processo $\mathrm{UVC} / \mathrm{H}_{2} \mathrm{O}_{2}$, experimentos 1-18).

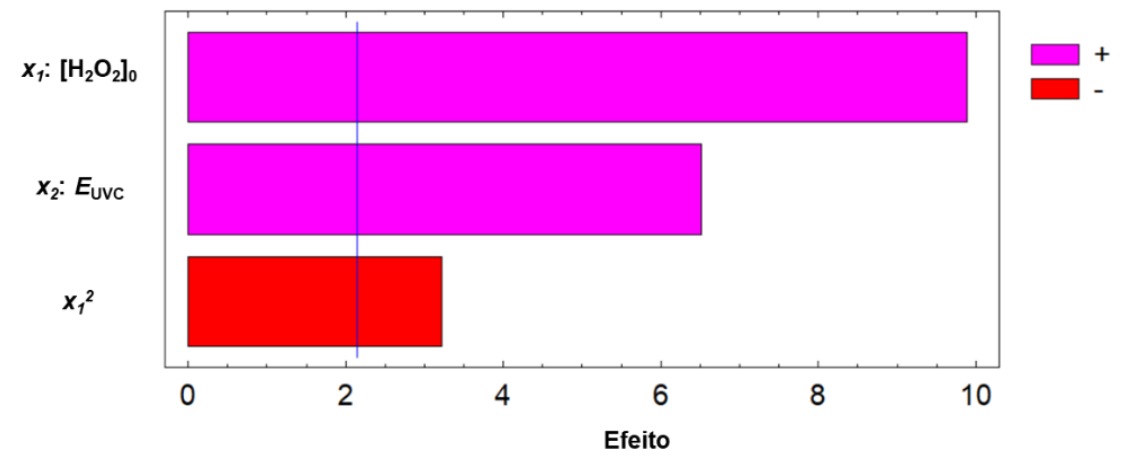

Fonte: Resultados da autora.

Figura 24 - Gráfico de Pareto para kIMD (processo UVC/ $\mathrm{H}_{2} \mathrm{O}_{2}$, experimentos 1-18).

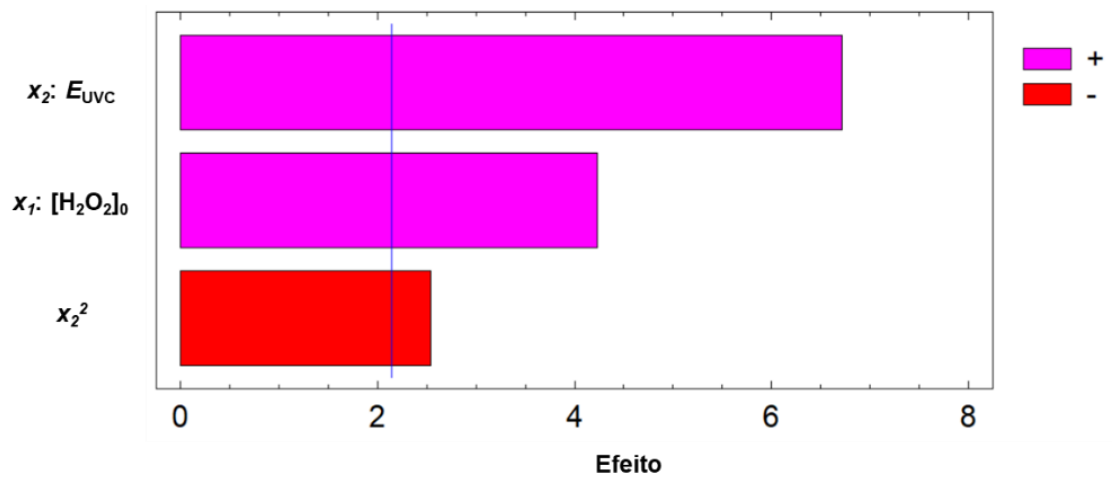

Fonte: Resultados da autora.

Para AZO e DFZ, a concentração inicial de peróxido de hidrogênio, $\left[\mathrm{H}_{2} \mathrm{O}_{2}\right]$, parece ser 0 fator de maior influência em $k_{A Z O}$ e $k_{D F Z}$, enquanto a irradiância demonstrou ser mais importante no que se refere ao $\mathrm{k}$ IMD. $O$ efeito quadrático negativo para Euvc foi estatisticamente significativo a um nível de confiança de $95 \%$ para AZO e IMD, mostrando que as taxas de fotodegradação dos três pesticidas aumentam com o aumento da irradiância, atingem um valor máximo, seguido de estabilização. Em contrapartida, para o DFZ, o efeito quadrático da concentração inicial de peróxido foi estatisticamente significativo e negativo, evidenciando que $k_{D F z}$ aumenta com $\left[\mathrm{H}_{2} \mathrm{O}_{2}\right] 0$ e então diminui, sugerindo um efeito de captura das espécies radicalares pelo oxidante, o que não foi observado para a AZO e tampouco para o IMD. As superfícies de resposta e as curvas de contorno correspondentes (Figuras 25-27) confirmam essa tendência para os três IA estudados. 
Figura 25 - Superfície de resposta e gráfico de contorno para kAzo (processo UVC/ $/ \mathrm{H}_{2} \mathrm{O}_{2}$, experimentos 1-18). Condições: $[A Z O]_{0}=(2,81 \pm 0,23) \mathrm{mg} \mathrm{L}^{-1} ;[D F Z]_{0}=$ $(1,86 \pm 0,16) \mathrm{mg} \mathrm{L}^{-1} ;[\mathrm{IMD}]_{0}=(2,71 \pm 0,19) \mathrm{mg} \mathrm{L}^{-1}$.

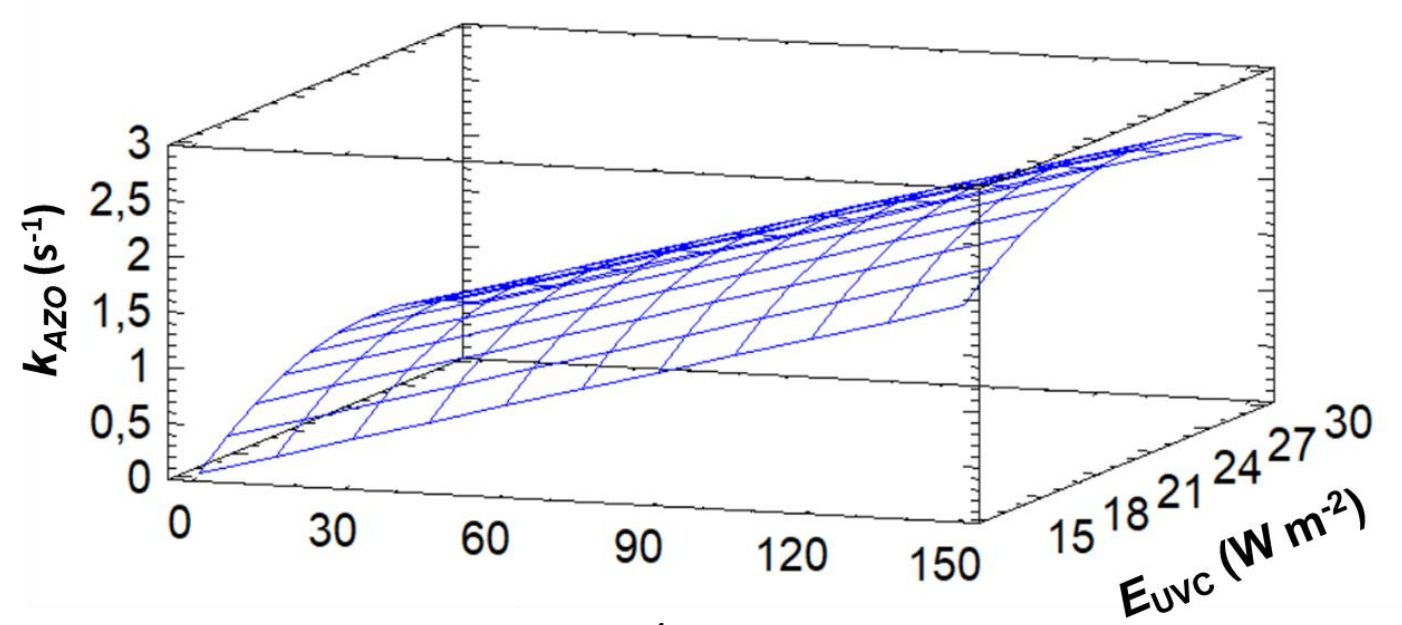

$\left[\mathrm{H}_{2} \mathrm{O}_{2}\right]_{0}\left(\mathrm{mg} \mathrm{L}^{-1}\right)$

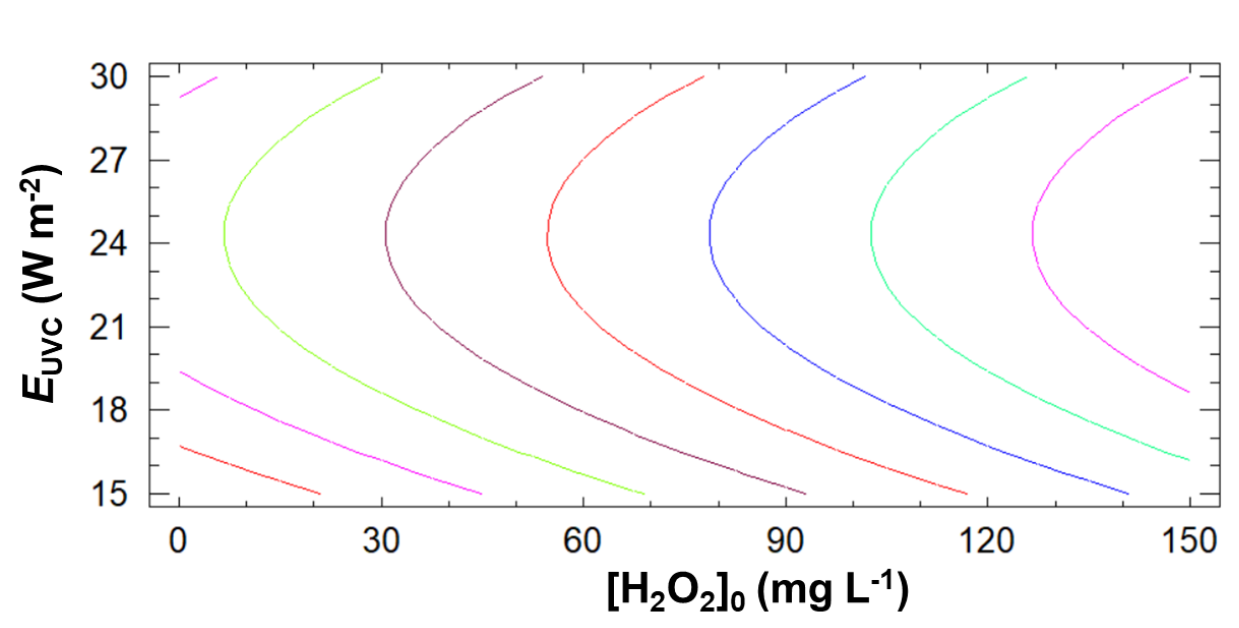

$k_{A Z O}\left(\mathrm{~s}^{-1}\right)$

Fonte: Resultados da autora. 
Figura 26 - Superfície de resposta e gráfico de contorno para $k_{D F Z}$ (processo UVC/ $\mathrm{H}_{2} \mathrm{O}_{2}$, experimentos 1-18). Condições: $[A Z O]_{0}=(2,81 \pm 0,23) \mathrm{mg} \mathrm{L}^{-1} ;[D F Z]_{0}=$ $(1,86 \pm 0,16) \mathrm{mg} \mathrm{L}^{-1} ;[\mathrm{IMD}]_{0}=(2,71 \pm 0,19) \mathrm{mg} \mathrm{L}^{-1}$.

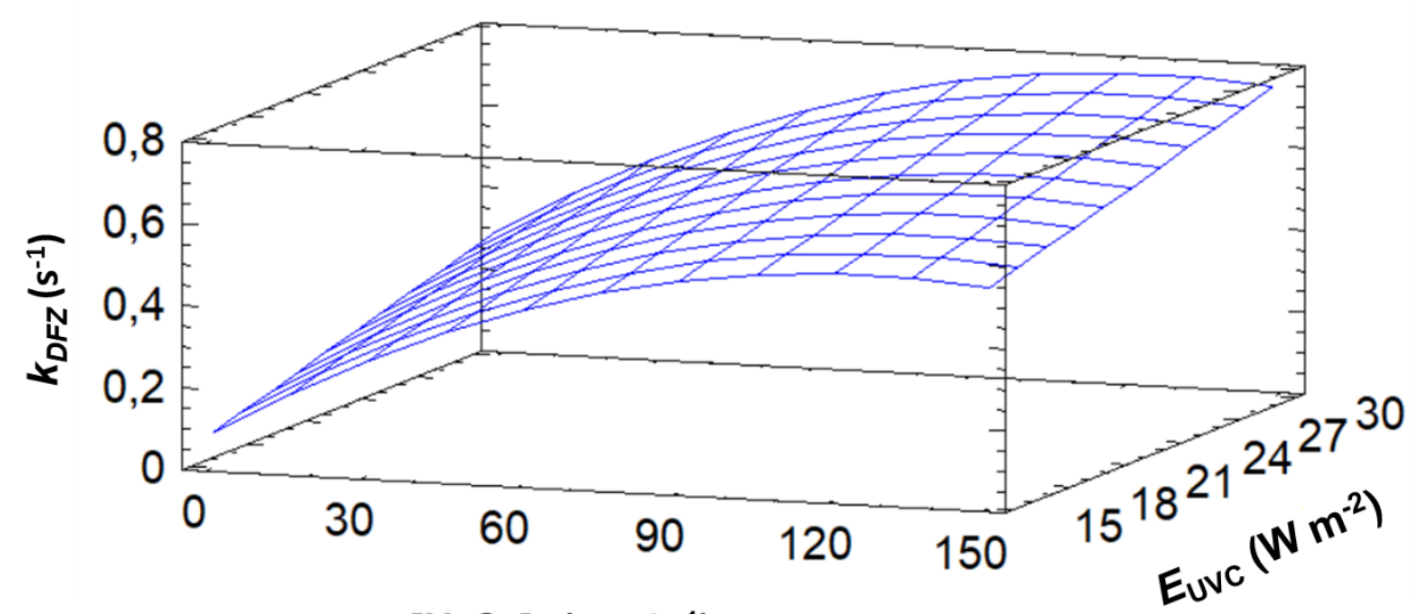

$\left[\mathrm{H}_{2} \mathrm{O}_{2}\right]_{0}\left(\mathrm{mg} \mathrm{L}^{-1}\right)$

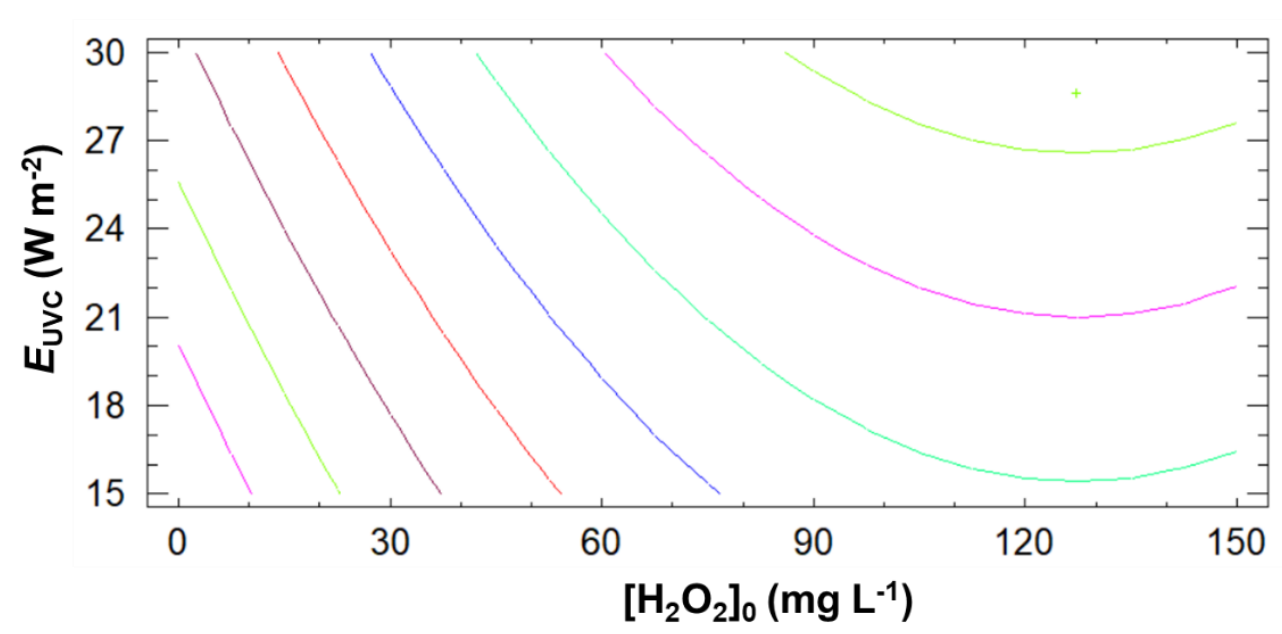

$k_{D F Z}\left(s^{-1}\right)$

- 0,08

0,16

$-0,24$

0,32

$-0,4$

$-0,48$

$-0,56$

$-0,64$

0,72

$-0,8$

Fonte: Resultados da autora. 
Figura 27 - Superfície de resposta e gráfico de contorno para kIMD (processo UVC/ $/ \mathrm{H}_{2} \mathrm{O}_{2}$, experimentos 1-18). Condições: $[A Z O]_{0}=(2,81 \pm 0,23) \mathrm{mg} \mathrm{L}^{-1} ;[D F Z]_{0}=$ $(1,86 \pm 0,16) \mathrm{mg} \mathrm{L}^{-1} ;[\mathrm{IMD}]_{0}=(2,71 \pm 0,19) \mathrm{mg} \mathrm{L}^{-1}$.
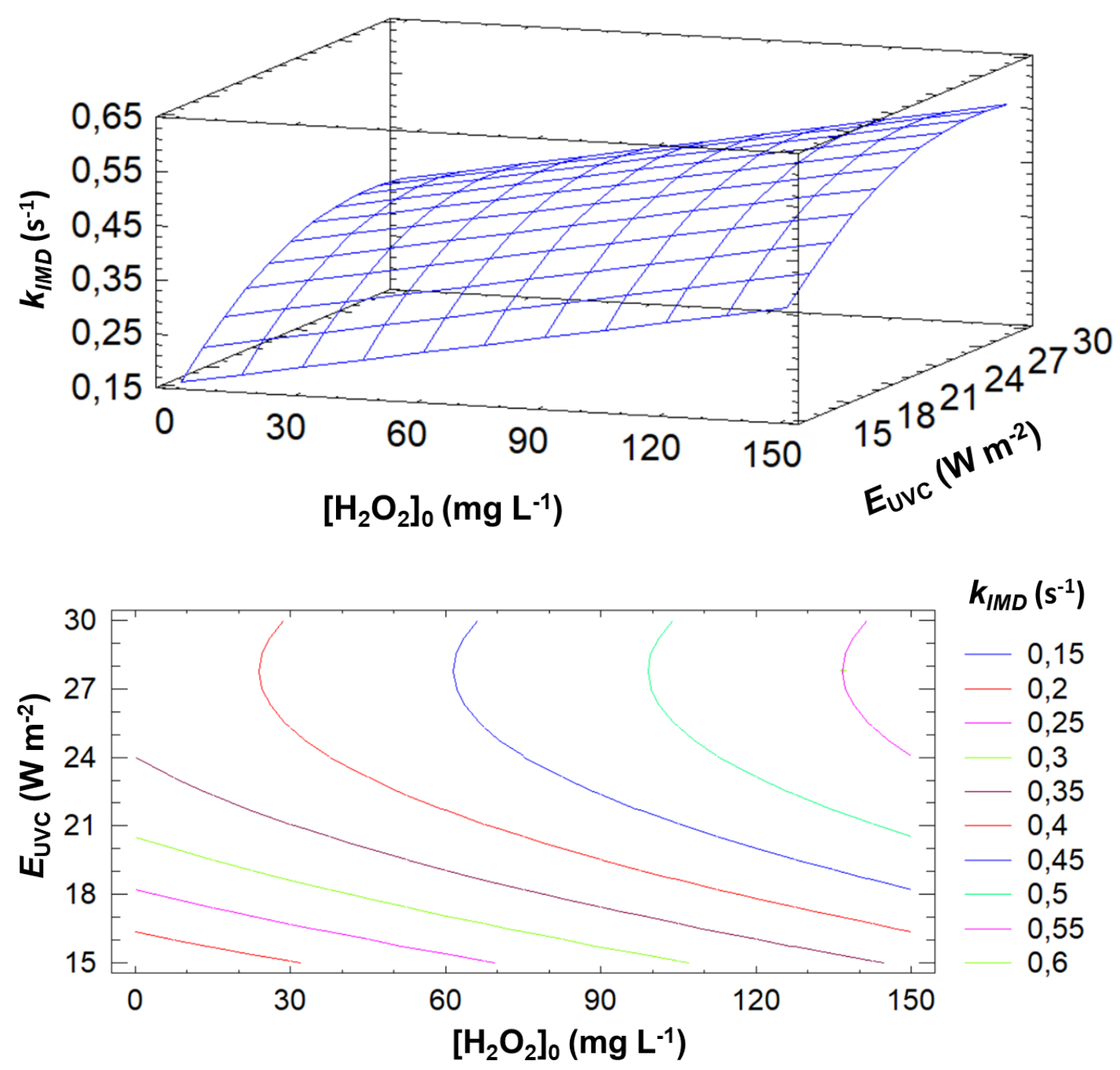

$k_{I M D}\left(\mathbf{s}^{-1}\right)$

Fonte: Resultados da autora.

A análise estatística usando o software STATGRAPHICS Plus ${ }^{\circledR}$ possibilitou a obtenção dos modelos da superfície quadrática de resposta para as variáveis dependentes KAZO, KDFZ e kIMD (Equações 34-36) em termos das variáveis independentes, considerando apenas os fatores significativos. Os valores correspondentes de $R^{2}$ foram 0,827, 0,923 e 0,834 respectivamente, confirmando que os modelos se ajustam bem aos dados experimentais. A partir dos modelos quadráticos dados pelas Equações 34-36, foram estimadas as condições ótimas para degradação dos IA como sendo $\left[\mathrm{H}_{2} \mathrm{O}_{2}\right] 0=136,8 \mathrm{mg} \mathrm{L}^{-1}$ e Euvc $=24,3 \mathrm{~W} \mathrm{~m}^{-2}\left(k_{\text {AZO }}=\right.$ $\left.2,53 \mathrm{~s}^{-1}\right) ;\left[\mathrm{H}_{2} \mathrm{O}_{2}\right]_{0}=127,3 \mathrm{mg} \mathrm{L}^{-1}$ e Euvc $=28,6 \mathrm{~W} \mathrm{~m}^{-2}\left(k_{\mathrm{DFZ}}=0,75 \mathrm{~s}^{-1}\right) ;\left[\mathrm{H}_{2} \mathrm{O}_{2}\right]_{0}=136,8$ $\mathrm{mg} \mathrm{L}^{-1}$ e Euvc $=27,8 \mathrm{~W} \mathrm{~m}^{-2}\left(k_{\mathrm{IMD}}=0,55 \mathrm{~s}^{-1}\right)$. 


$$
\begin{aligned}
& k_{A Z 0}=-4,48949+0,01249 x_{1}+0,43657 x_{2}-0,00898 x_{2}^{2} \\
& k_{D F Z}=-0,12759+0,00733 x_{1}+0,01435 x_{2}-0,00003 x_{1}^{2} \\
& k_{I M D}=-0,62688+0,00133 x_{1}+0,071654 x_{2}-0,00129 x_{2}^{2}
\end{aligned}
$$

\subsection{Aplicação do processo $\mathrm{UVC} / \mathrm{H}_{2} \mathrm{O}_{2}$ ao tratamento de matrizes reais}

A partir da análise estatística dos resultados dos experimentos conduzidos segundo a Matriz Doehlert empregando água de lavagem sintética e obtidas as condições ótimas experimentais para os IA, foi investigada a influência da matriz real nas taxas específicas de degradação de pseudo-primeira ordem dos pesticidas estudados. Dessa forma, foram realizados ensaios utilizando duas matrizes reais coletadas em diferentes etapas da lavagem de tomates em uma indústria (prélavagem e esteira de lavagem); a Tabela 21 apresenta os resultados dos parâmetros físico-químicos determinados a partir da caracterização dessas matrizes aquosas. Inicialmente as amostras foram injetadas em HPLC para verificar a presença dos IA na água de lavagem. Visto que não foi constatada a existência dos mesmos em níveis detectáveis pela técnica analítica utilizada, as amostras foram então dopadas com os produtos comerciais Amistar Top ${ }^{\circledR}$ e Provado $200 \mathrm{SC}^{\circledR}$ para as concentrações de AZO, DFZ e IMD nominais de trabalho $\left(3,0,2,0\right.$ e $3,0 \mathrm{mg} \mathrm{L}^{-1}$, respectivamente) e tratadas pelo processo $\mathrm{UVC} / \mathrm{H}_{2} \mathrm{O}_{2}$ empregando $\left[\mathrm{H}_{2} \mathrm{O}_{2}\right] 0=130 \mathrm{mg} \mathrm{L}^{-1}$ e Euvc $=28,6 \mathrm{~W} \mathrm{~m}^{-2}$, condição ótima mais abrangente para os três IA. A Figura 28 apresenta os resultados obtidos.

Tabela 21 - Resultados da caracterização das amostras de matriz real coletadas na indústria.

\begin{tabular}{cccc}
\hline Parâmetro & Pré-lavagem & Esteira de lavagem & Unidade \\
\hline pH & 5,0 & 6,0 & - \\
Temperatura & 25,5 & 25,5 & ${ }^{\circ} \mathrm{C}$ \\
Condutividade & 741 & 273 & $\mu \mathrm{cm}^{-1}$ \\
TOC & 446 & 102 & $\mathrm{mg} \mathrm{L}^{-1}$ \\
Sólidos Totais & 4682 & 560 & $\mathrm{mg} \mathrm{L}^{-1}$ \\
Sólidos Totais Voláteis & 1500 & 318 & $\mathrm{mg} \mathrm{L}^{-1}$ \\
Sólidos Dissolvidos Totais & 1250 & 400 & $\mathrm{mg} \mathrm{L}^{-1}$ \\
Absorbância em 254 nm & 0,526 & 0,112 & $\mathrm{u}$ a. \\
\hline
\end{tabular}

Fonte: Resultados da autora.

Ambas as matrizes aquosas absorvem a radiação UVC em $254 \mathrm{~nm}$, enquanto a água gerada durante a operação de pré-lavagem possua um conteúdo elevado de 
TOC e sólidos (Tabela 21). Apesar dessas características, a remoção total do AZO ocorreu para ambas as matrizes após 15 minutos, ao passo que, para o DFZ e IMD, isso só ocorreu para a matriz coletada na esteira de lavagem, enquanto para a água de pré-lavagem, as remoções obtidas foram de aproximadamente $70 \%$ e $79 \%$, respectivamente (Figura 28).

Figura 28 - Decaimento das concentrações relativas de AZO, DFZ e IMD em função do tempo para experimentos com as matrizes reais obtidas na lavagem de tomates na indústria, dopadas com os produtos comerciais Amistar Top ${ }^{\circledR}$ e Provado 200 SC $^{\circledR}$ e submetidas ao processo $\mathrm{UVC} / \mathrm{H}_{2} \mathrm{O}_{2}$ nas condições $\left[\mathrm{H}_{2} \mathrm{O}_{2}\right]_{0}=130 \mathrm{mg} \mathrm{L}^{-1}$ e Euvc $=$ $28,6 \mathrm{~W} \mathrm{~m}^{-2}$. Amostras de água da pré-lavagem (o) e esteira de lavagem ( $\square$ ). [AZO]0 $=2,22 \pm 0,05 ;[D F Z]_{0}=1,48 \pm 0,04 ;\left[I_{M D}\right]_{0}=2,94 \pm 0,14 \mathrm{mg} \mathrm{L}^{-1}$. Os erros médios são $5,5 \%$ (AZO), $13,9 \%$ (DFZ) e 2,75\% (IMD).
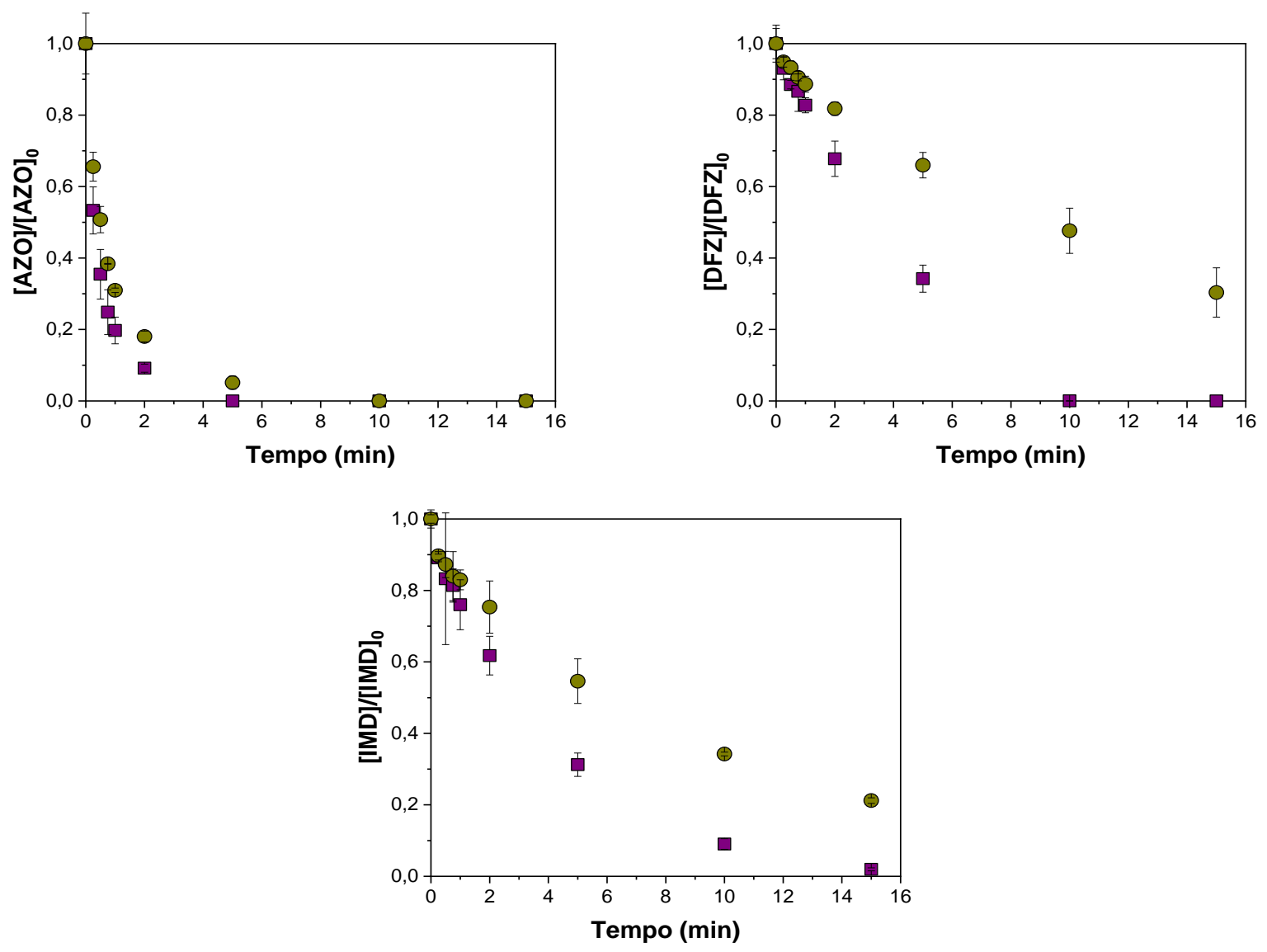

Fonte: Resultados da autora.

A Tabela 22 apresenta os valores das taxas de degradação de pseudo-primeira ordem obtidos para os ensaios com as matrizes reais. 
Tabela 22 - Taxas de degradação de pseudo-primeira ordem ( $k$ ") para AZO, DFZ e IMD em ensaios $\mathrm{UVC} / \mathrm{H}_{2} \mathrm{O}_{2}$ com as matrizes reais obtidas na lavagem de tomates na indústria.

\begin{tabular}{cccc}
\hline Matriz & $\boldsymbol{k}^{\prime \prime}$ AZO $\left(\mathbf{s}^{-1}\right)$ & $\boldsymbol{k}^{\prime \prime}$ 'DFZ $\left(\mathbf{s}^{-1}\right)$ & $\boldsymbol{k}^{\prime \prime}$ IMD $\left(\mathbf{s}^{-1}\right)$ \\
\hline Pré-lavagem & $0,128 \pm 0,002\left(R^{2}=0,902\right)$ & $0,025 \pm 0,005\left(R^{2}=0,985\right)$ & $0,129 \pm 0,004\left(R^{2}=0,995\right)$ \\
Esteira & $0,249 \pm 0,004\left(R^{2}=0,928\right)$ & $0,055 \pm 0,000\left(R^{2}=0,997\right)$ & $0,266 \pm 0,022\left(R^{2}=0,994\right)$ \\
\hline
\end{tabular}

Fonte: Resultados da autora.

Em comparação com os valores de $k$ obtidos para a água de lavagem sintética (Figura 29), esses valores confirmam que a matriz real não influencia na remoção do AZO, ao contrário do DFZ e IMD. Dessa forma, vislumbrando uma remoção completa dos ingredientes ativos após 15 minutos, o processo $\mathrm{UVC} / \mathrm{H}_{2} \mathrm{O}_{2}$ pode ser considerado uma alternativa viável para tratamento localizado da água de lavagem gerada nas esteiras.

Figura 29 - Taxas de degradação de pseudo-primeira ordem para ensaios da matriz Doehlert (experimentos 1-18) e ensaios realizados com as matrizes reais coletadas na indústria, dopadas com os produtos comerciais Amistar Top ${ }^{\circledR}$ e Provado 200 SC $^{\circledR}$ e submetidas ao tratamento $\mathrm{UVC} / \mathrm{H}_{2} \mathrm{O}_{2}$ nas condições de $\left[\mathrm{H}_{2} \mathrm{O}_{2}\right]_{0}=130 \mathrm{mg} \mathrm{L}^{-1} \mathrm{e}$ Euvc $=28,6 \mathrm{~W} \mathrm{~m}^{-2}$. E: água da esteira de lavagem; PL: água de pré-lavagem.

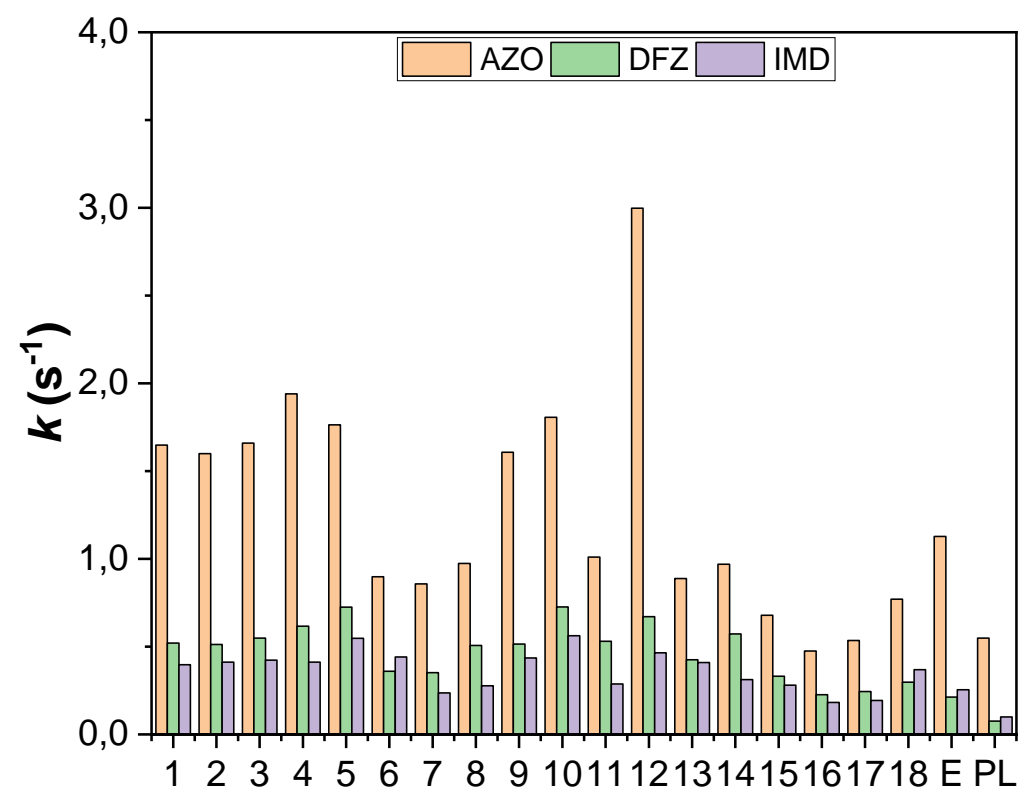

\section{Experimento}

Fonte: Resultados da autora. 


\subsection{Estudo da citotoxicidade e genotoxicidade com o organismo-teste Allium} cepa

Os ensaios de citotoxicidade e genotoxicidade com as matrizes reais foram realizados empregando como organismo teste bulbos de cebola ( $A$. cepa), dado que esse organismo tem sido bastante indicado para o monitoramento ambiental e é reconhecido como um bioindicador de toxicidade pelo Programa Internacional de Segurança Química das Nações Unidas (WHO, 1985) e pela Agência de Proteção Ambiental dos Estados Unidos (USEPA, 1996), devido à alta sensibilidade a compostos químicos e à presença de cromossomos de grande tamanho e número reduzido $(2 \mathrm{n}=16)$, o que permite verificar danos no DNA das células, tais como aberrações cromossômicas. Além disso, é um teste de fácil aplicabilidade, baixo custo e que vem apresentando resultados confiáveis na análise de diversos compostos, dentre os quais diversos pesticidas (LEME; MARIN-MORALES, 2009).

Inicialmente, bulbos de $A$. cepa foram expostos às soluções individuais dos padrões analíticos de AZO, DFZ e IMD, nas concentrações nominais previstas para a água de lavagem, antes e após o tratamento com processo $\mathrm{UVC} / \mathrm{H}_{2} \mathrm{O}_{2}$ nas condições ótimas estimadas para o processo, e a um controle negativo utilizando água de torneira. Em seguida, novos bulbos foram expostos às matrizes reais coletadas na indústria (pré-lavagem e esteira de lavagem). Os efeitos citotóxicos foram avaliados através dos valores calculados para o índice mitótico (IM) a partir da análise dos meristemas das raízes em microscópio. Os resultados são apresentados na Tabela 23. 
Tabela 23 - Índice mitótico (IM) das células meristemáticas das raízes de Allium cepa (para um aumento de $40 \times$ ) para ensaios com soluções dos padrões analíticos dos compostos e amostras reais coletadas na indústria, dopadas com os produtos comerciais Amistar Top ${ }^{\circledR}$ e Provado $200 \mathrm{SC}^{\circledR}$ e submetidas ao tratamento UVC/ $\mathrm{H}_{2} \mathrm{O}_{2}$ nas condições $\left[\mathrm{H}_{2} \mathrm{O}_{2}\right] 0=130 \mathrm{mg} \mathrm{L}^{-1}$ e Euvc $=28,6 \mathrm{~W} \mathrm{~m}^{-2}$ indicadas pela matriz Doehlert.

\begin{tabular}{cc}
\hline \multicolumn{2}{c}{ Padrões analíticos dos IA } \\
\hline Ensaio & IM (\%) \\
\hline Controle Negativo 1 (água de torneira) & $24,8 \pm 1,0$ \\
Solução AZO, antes do tratamento & $42,3 \pm 15,0$ \\
Solução DFZ, antes do tratamento & $39,7 \pm 18,6$ \\
Solução IMD, antes do tratamento & $15,2 \pm 1,9$ \\
Solução AZO, após tratamento UVC/ $\mathrm{H}_{2} \mathrm{O}_{2}$ & $24,8 \pm 4,2$ \\
Solução DFZ, após tratamento UVC/ $\mathrm{H}_{2} \mathrm{O}_{2}$ & $29,1 \pm 3,8$ \\
Solução IMD, após tratamento UVC/ $/ \mathrm{H}_{2} \mathrm{O}_{2}$ & $14,9 \pm 1,2$ \\
\hline \multicolumn{2}{c}{ Matrizes reais } \\
\hline Ensaio \\
\hline IM (\%) \\
\hline Controle Negativo 2 (água de torneira) & $74,7 \pm 6,2$ \\
Água de pré-lavagem, antes do tratamento & $66,4 \pm 5,5$ \\
Água da esteira de lavagem, antes do tratamento & $52,9 \pm 4,2$ \\
Água de pré-lavagem, após tratamento UVC/ $/ \mathrm{H}_{2} \mathrm{O}_{2}$ & $74,8 \pm 6,3$ \\
Água da esteira de lavagem, após tratamento UVC/ $\mathrm{H}_{2} \mathrm{O}_{2}$ & $77,6 \pm 4,0$ \\
\hline
\end{tabular}

Fonte: Resultados da autora.

No ensaio com as soluções dos IA padrão analítico, tem-se um aumento na divisão celular para as amostras de AZO e DFZ, resultando em um maior índice mitótico em comparação com o controle negativo. De acordo com Leme e Marin Morales (2009), valores de IM superiores aos do controle negativo são indicativos de um aumento na divisão celular, o que pode ser resultar na multiplicação desordenada das células e até na formação de tumores. Em contrapartida, para o IMD, o IM foi inferior ao do controle, o que aponta a ocorrência de alterações no crescimento e desenvolvimento dos organismos. No caso dos ensaios para as águas das matrizes reais (Tabela 23), para ambas as amostras o IM foi inferior ao do controle negativo, uma consequência da exposição das raízes aos três compostos investigados.

Após o tratamento $\mathrm{UVC} / \mathrm{H}_{2} \mathrm{O}_{2}$, ainda que este não tenha sido capaz de remover completamente todos os pesticidas na matriz real da pré-lavagem, o processo mostrou-se eficiente no que se refere aos valores de IM próximos ao valor calculado para o controle negativo em água. Isso também ocorre no caso das soluções do AZO e DFZ, que são completamente removidos pelo processo $U V \mathrm{~V} / \mathrm{H}_{2} \mathrm{O}_{2}$ após os 15 minutos, mas não para o IMD, que apresenta IM ainda inferior ao do controle negativo, o que pode estar relacionado com a presença e características de seus produtos de transformação em concentração residual.

Para entender as diferenças entre os compostos em padrão analítico e nas 
matrizes reais, foi feita a parametrização dos resultados, considerando os controles 1 e 2 como valor igual a 1, e calculando as taxas médias, através da razão entre o IM obtido para cada amostra e seu respectivo controle. Os resultados obtidos para as taxas médias são apresentados na Tabela 24.

Tabela 24 - Valores para a taxa média obtidos através da parametrização dos dados experimentais para IM.

\begin{tabular}{cc}
\hline Ensaio & Taxa média \\
\hline Controle Negativo (água de torneira) & $1,0 \pm 0,0$ \\
Solução AZO, antes do tratamento & $1,71 \pm 0,60$ \\
Solução DFZ, antes do tratamento & $1,61 \pm 0,75$ \\
Solução IMD, antes do tratamento & $0,61 \pm 0,08$ \\
Solução AZO, após tratamento $\mathrm{UVC} / \mathrm{H}_{2} \mathrm{O}_{2}$ & $1,0 \pm 0,17$ \\
Solução DFZ, após tratamento $\mathrm{UVC} / \mathrm{H}_{2} \mathrm{O}_{2}$ & $1,17 \pm 0,15$ \\
Solução IMD, após tratamento $\mathrm{UVC} / \mathrm{H}_{2} \mathrm{O}_{2}$ & $0,60 \pm 0,05$ \\
Água de pré-lavagem, antes do tratamento & $0,89 \pm 0,07$ \\
Água da esteira de lavagem, antes do tratamento & $0,71 \pm 0,06$ \\
Água de pré-lavagem, após tratamento UVC/ $/ \mathrm{H}_{2} \mathrm{O}_{2}$ & $1,0 \pm 0,08$ \\
Água da esteira de lavagem, após tratamento UVC $/ \mathrm{H}_{2} \mathrm{O}_{2}$ & $1,04 \pm 0,05$ \\
\hline
\end{tabular}

Fonte: Resultados da autora.

Com a parametrização dos dados, é possível perceber que, em relação ao controle negativo, as amostras de AZO e DFZ causaram um aumento no IM, enquanto no IMD e as amostras reais ocasionaram uma diminuição do IM, antes da aplicação do processo $\mathrm{UVC} / \mathrm{H}_{2} \mathrm{O}_{2}$. O maior aumento foi ocasionado pela AZO. A solução de IMD não apresentou grandes variações no seu valor de IM antes e após o tratamento, e ainda que esse composto tenha sido removido completamente na solução em padrão analítico, a presença de compostos intermediários desconhecidos pode ter influenciado na diminuição da divisão celular.

Com relação aos efeitos genotóxicos, foi observada a ocorrência de anormalidades nas células apenas para a matriz real da pré-lavagem, para a qual foram encontrados micronúcleos nas células expostas à amostra antes do tratamento (Figura 30i), que está associada à diminuição na divisão celular, confirmada pelo valor inferior de IM encontrado. De acordo com Fernandes, Mazzeo e Marin-Morales (2007), a ocorrência dos micronúcleos é entendida geralmente como indicação de danos ao material genético quando na exposição a agentes mutagênicos, ainda que eles possam ocorrer de maneira espontânea. Além disso, para amostra da água de prélavagem após a aplicação do processo $\mathrm{UVC} / \mathrm{H}_{2} \mathrm{O}_{2}$ (Figura 30k) foram observadas pontes telóficas. Os resultados obtidos enfatizam a importância de analisar ambos os efeitos, citotóxicos e genotóxicos, em testes toxicológicos, pois ainda que a amostra 
da água gerada na pré-lavagem após tratamento tenha apresentado valores de IM próximos ao do controle negativo, a taxa de divisão celular próxima à observada para o controle não garante que as aberrações cromossômicas sejam evitadas, tendo sido provavelmente ocasionadas devido à presença dos compostos remanescentes e de seus intermediários de degradação.

Para demais amostras não foram observadas alterações e ainda que o IM calculado para o IMD esteja abaixo do valor obtido para o controle negativo 1 e o da água da esteira de lavagem um pouco acima do controle negativo 2 , as células estavam saudáveis, demonstrando a eficiência do processo $\mathrm{UVC} / \mathrm{H}_{2} \mathrm{O}_{2}$ do ponto de vista toxicológico (Figuras $30 \mathrm{e}, 30 \mathrm{f}, 30 \mathrm{~g}$ e $30 \mathrm{l}$ ), em que os três ingredientes ativos foram completamente removidos após os 15 minutos. 
Figura 30 - Observações visuais dos efeitos genotóxicos em $A$. cepa, empregando ampliações de $40 \times$, para ensaios com os IA padrão analítico e matrizes reais coletadas na indústria, dopadas com os produtos comerciais Amistar Top ${ }^{\circledR} \mathrm{e}$

Provado $200 \mathrm{SC}^{\circledR}$. (a) controle negativo 1 (água de torneira) (b) solução AZO, antes do tratamento, (c) solução DFZ, antes do tratamento, (d) solução IMD, antes do tratamento, (e) solução AZO, após tratamento $\mathrm{UVC} / \mathrm{H}_{2} \mathrm{O}_{2}$, (f) solução $\mathrm{DFZ}$, após tratamento UVC/ $\mathrm{H}_{2} \mathrm{O}_{2}$, (g) solução IMD, após tratamento UVC/ $\mathrm{H}_{2} \mathrm{O}_{2}$, (h) controle negativo 2 (água de torneira), (i) água de pré-lavagem, antes do tratamento, (j) água da esteira de lavagem, antes do tratamento, (k) água de pré-lavagem, após tratamento UVC/ $/ \mathrm{H}_{2} \mathrm{O}_{2}$, (I) água da esteira de lavagem, após tratamento $\mathrm{UVC} / \mathrm{H}_{2} \mathrm{O}_{2}$.

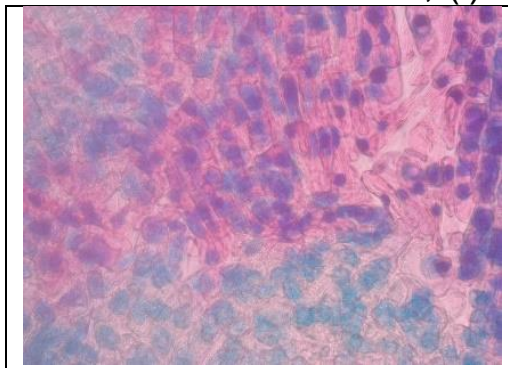

(a)

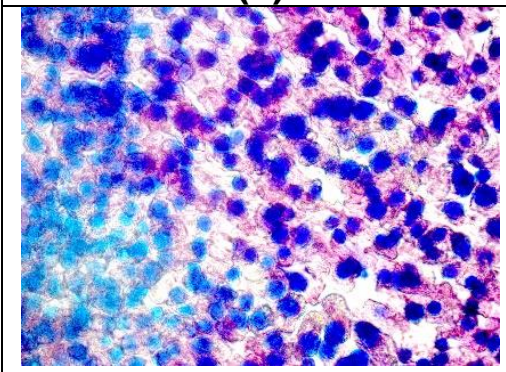

(d)

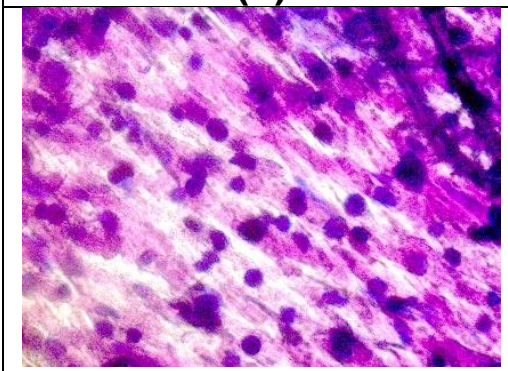

(g)

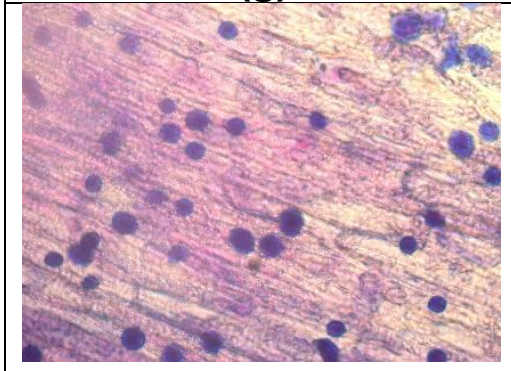

(j)

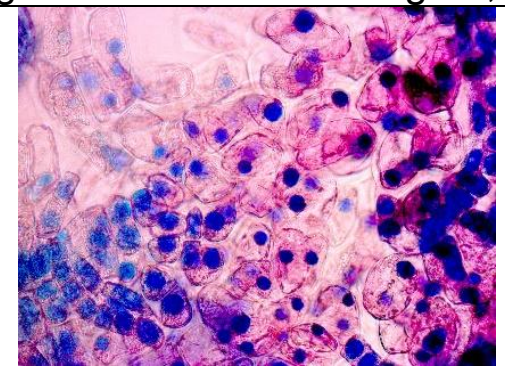

(b)

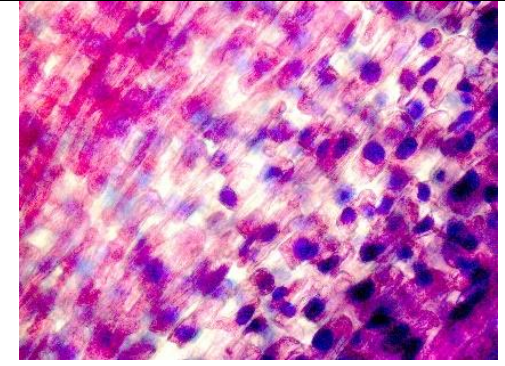

(e)

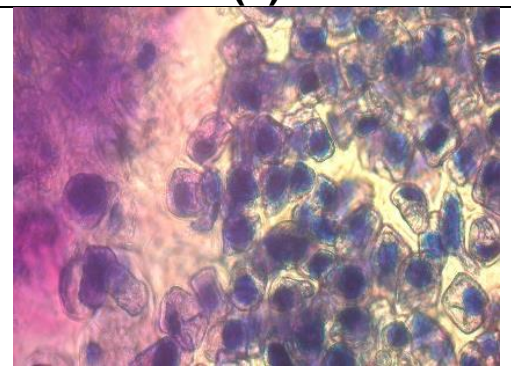

(h)

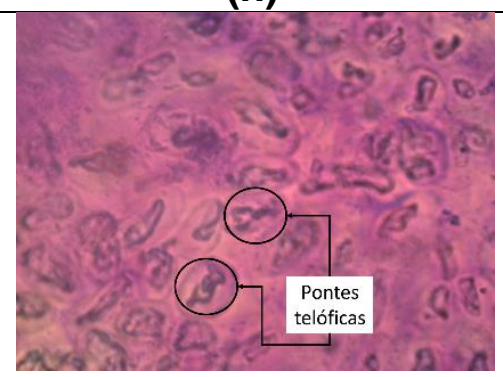

(k)

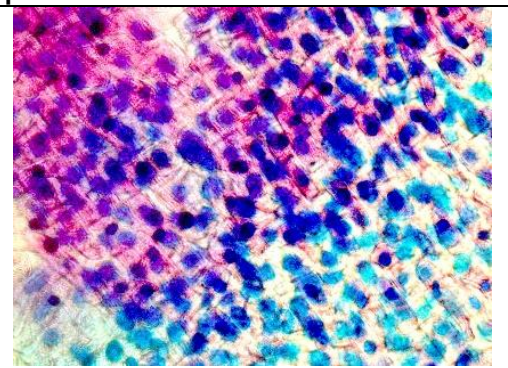

(c)

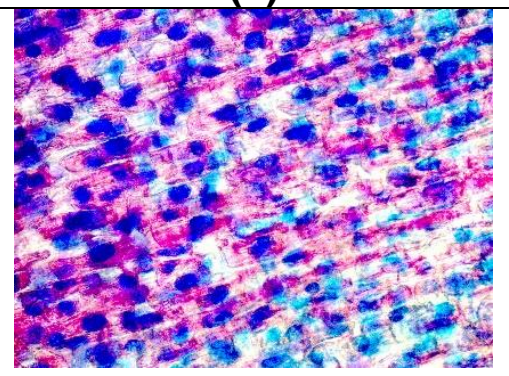

(f)

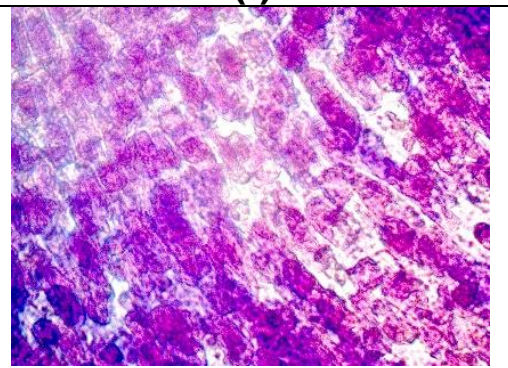

(i)

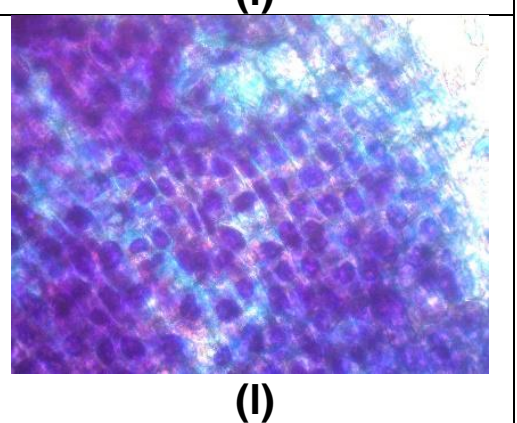

Fonte: Resultados da autora.

Para melhor compreender como os IA e seus intermediários contribuem para os efeitos observados, são necessárias investigações adicionais acerca da rota de transformação dos mesmos. 
Na literatura, são encontrados poucos estudos que investigaram os efeitos cito e genotóxicos do DFZ e IMD isoladamente e em mistura utilizando o organismo $A$. cepa. Bernardes et al. (2015) observaram efeitos fitotóxicos, genotóxicos e genotóxicos do DFZ após 96 h de exposição a concentrações variando de 7,81 a 125,0 $\mu \mathrm{g} \mathrm{L}^{-1}$ e verificaram diminuição do IM e aumento na incidência de aberrações celulares com o aumento da concentração de DFZ. Ainda, foi observado que apesar dos maiores danos fitotóxicos ocorrerem para maiores concentrações, o DFZ causa mutações no DNA com maior frequência em concentrações residuais. Bianchi, Fernandes e Marin-morales (2016) investigaram os efeitos individuais e em mistura do IMD com o herbicida sulfentrazona e após 24 h de exposição e períodos de 48 e $72 \mathrm{~h}$, foram percebidos efeitos genotóxicos indiretos do IMD, com a presença de aberrações cromossômicas, em sua maioria de pontes e aderências cromossômicas. Em mistura, os dois compostos apresentaram efeitos genotóxicos e citotóxicos, reduzindo o valor de IM das células. O mesmo comportamento genotóxico do IMD foi observado por Fioresi et al. (2020), e as soluções com maior concentração causaram redução no valor de $\mathrm{IM}$. Para a AZO não foram publicados estudos utilizando o organismo teste $A$. cepa, o que realça a contribuição do presente trabalho, não apenas no que se refere à aplicabilidade do $\mathrm{POA} U \mathrm{UV} / \mathrm{H}_{2} \mathrm{O}_{2}$ no tratamento de efluentes, como ao seu potencial de redução toxicológica. 



\section{CONCLUSÕES}

Os resultados do presente trabalho mostram que os ingredientes ativos azoxistrobina (AZO), difenoconazol (DFZ) e imidacloprido (IMD), largamente utilizados no Brasil e eventualmente transferidos para a água de lavagem de tomates gerada pela agroindústria, são estáveis em pH próximo ao neutro, e que a fotólise direta UVC segue cinética de pseudo-primeira ordem, com AZO e IMD atingindo concentrações abaixo dos limites de detecção após 15 minutos de irradiação, para irradiâncias de 21,8 e $28,6 \mathrm{~W} \mathrm{~m}^{-2}$. Por outro lado, para o DFZ a máxima remoção obtida foi de $51,7 \%$, usando $28,6 \mathrm{~W} \mathrm{~m}^{-2}$.

No que se refere aos ensaios $\mathrm{UVC} / \mathrm{H}_{2} \mathrm{O}_{2}$, a remoção total dos pesticidas ocorre nos primeiros 10 minutos para a maioria das condições de [ $\left.\mathrm{H}_{2} \mathrm{O}_{2}\right]$ o e irradiância (Euvc). Os resultados ainda sugerem que a contribuição da fotólise direta para a taxa de degradação inicial dos pesticidas durante o processo segue a ordem IMD > AZO > DFZ, o que é esperado, considerando a competição entre as moléculas de $\mathrm{H}_{2} \mathrm{O}_{2}$ e dos IA quanto à absorção dos fótons incidentes. Por sua vez, a análise estatística aplicando o projeto experimental sequencial Doehlert possibilitou melhor compreensão da influência das variáveis de processo. Dessa maneira, a concentração inicial de peróxido de hidrogênio $\left(\left[\mathrm{H}_{2} \mathrm{O}_{2}\right] 0\right)$ mostrou ser mais importante quanto às taxas de degradação da AZO e do DFZ, enquanto a degradação do IMD aparenta ser mais impactada pela irradiância. Ainda, o efeito quadrático negativo de Euvc foi estatisticamente significativo para a $A Z O$ e para o IMD, enquanto a $\left[\mathrm{H}_{2} \mathrm{O}_{2}\right] 0$ foi significativa para o DFZ, em um nível de confiança de $95 \%$. Os modelos quadráticos de superfície de resposta obtidos confirmaram que as condições ótimas para as taxas de remoção dos $I A$ foram $\left[\mathrm{H}_{2} \mathrm{O}_{2}\right]_{0}=130 \mathrm{mg} \mathrm{L}^{-1}$ e $E u v c=26,0 \mathrm{~W} \mathrm{~m}^{-2}$.

Nessas condições a remoção completa da AZO foi alcançada em amostras de água reais coletadas na indústria (água gerada na pré-lavagem e em esteiras de lavagem de tomates) e dopadas com os produtos comerciais. Nesse caso, a degradação total do DFZ e IMD ocorreu apenas para a água da esteira de lavagem (as remoções na água de pré-lavagem para esses IA foram de aproximadamente $70 \%$ e $79 \%$, respectivamente).

No tocante aos estudos de citotoxicidade e genotoxicidade, células de raízes de bulbos de cebola ( $A$. cepa) expostas à água de pré-lavagem apresentaram valores de índice mitótico próximos aos do controle negativo (água de torneira), tendo sido 
identificadas anormalidades cromossômicas, o que se deve provavelmente à presença de moléculas remanescentes dos IA e/ou de seus produtos de transformação. Já para a água da esteira, os três ingredientes ativos foram completamente removidos após os 15 minutos pelo tratamento $\mathrm{UVC} / \mathrm{H}_{2} \mathrm{O}_{2}$, e não foram observadas anormalidades durante a divisão celular. O mesmo ocorreu para os testes com os compostos em padrão analítico, conduzidos a fim de verificar os efeitos individuais dos IA e de seus produtos de transformação nas células meristemáticas das raízes da $A$. cepa. Com o intuito de compreender melhor a natureza dos compostos gerados a partir da degradação utilizando o processo $\mathrm{UVC} / \mathrm{H}_{2} \mathrm{O}_{2}$, novos estudos com respeito aos intermediários devem ser considerados futuramente.

Isto posto, este trabalho contribuiu para o entendimento do comportamento dos ingredientes ativos AZO, DFZ e IMD em mistura e na interação com a radiação UVC. Foi demonstrada a eficiência do processo $\mathrm{UVC} / \mathrm{H}_{2} \mathrm{O}_{2}$, podendo ser considerado uma alternativa viável para tratamento localizado da água de lavagem gerada nas esteiras de lavagem durante o processamento na indústria, com foco no possível reuso da água tratada. 


\section{REFERÊNCIAS BIBLIOGRÁFICAS}

ACERO, J. L. et al. Degradation of neonicotinoids by UV irradiation: kinetics and effect of real water constituents. Separation and Purification Technology, v. 211, p. 218226, 2019.

AGROFIT. Banco de Informações sobre os produtos agroquímicos e afins registrados no Ministério da Agricultura. Disponível em: $<$ http://www.agricultura.gov.br/assuntos/insumos-agropecuarios/insumosagricolas/agrotoxicos/agrofit> Acesso em $01 \mathrm{fev} .2021$

ALBUQUERQUE, A. F. et al. Pesticides in brazilian freshwaters: a critical review. Environmental Science: Processes and Impacts, v. 18, n. 7, p. 779-787, 2016

ALI, A. A. I.; DESOKY, E. M.; RADY, M. M. Application of azoxystrobin fungicide improves drought tolerance in tomato, via enhancing physio-biochemical and anatomical feature. International Letters of Natural Sciences, v. 76, p. 24-49, 2019.

ALISTE, M. et al. Solar-driven photocatalytic treatment as sustainable strategy to remove pesticide residues from leaching water. Environmental Science and Pollution Research, v. 27, p. 7222-7233, 2020.

AL-RIMAWI, F. A HPLC-UV method for determination of three pesticides in water. International Journal of Advances in Chemistry, v. 2, n. 2, p. 1-8, 2016.

AMETA, S. C.; AMETA, R. Introduction. In: AMETA, S. C.; AMETA, R. (Ed.) Advanced oxidation processes for wastewater treatment: emerging green chemical technology. Londres: Elsevier, 2018. cap. 1, p.1-8.

ANDRADE, G. C. R. M. et al. Effects of types of washing and peeling in relation to pesticide residues in tomatoes. Journal of the Brazilian Chemical Society, v. 26, n. 10, p. 1994-2002, 2015.

ANVISA. Agrotóxicos: guia número 12, versão 1, de 19 de janeiro de 2018.

Disponível em:

<http://portal.anvisa.gov.br/documents/10181/4016300/GUIA++Elabora\%C3\%A7\%C

$3 \% \mathrm{~A} 30+\mathrm{de}+\mathrm{R} \% \mathrm{C} 3 \% \mathrm{~B} 3$ tulo+e+Bula+-+vers\%C3\%A3o+28-9-

2017+DIARE.pdf/85a0fb5f-a18b-478c-b6ea-e6ae58d9202a?version=1.0 >. Acesso em: 18 jun. 2019.

ANVISA. Índice monográfico. Disponível em:

<http://portal.anvisa.gov.br/documents/111215/117782/113\%2B\%2BImidacloprido.pdf /9d08c7e5-8979-4ee9-b76c-1092899514d7> Acesso em: 11 jun. 2019.

APHA. Standard methods for the Examination of water and wastewater. 23 ed. Washington: American Public Health Association, 2017. 1504p.

ARAGAHEGN, K. Z. et al. Photochemistry of thin solid films of the neonicotinoid imidacloprid on surfaces. Environmental Science and Technology, v. 51, p. 26602668, 2016. 
ARAGÃO, F. B. et al. Cyto(geno)toxicity of commercial fungicides based on the active compounds tebuconazole, difenoconazole, procymidone, and iprodione in Lactuca sativa L. meristematic cells. Water, Air and Soil Pollution, v. 205, n. 25, p. 1-9, 2019.

BAGHIRZADE, B. S.; YETIS, U.; DILEK, F. B. Imidacloprid elimination by $\mathrm{O}_{3}$ and $\mathrm{O}_{3} / \mathrm{UV}$ : kinetics study, matrix effect, and mechanism insight. Environmental Science and Pollution Research, 2020. https://doi.org/10.1007/s11356-020-09355-2

BANIC, N. D. et al. Photodegradation of neonicotinoid active ingredients and their commercial formulations in water by different advanced oxidation processes. Water, Air and Soil Pollution, v. 225, n. 1954, 2014. https://doi.org/10.1007/s11270-0141954-5

BARBOSA, M. O. et al. Occurrence and removal of organic micropollutants: An overview of the watch list of EU Decision 2015/495. Water Research, v. 94, p. 257279, 2016.

BARLETT, A. J. et al. Acute and chronic toxicity of neonicotinoid and butenolide insecticides to the freshwater amphipod, Hyalella azteca. Ecotoxicology and Environmental Safety, v. 175, p. 215-223, 2019.

BETHI, B. et al. Nanomaterials-based advanced oxidation processes for wastewater treatment: a review. Chemical Engineering and Processing, v. 109, p. 178-189, 2016.

BERNARDES, P. M. et al. Toxicity of difenoconazole and tebuconazole in Allium cepa. Water Air Soil Pollution, v. 226, n. 207, 2015. https://doi.org/10.1007/s11270-015$2462-y$

BESSERGENEV, V. G. et al. Photocatalytic reactor, CVD technology of its preparation and water purification from pharmaceutical drugs and agricultural pesticides. Chemical Engineering Journal, v. 312, p. 306-316, 2017.

BIANCHI, J.; FERNANDES, T. C. C.; MARIN-MORALES, M. A. Induction of mitotic and chromosomal abnormalities on Allium cepa cells by pesticides imidacloprid and sulfentrazone and the mixture of them. Chemosphere, v. 144, p. 475-483, 2016.

BOFF, L. Sustentabilidade: o que é, o que não é? Petrópolis: Vozes, 2012. 200p.

BOLTON, J. R. et al. Figures-of merit for the technical development and application of advanced oxidation processes. Journal of Advanced Oxidation Technologies, v. 1, p. 13-17, 1996.

BOMBARDI, L. M. Geografia do uso de agrotóxicos no Brasil e conexões com a União Europeia. São Paulo: FFLCH-USP, 2017. 296p.

BORTOLUZZI, E. C. et al. Contaminação de águas superficiais por agrotóxicos em função do uso do solo numa microbacia hidrográfica de Agudo, RS. Revista Brasileira de Engenharia Agrícola e Ambiental, v. 10, n. 4, p. 881-887, 2006. 
BOUDINA, A. et al. Photochemical transformation of azoxystrobin in aqueous solutions. Chemosphere, v. 68, p. 1280-1288, 2007.

BOURGIN, M. et al. Ozonation of imidacloprid in aqueous solutions: reaction monitoring and identification of degradation products. Journal of Hazadous Materials, v. 190, p. 60-68, 2011.

BRASIL. Lei no 7802, de 11 de julho de 1989. Dispõe sobre a pesquisa, a experimentação, a produção, a embalagem e rotulagem, o transporte, o armazenamento, a comercialização, a propaganda comercial, a utilização, a importação, a exportação, o destino final dos resíduos e embalagens, o registro, a classificação, o controle, a inspeção e a fiscalização de agrotóxicos, seus componentes e afins, e dá outras providências. Diário Oficial da União, Brasília, DF, 12 jul. 1989.

BRASIL. Ministério da Saúde. Portaria n 2.914, de 12 de dezembro de 2011. Dispõe sobre os procedimentos de controle e de vigilância da qualidade da água para consumo humano e seu padrão de potabilidade. Diário Oficial da União, Brasília, DF, 12 dez. 2011.

BRAUN, A. M.; MAURETTE, M.T.; OLIVEROS, E. Photochemical technology. Chischester: John Wiley, 1991. 580p.

BRITO, L. T. L.; MELO, R. F.; GIONGO, V. (Ed.). Impactos ambientais causados pela agricultura no Semiárido brasileiro. Petrolina: Embrapa Semiárido, 2010.

CALDAS, L. F. S. et al. Application of a four-variables Doehlert design for the multivariate optimization of copper determination in petroleum-derived insulating oils by GFAAS employing the dilute-and-shot approach. Fuel, v. 105, p. 503-511, 2013.

CALZA, P. et al. Light-induced transformations of fungicides on titanium dioxide: pathways and by-products evaluation using the LC-MS technique. International Journal of Environmental Analytica Chemistry, v. 86, n. 3-4, p. 267-275, 2006.

CAO, F. et al. Parental exposure to azoxystrobin causes developmental effects and disrupts gene expression in F1 embryonic zebrafish (Danio rerio). Science of the Total Environment, v. 646, p. 595-605, 2019.

CARNEIRO, F. F. et al. (Org.). Dossiê Abrasco: um alerta sobre os impactos dos agrotóxicos na saúde. Rio de Janeiro: EPSJV; São Paulo: Expressão Popular, 2015.

CERRETA, G. et al. Contaminants of emerging concern removal from real wastewater by UV/free chlorine process: a comparison with solar/free chlorine and $\mathrm{UV} / \mathrm{H}_{2} \mathrm{O}_{2}$ at pilot scale. Chemosphere, v. 236, p. 2019. https://doi.org/10.1016/j.chemosphere.2019.124354

CONAMA. Resolução nํ 430, de 13 de maio de 2011. Dispõe sobre as condições e padrões de lançamento de efluentes, complementa e altera a Resolução nํ 357, de 17 de março de 2005, do Conselho Nacional do Meio Ambiente. Diário Oficial da União, Brasília, DF, 13 maio 2011. 
CYCON, M. et al. Imidacloprid induces changes in the structure, genetic diversity and catabolic activity of soil microbial communities. Journal of Environmental Management, v. 131, p. 55-65, 2013.

DAAM, M. A. et al. Preliminary aquatic risk assessment of imidacloprid after application in an experimental rice plot. Ecotoxicology and Environmental Safety, v. 97, p. 7885, 2013.

DENG, Y.; ZHAO, R. Advanced oxidation processes (AOPs) in wastewater treatment. Current Pollution Reports, v. 1, p. 167-176, 2015.

DEZOTTI, Márcia. Processos e técnicas para o controle ambiental de efluentes líquidos. Rio de Janeiro: E-papers, 2008. 360p.

FAST, S. A. et al. A critical evaluation of advanced oxidation processes for emerging contaminants removal. Environmental Processes, v. 4, p. 283-302, 2017.

FENOLL, J. et al. Photodegradation of neonicotinoid insecticides in water by semiconductor oxides. Environmental Science and Pollution Research International, v. 22, n. 19, p. 15055-15066, 2015.

FERNANDES, T. C, C.; MAZZEO, D. E. C.; MARIN-MORALES, M. A. Mechanism of micronuclei formation in polyploidizated cells of Allium cepa exposed to trifluralin herbicide. Pesticide Biochemistry and Physiology, v. 88, p. 252-259, 2007.

FERREIRA, S. L. C. et al. Doehlert matrix: a chemometric tool for analytical chemistry - review. Talanta, v. 63, p. 1061-1067, 2004.

FIORENZA, R. et al. $\mathrm{CeO}_{2}$ for water remediation: Comparison of various advanced oxidation processes. Catalysts, v. 10, n. 446, 2020. https://doi.org/10.3390/catal10040446

FIORESI, V. S. et al. Cytogenotoxic activity of the pesticides imidacloprid and iprodione on Allium cepa root meristem. Environmental Science and Pollution Research, v. 27, p. 28066-28076, 2020.

FISKESJÖ, G. The Allium test as a standard in environmental monitoring. Hereditas, v. 102, p. 99-112, 1985.

GARRIDO, I. et al. Solar reclamation of agro-wastewater polluted with eight pesticides by heterogeneous photocatalysis using a modular facility. A case study. Chemosphere, v. 249, p. 126-156, 2020.

HALM, M. P. et al. New risk assessment approach for systemic insecticides: the case of honeybees and imidacloprid (Gaucho). Environmental Science and Technology, v. 40, p. $2448-2454,2006$.

HAN, Y. et al. Genotoxicity and oxidative stress induced by the fungicide azoxystrobin in zebrafish (Danio rerio) livers. Pesticide Biochemistry and Physiology, v. 133, p. 13-19, 2016. 
HESHMATI, A.; NAZEMI, F. Dichlorvos (DDVP) residue removal from tomato by washing with tap and ozone water, a commercial detergent solution and ultrasonic cleaner. Food Science and Technology, v. 38, n. 3, p. 441-446, 2017.

IBAMA. Relatórios de comercialização de agrotóxicos. Disponível em: < https://www.ibama.gov.br/index.php?option=com_content\&view=article\&id=594\&ltem id=54>. Acesso em: 30 jan. 2021.

IKEHATA, K; EL-DIN, M. G. Aqueous pesticide degradation by hydrogen peroxide/ultraviolet irradiation and Fenton-type advanced oxidation processes: a review. Journal of Environmental Engineering and Sciences, v. 5, p. 81-135, 2006.

KATSOYIANNIS, I. A; CANONICA, S.; VON GUNTEN, U. Efficiency and energy requirements for the transformation of organic micropollutants by ozone, $\mathrm{O}_{3} / \mathrm{H}_{2} \mathrm{O}_{2}$ and UV/ $\mathrm{H}_{2} \mathrm{O}_{2}$. Water Research, v. 45, p. 3811-3822, 2011.

KUMAR, A.; VERMA, A.; KUMAR, A. Accidental human poisoning with a neonicotinoid insecticide, imidacloprid: a rare case report from rural India with a brief review of literature. Egyptian Journal of Forensic Sciences, v. 3, p. 123-126, 2013.

LASTRE-ACOSTA, A. M. et al. Photo-Fenton reaction at mildly acidic conditions: assessing the effect of bio-organic substances of different origin and characteristics through experimental design. Journal of Environmental Science and Health, Part A, v. 54, p. 711-720, 2019.

LEME, D. M; MARIN-MORALES, M. A. Allium cepa test in environmental monitoring: a review on its application. Mutation Research, v. 682, p. 71-81, 2009.

LI, Y.; MA, X.; LU, G. Systematic investigation of the toxic mechanism of difenoconazole on protein by spectroscopic and molecular modeling. Pesticide Biochemistry and Physiology, v. 105, n. 3, p. 155-160, 2013.

LIN, R. et al. Sublethal and transgenerational effects of acetamiprid and imidacloprid on the predatory bug Orius sauteri (Poppius) (Hemiptera: Anthocoridae). Chemosphere, v. 255, n. 126778, 2020.

LIU, W. et al. Sorption and degradation of imidacloprid in soil and water. Journal of Environmental Science and Health, Part B, v. 41, p. 623-634, 2007. https://doi.org/10.1016/j.chemosphere.2020.126778

LOPES, C. V. A.; ALBUQUERQUE, G. S. C. Agrotóxicos e seus impactos na saúde humana e ambiental: uma revisão sistemática. Saúde Debate, v. 42, n. 117, p. 518534, 2018.

MAPA. Boas práticas agrícolas. 2017. Disponível em: < http://www.agricultura.gov.br/assuntos/sustentabilidade/producao-integrada/boaspraticas-agricolas>. Acesso em: 11 jun. 2019. 
MAPA (2020) Informações técnicas. Disponível em: < http://www.agricultura.gov.br/assuntos/insumos-agropecuarios/insumosagricolas/agrotoxicos/informacoes-tecnicas>. Acesso em: 29 jun. 2020.

MAURYA, R. et al. Effect of difenoconazole fungicide on physiological responses and ultrastructural modifications in model organism Tetrahymena pyriformis. Ecotoxicology Environmental Safety, v. 182, p. 109-375. 2019.

MELNIKOV, N. N. Chemistry of pesticides. New York: Springer-Verlag, 1971. 480p.

MIERZWA, J. C.; RODRIGUES, R.; TEIXEIRA, A. C. S. C. UV-Hydrogen Peroxide processes. In: AMETA, S. C.; AMETA, R. (Ed.) Advanced oxidation processes for wastewater treatment: emerging green chemical technology. London: Elsevier, 2018. cap. 2. pp.13-48.

MIKLOS, D. B. et al. Evaluation of advanced oxidation processes for water and wastewater treatment - A critical review. Water Research, v. 139, p. 118-131, 2018.

MONSALVO, V. M. et al. Anerobic biodegradability of mixtures of pesticides in an expanded granular sludge bed reactor. Water Science and Technology, v. 69, p. 532-538, 2014.

MONTAGNER, C. C. et al. Trace analysis of pesticides and an assessment of their occurrence in surface and drinking waters from the State of São Paulo (Brazil). Analytical Methods, v. 6, p. 6668-6677,2014.

NAVARRO, S. et al. Photocatalytic degradation of eight pesticides in leaching water by use of $\mathrm{ZnO}$ under natural sunlight. Journal of Hazardous Materials, v. 172, p. 1303-1310, 2009.

NAVARRO, S. et al. Removal of ten pesticides from leaching water at pilot plant scale by photo-Fenton treatment. Chemical Engineering Journal, v. 167, p. 42-49, 2011.

NOVAES, C. G. et al. Otimização de métodos analíticos usando metodologia de superficies de resposta - Parte l: variáveis de processo. Revista Virtual de Química, v. 9, n. 3, p. 1184-1215, 2017.

OLVIK, P. A. et al. Effects of the fungicide azoxystrobin on Atlantic salmon (Salmo salar L.) smolt. Ecotoxicology and Environmental Safety, v. 73, p. 1852-1861, 2010.

OPPENLÄNDER, T. Photochemical purification of water and air: advanced oxidation processes (AOPs): principles, reaction mechanisms, reactor concepts. Weinheim: Wiley-VCH, 2003. 368p.

PAN, L. et al. The fungicide difenoconazole alters mRNA expression levels of human CYP3A4 in HepG2 cells. Environmental Chemistry Letters, v. 15, p. 673-678, 2017.

PARSONS, S. (Ed.) Advanced oxidation processes for water and wastewater treatment. London: IWA Publishing, 2005. 356p. 
PATIL, P. N.; BOTE, S. D.; GOGATE, P. R. Degradation of imidacloprid using combined advanced oxidation processes based on hydrodynamic cavitation. Ultrasonics Sonochemistry, v. 21, p. 1770-1777, 2014.

PERES, F.; MOREIRA, J. C. (Org.). É veneno ou é remédio? Agrotóxicos, saúde e ambiente. Rio de Janeiro: Editora Fiocruz, 2003. 384p.

PÉREZ-IGLESIAS, J. M. et al. The genotoxic effects of the imidacloprid-based insecticide formulation Glacoxan Imida on Montevideo tree frog Hypsiboas pulchellus tadpoles (Anura, Hylidae). Ecotoxicology and Environmental Safety, v. 104, p. 120126, 2014.

PIGNATI, W. A. et al. Distribuição espacial do uso de agrotóxicos no Brasil: uma ferramenta para a vigilância em saúde. Ciência e Saúde Coletiva, v. 22, n. 10, p. 3281-3293, 2017.

POYATOS, J. M. et al. Advanced Oxidation Processes for Wastewater Treatment: State of the Art. Water, Air and Soil Pollution, v. 205, p. 187-204, 2010.

PUSHKAREVA, T. I.; ZENKEVICH, I. G. Electrochemical oxidation of difenoconazole in solutions: LC/MS identification of reaction products. Moscow University Chemistry Bulletin, v. 74, p.127-133, 2019.

RASOLONJATOVO, M. A. et al. Reduction of methomyl and acetamiprid residues from tomatoes after various household washing solutions. International Journal of Food Properties, v. 20, n. 11, p. 2748-2759, 2017.

RIBANI, M. et al. Validação em métodos cromatográficos e eletroforéticos. Química Nova, v. 27, p. 771-780, 2004.

RIBEIRO, A. R. et al. An overview on the advanced oxidation processes applied for the treatment of water pollutants defined in the recently lanched Directive 2013/39/EU. Environmental International, v. 75, p. 33-51, 2015.

RODRIGUES, A. A. Z. et al. Pesticide residue removal in classic domestic processing of tomato and its effects on product quality. Journal of Environmental Science and Health, Part B, v. 52, n. 12, p. 850-857, 2017.

RÓZSA, G. et al. Photocatalytic, photolytic and radiolytic elimination of imidacloprid from aqueous solution: reaction mechanism, efficiency and economic considerations. Applied Catalysis B: Environmental, v. 250, p. 429-439, 2019.

SABLAS, M. M. et al. Percarbonate mediated advanced oxidation completely degrades recalcitrant pesticide imidacloprid: Role of reactive oxygen species and transformation products. Separation and purification technology, v. 250, p. 117-269, 2020.

SEGUNDA CARTA A TIMÓTEO. In: A Bíblia: tradução ecumênica. São Paulo: Paulinas, 2012. 
SENA, A. R. et al. Application of doehlert experimental design in the optimization of experimental variables for the pseudozyma sp. (CCMB 306) and pseudozyma sp. (CCMB 300) cell lysis. Ciência e Tecnologia de Alimentos, v. 32, p. 761-767, 2012.

SILVA, C. M. M. S.; FAY, E. F. Agrotóxicos e ambiente.1 Edição. Brasília: Embrapa Informação Tecnológica, 2004. 400p.

SILVA, M. B. et al. Efeitos do imidacloprido sobre o comportamento das abelhas Scaptotrigona postica Latreille, 1807 (Hymenoptera, Apidae). Revista Ciência, Tecnologia e Ambiente, v. 3, n. 1, p. 21-28, 2016.

SKOOG, D. A; HOLLER, F. J.; CROUCH, S. R Principles of instrumental analysis. Boston: Cengage Learning, 2017. 1088p.

TANG, W. Z. Physicochemical treatment of hazardous wastes. Florida: CRC Press LLC, 2004. 584p.

TERRA, F. H. B.; PELAEZ, V. M. A evolução da indústria de agrotóxicos no Brasil de 2001 a 2007: a expansão da agricultura e as modificações na lei de agrotóxicos. In: XLVI Congresso da Sociedade Brasileira de Economia, Administração e Sociologia Rural Anais...Curitiba, PR, 2017.

TIŠLER, T. et al. Hazard identification of imidacloprid to aquatic environment. Chemosphere, v. 76, p. 907-914, 2009.

TODEY, S. A.; FALLON, A. M; ARNOLD, W. A. Neonicotinoid insecticide hydrolysis and photolysis: rates and residual toxicity. Environmental Toxicology and Chemistry, v. 37, p. 2797-2809, 2018.

TROPICAL FOOD MACHINERY. Sistema hídrico de recebimento de tomate. Disponível em: <http://www.tropicalfood.com.br/solucoes/sistema-hidricorecebimento-tomate.php> Acesso em: 16 jun. 2019.

TSOCHATZIS, E. D. et al. Development and validation of an HPLC-DAD method for the simultaneous determination of most common rice pesticides in paddy water systems. International Journal of Environmental Analytical Chemistry, v. 92, p. 548-560, 2011.

UNIÃO EUROPEIA. Diretiva 2008/105/CE do parlamento europeu e do conselho, de 16 de dezembro de 2008. Relativa às normas de qualidade ambiental no domínio da política da água, que altera e subsequentemente revoga as Diretivas 82/176/CEE, 83/513/CEE, 84/156/CEE, 84/491/CEE e 86/280/CEE do Conselho, e que altera a Diretiva 2000/60/CE. Disponível em: < https://eur-lex.europa.eu/legalcontent/PT/TXT/PDF/?uri=CELEX:32008L0105\&from=EN>. Acesso em: 11 jun. 2019.

USEPA. Seed germination/root elongation toxicity test, OPPTS 50.4200, EPA 712/C96/154. Ecological effects test guidelines. Washington, DC, 1996. 
VENANCIO, W. S. et al. Physiological effects of strobilurin fungicides on plants. Publica UEPG Ciências Exatas e da Terra, Ciências Agrárias e Engenharias, v.9, n. 3, p.59-68, 2003.

WANG, L. et al. Occurrence and profile Characteristics of the pesticide imidacloprid, preservative parabens, and their metabolites in human urine from rural and urban China. Environmental Science and Technology, v. 49, p. 14633-14640, 2015.

WANWIMOLRUK, S. et al. Food safety in Thailand 5: the effect of washing pesticide residues found in cabbages and tomatoes. Journal of Consumer Protection and Food Safety, v. 12, p. 209-221, 2017.

WORLD HEALTH ORGANIZATION. Guide to short-term tests for detecting mutagenic and carcinogenic chemicals. Geneva: Environ Health Criteria 51, 1985. 208p.

YANG, H. et al. The phase transformation and formation mechanism of isostructural solvates: a case study of azoxystrobin. Crystal Growth and Design, v. 9, p. 15501558, 2019.

YAQUB, G. et al. Rapid determination of residual pesticides and polyaromatic hydrocarbons in different environmental samples by HPLC. Pakistan Journal of Agricultural Sciences, v. 54, n. 2, p. 355-361, 2017.

ZHENG, W. et al. Photochemistry of insecticide imidacloprid: direct and sensitized photolysis in aqueous medium. Journal of Environmental Sciences, v. 16, p. 539542, 2004. 



\section{APÊNDICE A - CURVAS DE CALIBRAÇÃO CROMATOGRÁFICA}

Figura A1 - Curvas de calibração em HPLC obtida para os padrões analíticos dos compostos AZO, DFZ e IMD.

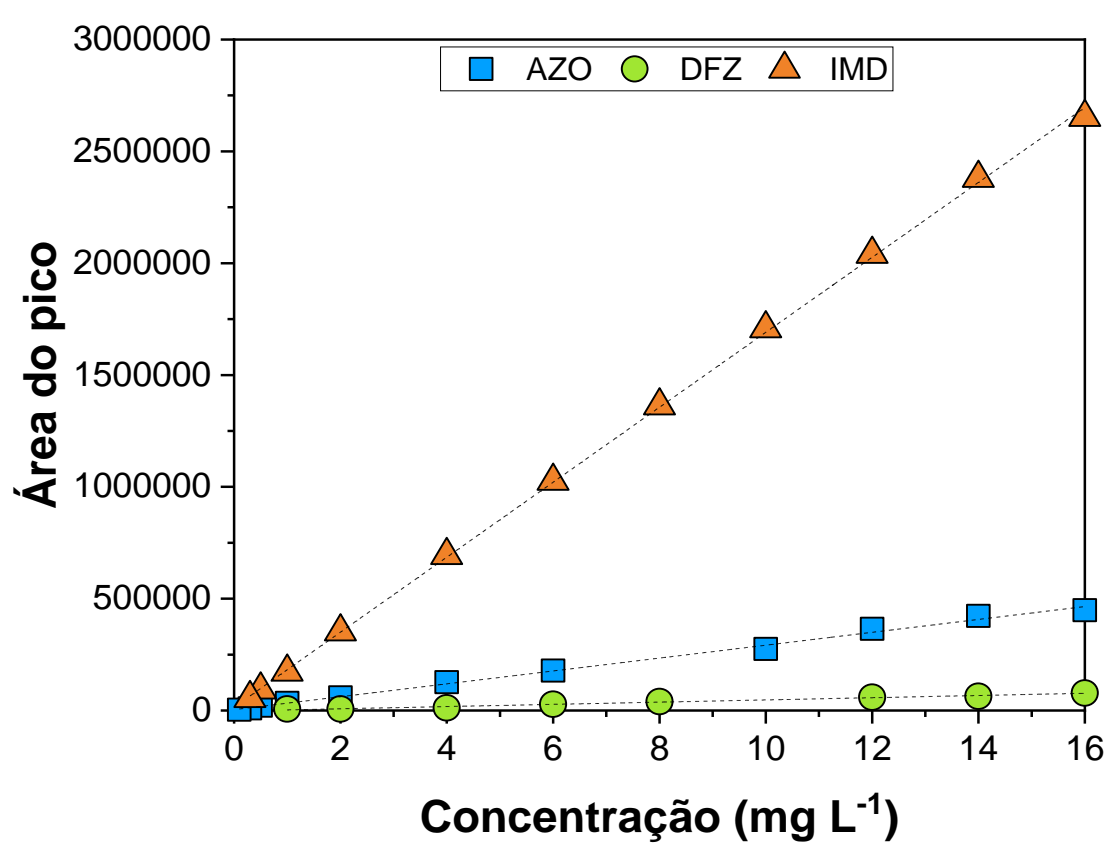

Fonte: Resultados da autora.

Figura A2 - Curvas de calibração em HPLC obtida para os compostos AZO, DFZ e IMD em soluções obtidas a partir dos produtos formulados Amistar Top ${ }^{\circledR}$ e Provado 200 SC $^{\circledR}$.

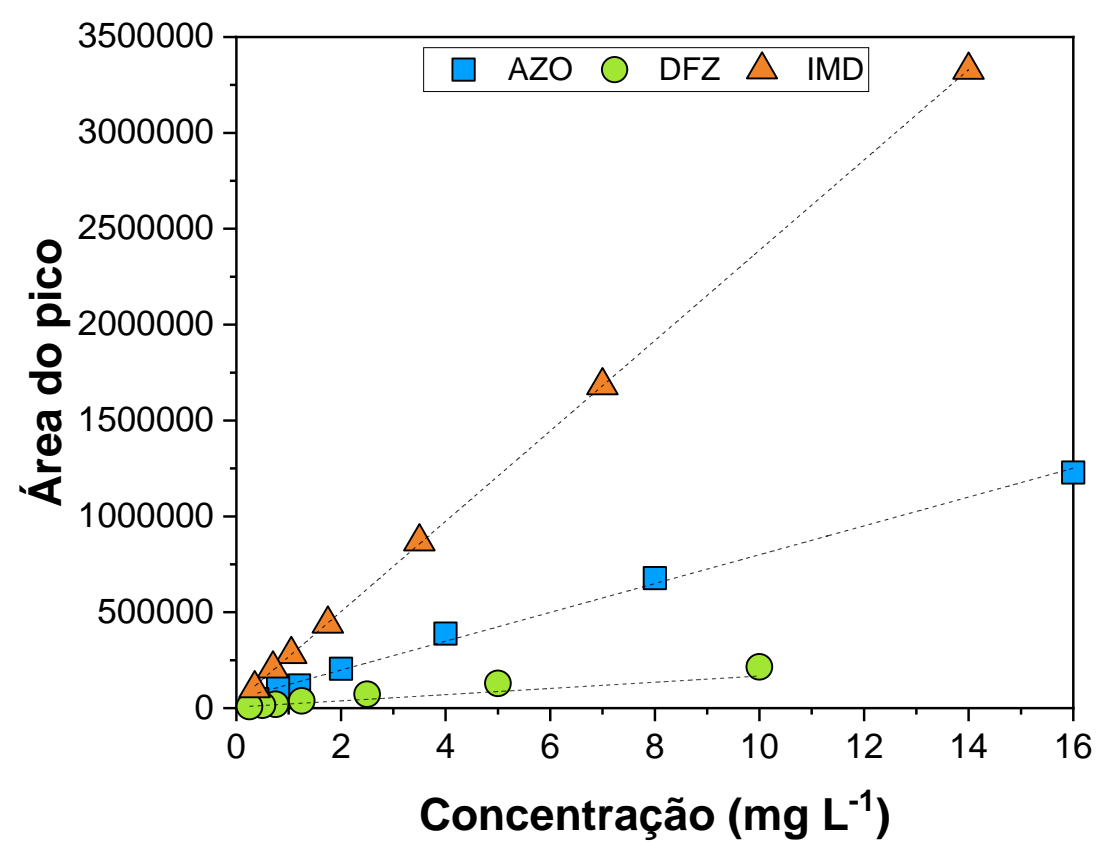

Fonte: Resultados da autora. 